\title{
HETEROGENEITY IN TWO-COMPONENT SIGNALING SYSTEMS WITHIN DIFFERENT STRAINS OF INFLAMMATORY BOWEL DISEASE ASSOCIATED ESCHERICHIA COLI.
}

\author{
By: Adam Khan, \\ Honours Bachelor of Science, 2016 University of Toronto
}

\begin{abstract}
A thesis
presented to Ryerson University in partial fulfillment of the requirements for the degree of Master of Science

in the program of Molecular Science
\end{abstract}

Toronto, Ontario, Canada, 2019

(C) Adam Khan, 2019 


\section{AUTHOR'S DECLARATION FOR ELECTRONIC SUBMISSION OF A THESIS}

I hereby declare that I am the sole author of this thesis. This is a true copy of the thesis, including any required final revisions, as accepted by my examiners.

I authorize Ryerson University to lend this thesis to other institutions or individuals for the purpose of scholarly research.

I further authorize Ryerson University to reproduce this thesis by photocopying or by other means, in total or in part, at the request of other institutions or individuals for the purpose of scholarly research.

I understand that my thesis may be made electronically available to the public. 


\begin{abstract}
Heterogeneity in two-component signaling systems within different strains of inflammatory bowel disease associated Escherichia coli.
\end{abstract}

Adam Khan, Master of Science, Molecular Science, Ryerson University, 2019

Resistance to host-defense peptides is a critical feature of many pathogens. Previous work in the McPhee lab has demonstrated that different strains of inflammatory bowel diseaseassociated Escherichia coli exhibit diverse resistance to host defense peptides. The PhoPQ twocomponent system is a well-characterized signaling pathway that regulates the expression of genes involved in resistance to these peptides. We hypothesize that strains have an altered capacity to signal through this system, resulting in different resistance profiles. We created a promoter-GFP fusion of two PhoPQ regulated genes, $p m r D$ and $o m p T$, to monitor PhoPQ signaling in eight clinical isolates. Our data shows that strains have robust differences in signaling when cultured identical conditions, supporting our hypothesis. Further, our signaling match polymyxin B resistance when using the same isolates and conditions. Our data strongly suggests that strains have an altered potential to respond to environmental signals, ultimately resulting in a broad level of resistance phenotypes. 


\section{Table of Contents}

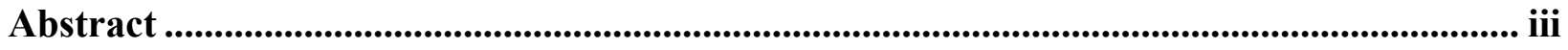

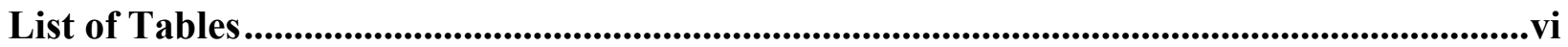

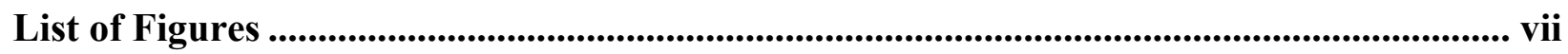

List of Abbreviations ...................................................................................................................... viii

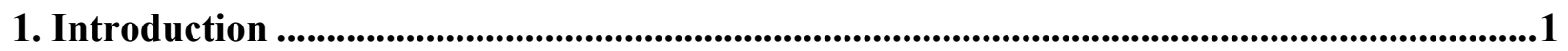

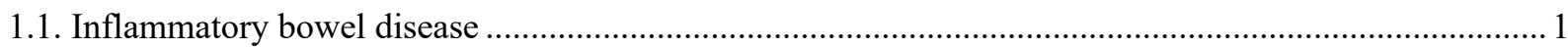

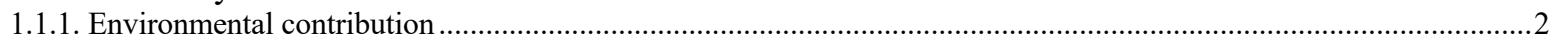

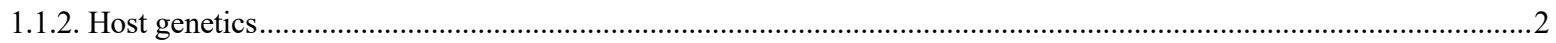

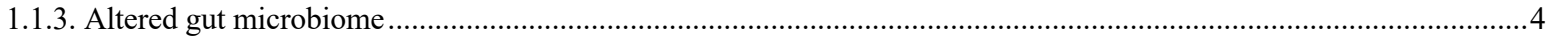

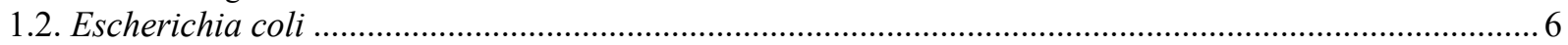

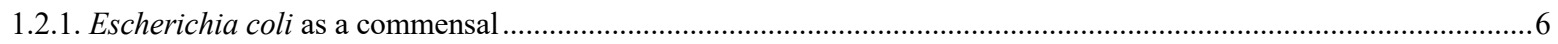

1.2.2. Pathovars of E. coli

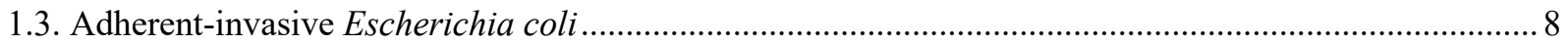

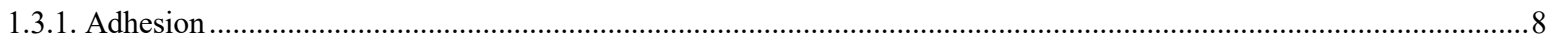

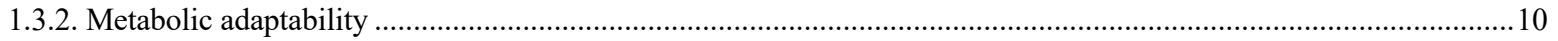

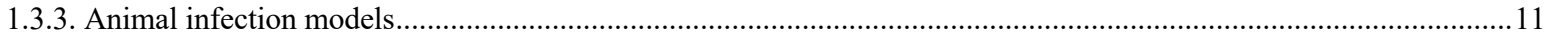

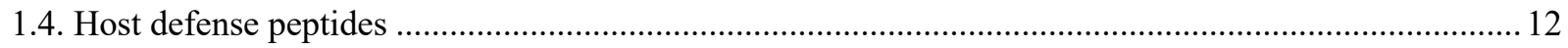

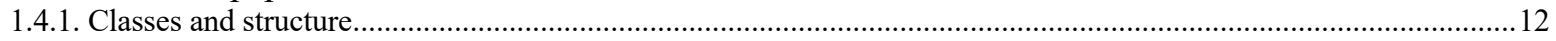

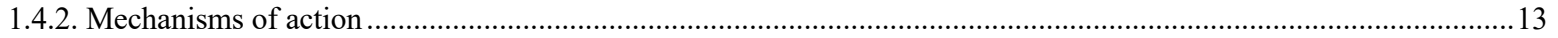

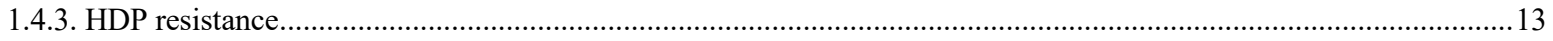

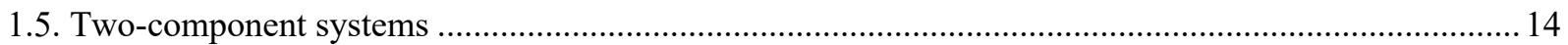

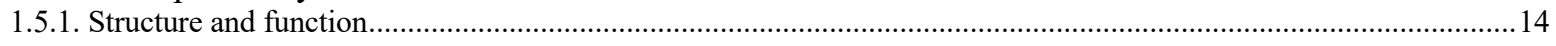

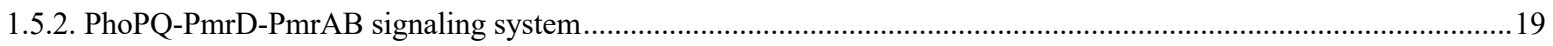

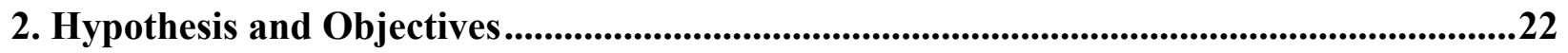

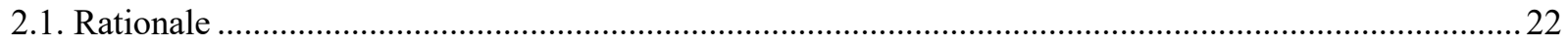

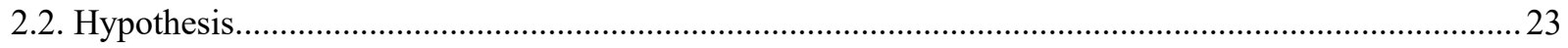

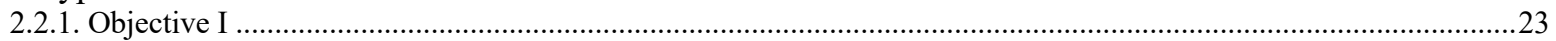

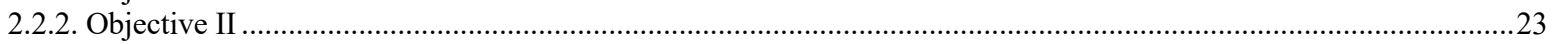

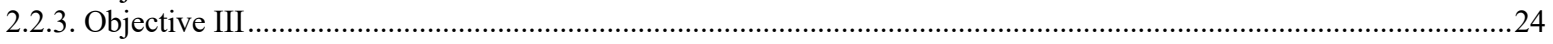

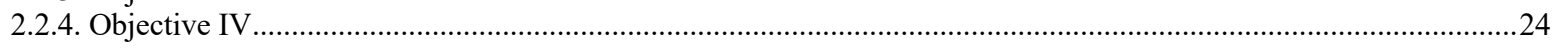

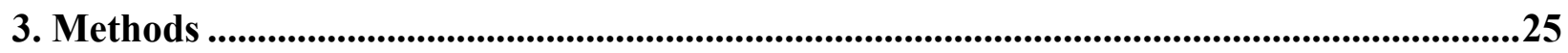

3.1. Amplification of $\operatorname{arnB}$, ompT and $\mathrm{pmr} D$ promoters using polymerase chain reaction..........................25

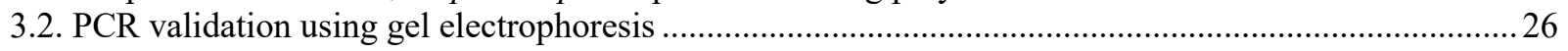

3.3. Amplification of $p a g P$ and $p m r D$ promoters using a temperature gradient PCR ................................2 27

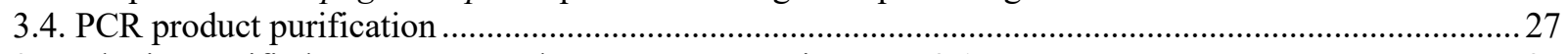

3.5. Cloning purified $a r n B$, pagP and $p m r D$ promoters into pCR2.1 TOPO Vector .................................22

3.6. Transformation of pCR2.1 TOPO with $\operatorname{arn} B$, pagP and $p m r D$ promoter inserts into MACH1 cells ..... 28

3.7. X-gal screening of transformed MACH1 colonies ................................................................................2 28

3.8. Confirmation of pCR2.1 TOPO with $\operatorname{arn} B$, pagP and $p m r D$ promoter inserts into MACH1 cells.........29

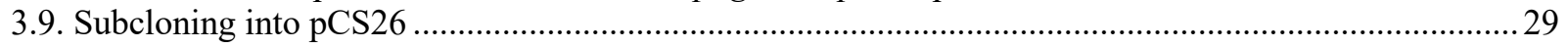

3.10. Verification of $\operatorname{arn} B, \operatorname{pag} P$ and $p m r D$ promoters cloned into pCS26 plasmid using colony PCR........ 30

3.11. Luciferase assay monitoring $p a g P$ and $p m r D$ upregulation in BW25113 and $\triangle p h o P$ BW25113 ........ 31

3.12. Production of $a r n B$, $p a g P$ and $p m r D$ promoter + green fluorescent protein fusions........................... 32

3.13. Cloning purified $\operatorname{arn} B$, pagP and $p m r D$ promoter fusions with GFP into pCR2.1 TOPO Vector........ 33

3.14. Transformation of $a r n B$, ompT and $p m r D$-GFP constructs into a panel of 8 clinical CD isolates using

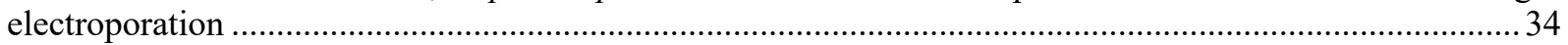

3.15. Fluorescence assay monitoring gene induction in panel of 8 clinical CD isolates ............................... 34

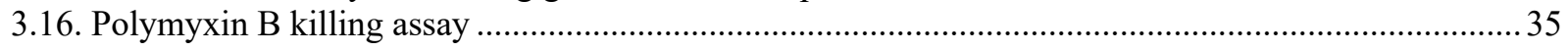




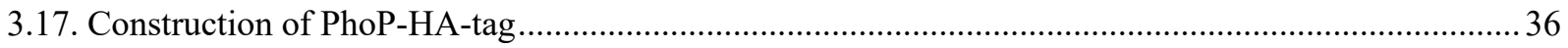

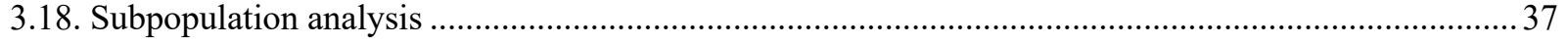

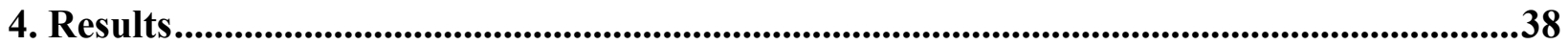

4.1. Differential regulation of $\mathrm{pmrD}$ and ompT are observed in divergent strains of IBDEC...................... 38

4.2. Strain-to-strain differences in the relationship between $\mathrm{Mg}^{2+}$ concentrations and PhoPQ signaling ...... 40

4.3. PMB resistance of IBDEC strains differs due PhoPQ signaling potential .......................................... 43

4.4. PmrA transcriptional feedback repression results in reduced $p m r D$ expression in IBDEC strain DK8944

4.5. Differential $p m r D$ and omp $T$ signaling in other pathogenic E. coli strains ....................................... 46

4.6. Subpopulation analysis highlights differential signaling potential and morphology among IBDEC

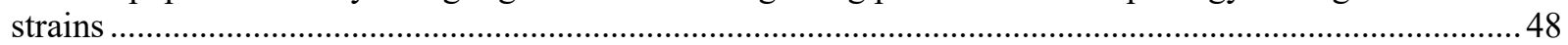

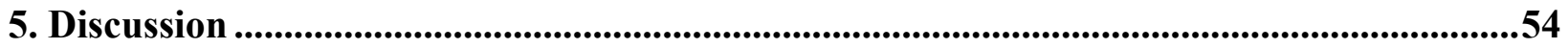

5.1. Heterogeneity in PhoPQ signaling among IBDEC isolates .............................................................. 55

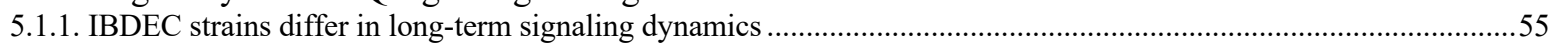

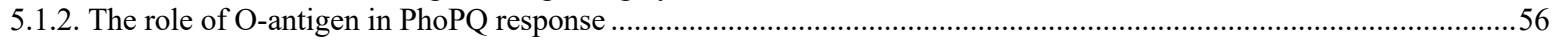

5.2. PhoPQ signaling as a predictive marker for resistance .......................................................................... 57

5.2.1. Heteroresistance within isogenic cultures causes unusual resistance patterns .............................................................58

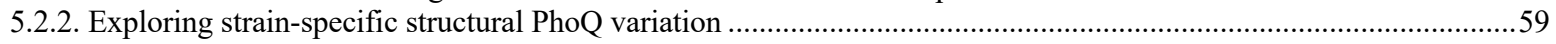

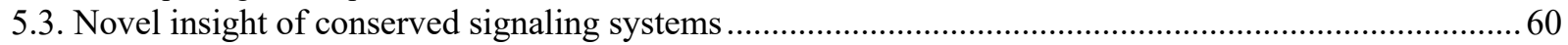

6. Future Directions ....................................................................................................................61

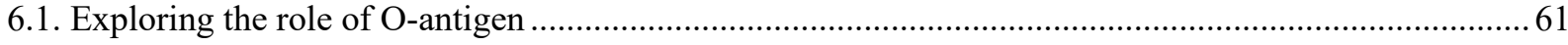

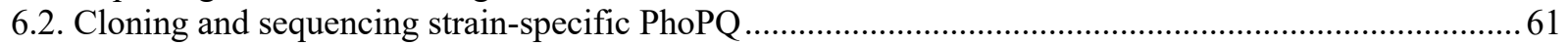

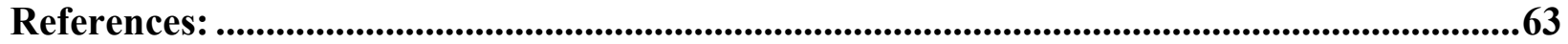




\section{List of Tables}

Table 1. Primers designed for amplification of arnB, pagP and pmrD promoters from BW25113_....................... 25

Table 2. Thermocycler configuration for amplification of arnB, pagP and pmrD promoters from BW25113......... 26

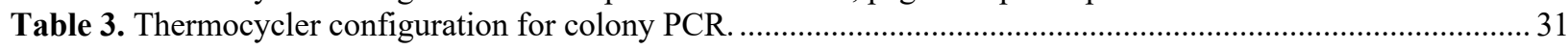

Table 4. Primers designed for amplification of GFP and arnB, pagP, pmrD promoters........................................... 33

Table 5. Primers designed for amplification of PhoP-HA-tag. ............................................................................ 36

Table 6. Resistance profiles of selected clinical isolates against HDPs LL-37 and hBD3...................................... 38 


\section{List of Figures}

Figure 1. Visual representation of the classical two-component pathway............................................................ 15

Figure 2. Visual representation of the unorthodox two-component pathway......................................................... 16

Figure 3. Phosphatase activity from the histidine kinase sensor...................................................................... 18

Figure 4. Schematic of the PhoPQ-PmrD-PmrAB two component system in E. coli. ............................................ 20

Figure 5. Resistance to LL-37 (a) or hBD3 (b) in IBDEC varies by the disease state of the patient from whom the

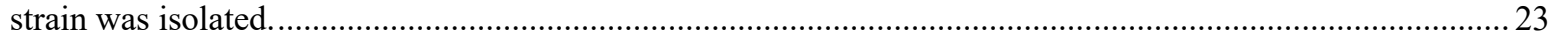

Figure 6. Example of 96-well plate layout for fluorescence assay testing for the PhoPQ TCS induction. ................ 35

Figure 7. Measuring PhoPQ signaling in K12 and CD isolates under fixed $\mathrm{Mg}^{2+}$ concentrations........................... 40

Figure 8. PhoPQ signaling response to increasing $\mathrm{Mg}^{2+}$ concentrations................................................................ 43

Figure 9. Polymyxin B resistance of K12 and CD isolates to increasing drug concentrations................................. 44

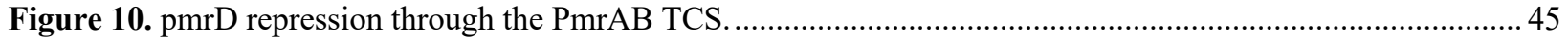

Figure 11. PhoPQ signaling in non-IBDEC pathovars of E. coli......................................................................... 47

Figure 12. Heteroresistance within isogenic cultures................................................................................... 48

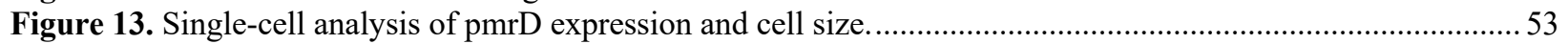




\section{List of Abbreviations}

$\mathrm{A} / \mathrm{E}=$ attaching and effacing

AIEC = adherent-invasive $E$. coli

$\mathrm{BP}=$ base pair

$\mathrm{CA}=$ catalytic and ATP-binding

$\mathrm{CAMP}=$ cationic antimicrobial peptides

$\mathrm{CD}=$ Crohn's disease

CEACAM = carcinoembryonic antigen-

related cell adhesion molecules

$\mathrm{CFU}=$ colony forming unit

DHp $=$ dimerization and histidine

phosphotransfer

DSS $=$ dextran sulphate sodium

DNA = deoxyribonucleic acid

$\mathrm{EA}=$ ethanolamine

$\mathrm{EHEC}=$ enterohemorrhagic E. coli

$\mathrm{EPEC}=$ enteropathogenic $E$. coli

ETEC $=$ enterotoxigenic $E$. coli

$\mathrm{FD}=$ fast digest

$\mathrm{Fe}=$ iron

$\mathrm{GFP}=$ green fluorescent protein

$\mathrm{GI}=$ gastrointestinal tract

GPL = glycerophospholipids

GWAS = genome wide association study

$\mathrm{hBD}=$ human beta defensin

$\mathrm{HA}=$ hemagglutinin

HDP $=$ host defense peptide

$\mathrm{HF}=$ high-fidelity

$\mathrm{HK}=$ histidine kinase

$\mathrm{Hpt}=$ histidine phosphotransferase

$\mathrm{HNP}=$ human neutrophil peptide/protein

IBD $=$ inflammatory bowel disease

IBDEC = IBD-associated $E$. coli

ICP = inductively coupled plasma

Ig = immunoglobulin

$\mathrm{IL}=$ interleukin

INF- $\gamma=$ interferon gamma

IS $=$ insertion sequence
$\mathrm{KB}=$ kilobase

$\mathrm{LB}=$ lysogeny broth

LEE $=$ locus of enterocyte effacement

LPS = lipopolysaccharide

MCS $=$ multiple cloning sites

MDP = muramyl dipeptide

$\mathrm{Mg}=$ magnesium

$\mathrm{MQ}=$ milli $\mathrm{Q}$

$\mathrm{NK}=$ natural killer cell

$\mathrm{NOD}=$ nucleotide oligomerization domain

OCCC $=$ Ontario Crohn's and Colitis Cohort

$\mathrm{OD}=$ optical density

$\mathrm{PBS}=$ phosphate buffer saline

$\mathrm{PCR}=$ polymerase chain reaction

$\mathrm{PD}=$ periplasmic domain

$\mathrm{PMB}=$ polymyxin $\mathrm{B}$

$\mathrm{REC}=$ receiver domain

$\mathrm{RFU}=$ relative fluorescence units

$\mathrm{RR}=$ response regulator

SAK = staphylokinase

SCFA $=$ short chain fatty acid

$\mathrm{SNP}=$ single nucleotide polymorphism

S.O.C. $=$ super optimal broth with catabolite repression

SOE-PCR = single overlap extension

polymerase chain reaction

T3SS = type III secretion system

TCS $=$ two-component system

Tir $=$ translocated intimin receptor

$\mathrm{TNF}=$ tumor necrosis factor

$\mathrm{UC}=$ ulcerative colitis

$\mathrm{UPEC}=$ uropathogenic $E$. coli

$\mathrm{UTI}=$ urinary tract infection

$\mathrm{UV}=$ ultraviolet

$\mathrm{WT}=$ wild-type 


\section{Introduction}

\subsection{Inflammatory bowel disease}

Inflammatory bowel disease (IBD) is a family of disorders that results in chronic inflammation of the gastrointestinal (GI) tract $^{7}$. The disease is further categorized into one of two conditions: ulcerative colitis (UC), which affects the colon, and Crohn's disease (CD), which is primarily localized to the ileum and caecum ${ }^{8}$. The onset of either condition results in symptoms such as abdominal pain, bloody diarrhea, fatigue, fever and decreased appetite ${ }^{7,8}$. The nature of IBD results in a cyclic pattern of disease flares followed by times of remission. This pattern, if not treated appropriately, can result in permanent damage to the intestine ${ }^{9}$. While no cure of the disease exists, the current treatment methods include reducing the symptoms during flares through the use of biological drugs, antibiotics, steroids, anti-inflammatories and surgery when drug therapy is unsuccessful ${ }^{7,10}$. The former of the treatment options has had an enormous impact on patients living with IBD, as this surgery has demonstrated the ability to heal the mucosa and substantially decrease disease progression or the further need for hospitalization ${ }^{10}$. Two antitumor necrosis factor (anti-TNF) drugs called infliximab and adalimumab are used as the most common methods of biologic therapy ${ }^{7,9,10}$. While the introduction and success of these drugs has been remarkable, two fundamental problems exist. 1) Approximately one third of patients do not respond to these drugs, and up to $40 \%$ of initial responders lose their response over time ${ }^{9} .2$ ) Biologic drugs are not a cure for IBD; therefore, the continuous prescription of this medication is required to reduce the chance of flares and progression of the disease, which has a large financial burden ${ }^{10}$.

While IBD is a global burden with a prevalence rate of $0.5 \%$ (as of 2015) per general population of the Western world (including North America, Europe, New Zealand and Australia $)^{11}$, Canada is in the top $20 \%$ for incidence rate for both UC and CD, corresponding to a $0.67 \%$ rate per general population ${ }^{7}$. This incidence rate, which translated to approximately 230,000 cases of both $\mathrm{UC}$ and $\mathrm{CD}$ in 2012, not only has huge implications on the quality of life for patients but is also a tremendous financial burden on the healthcare system. Direct medical costs such as hospitalization, surgery, medications, laboratory tests and procedures for the treatment of IBD in Canada accounted for upwards of $\$ 1.2$ billion in 2012. Of this, the majority 
of the funds were allocated to drug cost and inpatient hospitalization ${ }^{7}$. IBD is a complex and multifaceted disorder that contains a number of factors which influence the disease state ${ }^{11}$. The three predominate factors that influence the development of the disease are environmental exposures, genetics and the gut microbiota population. Therefore, in order to fully recognize the intricacies of the disease, comprehensive understanding of all three primary factors is needed to successfully mitigate the financial and personal burden of IBD. As a result, the remaining portion of this section will be devoted to discussing each of the three factors individually.

\subsubsection{Environmental contribution}

Environmental exposures play a significant role in the onset of IBD. IBD is most prevalent in developed countries such as Canada and the United States ${ }^{7,12,13}$. This trend of higher IBD rates in developed countries is supported by parallel increases of IBD and industrialization of developing countries ${ }^{11,12}$. Since the relationship between smoking and IBD was first reported by Harries et al., there has been extensive work on this interaction ${ }^{15}$. Interestingly, while there seems to be a causal relationship between smoking and IBD, the effect of smoking on the disease state, whether it is direct or inverse, depends on the condition being discussed ${ }^{11,12,14}$. There is a direct causal relationship of smoking on CD. Smokers who have active CD have a dysbiosis of the gut microbiota that could be a potential source of this causal relationship ${ }^{11,12,16}$. In contrast, smoking appears to have a protective role in relation to $\mathrm{UC}$, as most of the patients are either non-smokers or ex-smokers ${ }^{11,12,17}$. Further, the relationship between diet and IBD has also been extensively studied. The results from a variety of studies consistently demonstrate in showing that a high-fat diet, predominately from red-meat, margarine and fish was associated with developing IBD, while diets rich in carbohydrates seem to have a negative effect on $\mathrm{IBD}^{11,12}$. Together, these results support the complex and multifactorial nature of IBD causation.

\subsubsection{Host genetics}

Canada continues to have one of the highest rates of IBD globally due to rising pediatric IBD cases ${ }^{67-69}$. The Ontario Crohn's and Colitis Cohort (OCCC) completes population-based surveillance programs that monitor cases of IBD throughout the province. Data from 1991 - 
2008 showed increasing trends of pediatric IBD cases in children younger than the age of 10 years old while rates for adults and the elderly remained relatively stable ${ }^{69}$. Age of onset produces distinct disease phenotypes and different responses to genetic predisposition. Patients with early-onset $\mathrm{CD}$ (characterized by onset of disease under the age of 5) show more colonic involvement and rectal bleeding than onset of $\mathrm{CD}$ in children from the ages of 6-17, who display majority ileocolonic disease localization and more diverse range of symptoms ${ }^{70}$. Furthermore, genetic predisposition has more of a pronounced impact on pediatric onset patients, who exhibit a higher propensity for mutations in genes associated with the onset of $\mathrm{IBD}^{71}$.

Several large-scale genome-wide association studies (GWAS) have been completed that aim to find genetic differences between healthy individuals and patients with IBD. These studies have been very successful in identifying genes associated with disease predisposition, and close to 200 genes are currently known to predispose individuals to UC and/or CD. Of these, singlenucleotide polymorphisms (SNPs) in genes that confer strongest association with IBD are $N O D 2, I L 23 R$, and $A T G 16 L 1^{11,18-22}$. NOD2 is an intracellular receptor found on macrophages, dendritic cells, and Paneth cells that is able to sense muramyl dipeptide (MDP), a common component of both gram-positive and gram-negative peptidoglycan ${ }^{57,72}$. This detection results in the production of $\mathrm{NF}-\mathrm{\kappa B}$, a transcription factor that is crucial in propagating an immune response. Ogura and colleagues found that if the NOD2 protein is truncated via a cytosine insertion at nucleotide 3020 resulting in a premature stop codon, induction of NF- $\mathrm{kB}$ is lost. This frameshift mutation in NOD2 is associated with a susceptibility to $\mathrm{CD}^{20}$. IL23R is an immune receptor that is highly expressed on activated Th17 cells and natural killer (NK) cells. Downstream effects of inducing this receptor includes production of cytokines IL-17A, IL- 17F, IL-22 and IL-21, and proliferation and survival of Th17 cells. R381Q, an IL23R variant, seems to have a protective effect against CD and IBD. In 2011, Pidasheva et al. found evidence that R381Q achieves this protective outcome by diminishing signaling through the JAK/STAT pathway $^{21}$.

Lastly, ATG16L1 is a protein that is involved in an important cellular recycling process called autophagy that occurs by fusion of a double-membraned vesicle containing cytoplasmic cargo with a lysosome. A Thr300Ala SNP in the ATG16L1 increases the sensitization of 
ATG16L1 to capase-3 mediated cleavage, ultimately diminishing autophagy. This weakened response was correlated with a defect in the removal of ileal pathogen Yersinia enterocolitica and also resulted in higher induction of pro-inflammatory cytokines ${ }^{46}$. Mice raised with hypomorphic ATG16L1 display a defect in Paneth and epithelial cells. Paneth cells are specialized cells part of the ileal epithelium layer that serve a main function of secreting granules with antimicrobial peptides. The hypomorphic ATG16L1 protein in mice show distinct irregularities in the granular exocytic pathway and an increase in cytoplasmic vesicles. Interestingly, similar phenotypic defects have been reported in the Paneth cells of CD patients positive with the $A T G 16 \mathrm{~L} 1$ risk allele ${ }^{58,59}$. Mutation in ATG16L1 is also shown to affect the overall transcriptional profile of the cells, most importantly resulting in an increase of lipid metabolism genes and pro-inflammatory cytokines. Following LPS stimulation, NOD2 recruits ATG16L1 to the bacterial plasma membrane where the process of autophagy begins. Plantinga and colleagues (2011) showed that loss of autophagy due to polymorphism in ATG16L1 increases the production of pro-inflammatory cytokines IL-1 $\beta$ and IL-6 after NOD2 stimulation, linking the chronic inflammation phenotype seen in Crohn's disease patients ${ }^{73,78}$. Therefore, genes involved in the detection of microbes and in host immune response such as NOD2, IL23R, and $A T G 16 L 1$ have been reported by several groups as susceptibility genes for $\mathrm{IBD}^{18-24,58,59 \text {, }}$ $72,73,78$.

\subsubsection{Altered gut microbiome}

The human gut microbiome is a vast and tremendously complex system, with an estimated $10^{14}$ bacterial cells of approximately 1000 species residing in our gut ${ }^{25}$. This bacterial community, in healthy individuals, functions in a symbiotic manner with the host. However, in

patients with IBD, there is a shift in the composition of the microbial community ${ }^{25,26}$. A study by Gevers and colleagues in 2014 illustrated that samples from multiple gastrointestinal locations from early onset CD patients had increased numbers of Enterobacteriaceae, Pasteurellacaea, Veillonellaceae, and Fusobacteriaceae, while exhibiting a decreased numbers of Bacteroidetes, and Clostridia. Such changes are attributed to alterations in the overall gut environment, in particular the nutrient and oxygen environment which facilitates the growth of facultative anaerobes. 
Following inflammation of the GI tract, increase expression of pro-inflammatory cytokines such as interferon- $\gamma$ (INF- $\gamma$ ) promote the production nitric oxide, ultimately leading to nitrate production on the luminal surface of the gut. Members of the Enterobacteriaceae family have well conserved nitrate reductase enzymes that are able to utilize nitrate for respiration, while other families of obligate anaerobic bacteria such as Bacteroidetes and Clostridia fail to obtain such genes ${ }^{74-76}$. Additional nutrient production from host cells after inflammation promotes the selection of bacteria that can 'bloom' in such environmental niches. Phospholipids on the epithelial surface can be metabolized by microbes to ethanolamine (EA) to become a source of energy for ethanolamine degrading bacteria such as Salmonella, Escherichia coli and Clostridium difficile (C. difficile). Increased mucus production on the epithelial surface production is also associated with an inflamed gut. While the mucosal layer is traditionally known for providing a protective barrier for the host against bacterial threat, they are rich in amino acids such as proline, serine and threonine which can be glycosylated and used as a sugar nutrient source for invading microbes. As a result, there is often an enrichment of mucus degrading bacteria associated with inflammation of the GI tract ${ }^{74-76}$. This allows for a yet another nutrient advantage of invading pathogens over commensal bacteria, further narrowing the overall diversity of the gut microbiota. The host inflammatory response is also coupled with several antimicrobial effector mechanisms intended to eliminate infectious pathogens. Epithelial and Paneth cells increase the expression of several antimicrobial peptides in response to colitis. Invading pathogens have formed elegant systems to avoid killing through these peptides, ranging from cell-membrane modifications to expression of proteases that can degrade the peptides ${ }^{76-77}$.

Combating these bacteria with antibiotics as a first-line therapy for treating IBD may not be the best practice. Data from Gevers and colleagues' investigation revealed that the microbial community altered significantly more when antibiotics are administered ${ }^{27}$. Additionally, a more recent paper further discussed the link between antibiotics and dysbiosis of the gut. Perturbation of the gut microbiome via antibiotics or diets high in fat and sugar result in a lower production of short-chain fatty acids (SCFA), which are critical in mediating anti-inflammatory responses ${ }^{60}$. This line of reasoning is consistent with hypothesis of colonization resistance which will be discussed below, where loss of protective and beneficial microbes allows the chance for originating the proliferation of other non-beneficial taxa ${ }^{6,27}$. 


\subsection{Escherichia coli}

\subsubsection{Escherichia coli as a commensal}

Escherichia coli (E. coli) is a rod-shaped, gram-negative facultative anaerobe that belongs to the larger family of Enterobacteriaceae and colonizes the colon of the mammalian gastrointestinal tract ${ }^{1,2}$. As a gram-negative bacterium, E. coli has two membranes; an inner phospholipid membrane and outer membrane rich with proteins, lipopolysaccharide (LPS), and phospholipids $^{3}$. E. coli colonizes the mucosal membrane of the large intestine and is part of our large microbiota population that contains trillions of bacteria functioning in a symbiotic relationship with the host ${ }^{4,6,44}$. E. coli is among the first colonizers of the infant GI tract and an individual may be colonized by 10 or more individual strains of this bacterium at any one time. This mucosal colonization occurs as a result of a mixed-species biofilm formation upon the thin layer of mucus coating epithelial cells. The human gut is also protected by immunoglobulin A ( $\operatorname{IgA}$ ), an antibody important in both the prevention of bacterial overgrowth and subsequent translocation, and in facilitating biofilm formation of beneficial gut microbes. In particular, a study conducted by Bollinger and colleagues found that sIgA increased E. coli adherence to live cultured epithelial cells by $64 \%{ }^{45}$. Once colonization occurs, the nutrient source within this niche environment is from shed epithelial cells, diet-derived nutrients fiber and mucosal polysaccharides. E. coli is unable to degrade these polysaccharides; therefore, the species relies on other anaerobic bacteria within the mucosal layer to degrade these polysaccharides into smaller mono- and di-saccharides via secretion of extracellular polysaccharide hydrolases ${ }^{6}$.

This relationship between commensal E. coli and other anaerobic microbes in the mixed biofilms is referred to as the "Restaurant" hypothesis. In this hypothesis, commensal E. coli can associate with their own respective polysaccharide degrading mixed anaerobe species, which are able to 'feed' the degraded sugars to E. coli. Different commensal E. coli inhabit different 'restaurants' (or mixed species biofilms), ultimately leading to different metabolic capabilities depending largely on the population the commensal resides $\mathrm{in}^{79}$. In return, E. coli, among other commensal microbes, aid in the production of various nutrients and vitamins for the host, while the host provides an environmental niche enriched with nutrients of its own that allow the microbial communities to thrive within ${ }^{4,5}$. In particular, commensal bacteria directly protect the 
host from being colonized with potentially harmful microorganisms through a process of competitive exclusion. This mucosal protection, formally termed colonization resistance, occurs via the microbial community being able to out-compete invading species for limiting nutrients, thus making it difficult for new microorganisms to survive in a dense and competitive population of bacteria. The fundamental basis of this colonization resistance follows Dr. Rolf Freter's nutrient-niche hypothesis, which states that in order to successfully colonize and persist in the intestine, bacteria must grow faster and also be able to use at least one limiting nutrient better than all other bacterial species present in that community ${ }^{6}$. Disruption of this dynamic bacterial ecosystem can lead to invading pathogenic microbes to successfully colonize the intestine and become a source for infectious disease.

\subsubsection{Pathovars of $E$. coli}

E. coli is one of the best characterized and widely used prokaryotic model organisms. Most studies using E. coli as a model organism are completed with non-pathogenic, lap-adapted E. coli strains called K12. However, in reality, there is large amount of variation between commensals, lab-adapted strains and pathovars of $E$. coli ${ }^{80,81}$. What makes E. coli a commensal is successfully colonizing the colon without producing adverse effects to a healthy host at normal concentrations $^{82}$. On the other hand, well-studied pathovars such as enterohemorrhagic E. coli (EHEC), uropathogenic E. coli (UPEC) and enteropathogenic E. coli (EPEC) differ through the utilization of virulence factors such as adhesion genes and secretion systems acquired through horizontal DNA transfer, ultimately leading to pathogenicity. For instance, in addition to symptoms of severe abdominal pain and diarrhea, a hallmark of both EHEC and EPEC infection is the presence of attaching and effacing $(\mathrm{A} / \mathrm{E})$ lesions on the intestinal epithelial surface. This phenotype is attributed to the acquisition of a large pathogenicity island called the locus of enterocyte effacement (LEE) which codes for the adhesin intimin, a type III secretion system (T3SS), various effectors including a translocated intimin receptor (Tir) ${ }^{82-85}$. A/E lesions form in a highly organized manner by responding to environmental ques such as different carbon sources, hormones, and autoinducers ${ }^{85}$. UPEC, the main etiological agent for urinary tract infections (UTI), also has distinct virulence gene expressions that allow it to successfully colonize and replicate within the urinary tract. Snyder and colleagues (2004) analyzed the 
transcriptome of UPEC strain CFT073 after CBA/J mouse infection. They found of the 313 upregulated genes, 45 did not have homologs in E. coli K12. The majority of these genes encoded for virulence factors associated with iron uptake systems, fimbrial adhesion genes (primarily type 1 fimbriae), and capsular synthesis. Interestingly, the group reported up to a 4fold increase in the induction of genes coding for microcins, which are small antibiotic compounds often secreted by bacteria to outcompete other bacterial strains, illustrating the competitive edge this UPEC gains in a harsh and nutrient limiting area ${ }^{86}$. These examples highlight the diverse nature of $E$. coli as a bacterium, where it can be identified as a symbiont in the human gut microbiome, or a pathogenic microbe capable of causing severe disease.

\subsection{Adherent-invasive Escherichia coli}

Early work in 1978 showed that E. coli antibody titers were higher in both CD and UC patients when compared to a control population ${ }^{87}$. Since then, there has been extensive work to characterize a pathovar of IBD-associated E. coli. More recent studies from the Darfeuille group found that $E$. coli was highly prevalent (50-100\%) upon analysis of the aerobic and anaerobic bacterial community associated with the ileal lesions of CD patients ${ }^{28,29}$. Isolates from both chronic and early ileal lesions showed enhanced ability to better adhere to Caco- 2 cells $(84.6 \%$ and $78.9 \%$ respectively) when compared to isolates from healthy controls $(33.3 \%)$. One of the CD ileal isolates called LF82 showed that in addition to its adherent property, the strain has been reported to invade and persist within phagocytic cells such as macrophages ${ }^{29,88-90}$. Screens attempting to find virulent genes such as eae encoding for intimin in EHEC and EPEC or ipaC encoding for an invasin protein in Shigella flexneri in the IBD-associated E. coli isolates showed that these strains lacked any of the known virulence genes in other enteric pathogens ${ }^{28}$. Therefore, a new pathovar of E. coli called adherent-invasive Escherichia coli (AIEC), distinguished by its ability to invade epithelial cells, was created ${ }^{28,29}$.

\subsubsection{Adhesion}

While the adherent and invasive role of this bacteria is well established, the mechanisms by which this occurs is not well-characterized. As stated above, AIEC does not possess known 
type III secretion systems or exotoxin virulence genes common to different pathogenic E. coli strains such as EPEC, entero- toxigenic E. coli (ETEC), or EHEC, leaving numerous unresolved questions about how the bacterium might contribute to IBD pathogenesis. Despite the lack of obvious virulence factors, several groups have examined specific adhesins that might contribute to host colonization.

Common to most E. coli species are filamentous appendages called pili. Of these proteins, the most commonly found pili called the type 1 pili is involved in adhesion to various eukaryotic cell surfaces such that are rich in mannosylated glycoproteins. The entire pilus is composed of nine genes that encode for the protein itself, chaperone and usher proteins, and transcriptional regulators of the major subunit fimA. FimH is the adhesion located on the tip and is primarily responsible for the binding of mannosylated glycoproteins ${ }^{89}$. In 2001, Boudeau and colleagues showed evidence that AIEC strain LF82 uses a type 1 pili variant to adhere and invade intestinal epithelial cells. To confirm the role of the type 1 pili in the adherence and invasion properties of LF82, the group screened for an identified 11 non-invasive mutants in the strain using transposon mutagenesis within the fim operon. Of the 11 mutants, 10 resulted in complete loss of the type 1 pili, while the remaining mutant reduced type 1 pili synthesis. Nine out of the 11 strains, all of which lost the ability to synthesize the type 1 pili, showed reduced ability to adhere to and invade intestinal epithelial cells. Two strains that had insertions in fimF and fimI did not show changes in adherence of the strain. The fimF mutant resulted in the reduced type 1 pili synthesis, while the function of fimI is not well understood. When these noninvasive fim mutants were complemented with the entire type 1 pili operon, invasion phenotypes were restored to wildtype LF82 levels. Interesting, the complementation of the entire type 1 pili operon from LF82 to a non-invasive E. coli strain did not result in an 'invasive switch', insinuating strain-specific accessory genes and proteins involved in the overall adherence and invasive phenotype of LF82 ${ }^{89}$. Further, in 2007, Barnich et al. showed that there was an upregulation of glycosylated receptors of the type 1 pili variant called carcinoembryonic antigen-related cell adhesion molecules 5 and 6 (CEACAMs) on the apical surface of the ileal epithelium from CD patients ${ }^{31}$. The authors illustrated that the type 1 pili from LF82 preferentially binds CEACAM6 to manifest its invasive phenotype, shown by decreased LF82 adhesion after pretreatment of ileal enterocytes from CD patients with anti-CEACAM6 
antibodies. In 2009, Carvalho et al. expressed CEACAM6 in transgenic mice in order to determine if the AIEC strain LF82 could colonize the intestinal mucosa and induce subsequent inflammation. The authors found that strain LF82 was able to colonize the mucosal layer in the transgenic mice, and produced several pathogenic phenotypes including colitis, rectal bleeding, mucosal inflammation, increased proinflammatory cytokine expression, and weight loss ${ }^{30}$. These findings suggest 1) patients with overexpression of CEACAM6 might be at an increased risk of establishing the onset of IBD, and 2) elevated ileal expression of CEACAM6 might act as a biomarker for $\mathrm{CD}$ in undiagnosed patients.

\subsubsection{Metabolic adaptability}

The gut epithelial surface is highly colonized area where commensals and AIEC pathovars must compete for nutrients and resources. Critical for survival is exploiting different metabolic pathways and nutrient sources to create a metabolic niche in which the bacteria can thrive. AIEC strains have shown several ways to accomplish this. A recent study looking at the transcriptome of LF82 after exposure to bile salts highlighted up regulation of several gene clusters associated with degradation pathways ${ }^{91}$. In response to bile salts, 17 genes in the eut operon, which includes genes for the degradation and utilization of ethanolamine, were upregulated significantly (2.3 to 12.2-fold). When compared to a non-AIEC strain, LF82 grew more efficiently in minimal media supplemented with EA as the sole nitrogen source which correlated with significantly higher expression of genes in the eut operon in LF82 vs. non-AIEC strains. To associate this observation with intestinal colonization in mice, the authors orally challenged mice with a 1:1 ratio of LF82 and $\mathrm{LF} 82 \Delta e u t B$, a mutant unable to use EA as a nitrogen source. LF82 was significantly enriched in stool samples and ileal and colonic tissue when compared to LF82 $\Delta e u t B$, showing an overall increased fitness advantage ${ }^{91}$. The same authors also reported significant up-regulation of genes in the $p d u$ operon, a cluster of genes used in the degradation of 1,2-propanediol, the byproduct of fucose fermentation. While 1,2propanediol utilization systems are present in other gram-negatives such as Salmonella, they are not commonly found in non-AIEC E. coli strains. This form of fucose and subsequent propanediol utilization not only gives AIEC a unique competitive edge in nutrient sources, but also might enhance invasion and replication in macrophages as is seen in Salmonella ${ }^{91-93}$. Another similar approach looking at the entire genome of phylogenetically diverse AIEC isolates 
from CD patients, mice with ileitis, and dogs with colitis showed elevated expression of both the $p d u$ operon and the $c h u$ operon, which encodes for iron acquisition genes. Iron was shown to be essential for the growth of AIEC. Nutrient rich broth treated with iron chelator 2,2'-dipyridl significantly decreased growth of AIEC strain CUMT8. The growth decrease was restored through the addition of ferrous at levels higher than the $100 \mu \mathrm{M}$. Additionally, elevated production of $c h u A$, a gene encoding for a heme iron acquisition protein, resulted in enhanced survival inside macrophages ${ }^{93}$. These examples highlight the metabolic adaptability of AIEC as a pathogen, where it can utilize diverse pathways to gain a competitive edge in a nutrient scarce environment.

\subsubsection{Animal infection models}

Several attempts at establishing an animal model for AIEC infection have been described. In 2009, Carvalho et. al introduced using CEABAC10 transgenic mice, which express humans CEACAMs, to test whether LF82 could colonize the intestinal mucosa and cause subsequent inflammation. While LF82 was unable to colonize wild-type mice, the strain successfully colonized and caused severe inflammation in the transgenic mice after being orally challenged. A loss of colonization in this mouse line was shown after using a LF82 non-piliated mutant, confirming the role of the type 1 pili and CEACAM6 receptor interaction for the adhesion of LF82 to the mucosal surface ${ }^{94}$. A critical component of this AIEC infection model was to pretreated mice with a colitogenic chemical called dextran sulphate sodium (DSS) to induce colitis chemically. In 2013, members from the Coombes lab established another AIEC-mouse infection model that did not need coadministration of a chemical or a transgenic mouse line. The group used another AIEC strain NRG857c to infect streptomycin-treated conventional mice. NRG857c was able to outcompete LF82 when both strains were inoculated at 1:1 ratio in CD1 mice and showed consistently higher bacterial load when both strains where monocolonized. Upon NRG857c infection, the authors showed evidence for chronic inflammation within the gut, with pronounced phenotype present in the caecum. Interestingly, while levels of AIEC fell below the threshold for detection in mouse strain C57BL/6, the inflammation phenotype within the gut of the mice persisted. This phenomenon, as noted by the authors, provides insight into the 
potential lasting effect left by AIEC on the gut even after the bacteria is cleared or reduced to a miniscule scale ${ }^{32}$.

\subsection{Host defense peptides}

\subsubsection{Classes and structure}

Host defense peptides (HDPs) are cationic amphiphilic peptides that are present as an integral part of the innate immune system. The general structure of these antimicrobial peptides can be defined as $<100$ amino acids in length, with an overall positive charge, and containing a large portion of hydrophobic residues ${ }^{33}$. These peptides are found in abundance within mammals as they are expressed by a number of cells, including epithelial cells within the gut. Two primary classes of HDPs present in humans that contribute to intestinal epithelial defense include defensins and cathelicidins. Defensins are separated into two distinct classes, $\alpha$-defensins and $\beta$ defensins, both of which are stabilized through disulphide bounds between six cysteine residues $^{95-97}$. Both defensin classes have similar tertiary structures because of three disulphide bonds that result in triple stranded $\beta$-sheet structures with a $\beta$-hairpin loop that contains the cationic residue. In $\alpha$-defensins, the disulphide bonds are between cysteine residues C1-6, C2-4, and $\mathrm{C} 3-5$, and in $\beta$-defensins, the disulphide bonds are between $\mathrm{C} 1-5, \mathrm{C} 2-6$, and $\mathrm{C} 3-6^{96,97}$. $\alpha$ defensins are most prominently found in the granules of granulocytes in mammalian cells, such as the human $\alpha$-defensins human neutrophil peptide (HNP) 1-4, which are abundant proteins in neutrophils. Other $\alpha$-defensins called HD-5 and HD-6 are found expressed in the small intestinal crypts and within the granules of Paneth cells ${ }^{96,97,100}$. Conversely, $\beta$-defensins are more widely distributed throughout the body and can be sub-characterized in terms of expression. For instance, human beta-defensin-1 (hBD1) is constitutively expressed by intestinal epithelial cells, while hBD2 and hBD3 are up-regulated after enteric pathogen invasion and with inflammatory disorders, respectively ${ }^{95,97}$. LL-37, the only characterized human cathelicidin, is a dynamic HDP that is expressed by neutrophils, monocytes, natural killer (NK) cells, T cell, B cells, and in the GI tract ${ }^{97}$. LL-37 is capable of stimulating a wide range of responses including pro- and antiinflammatory activities, wound healing, chemoattractant for immune cells, antimicrobial activity 
and much more ${ }^{36,97}$. As a first line of defense, both classes of HDPs represent a critical mechanism of host-intestinal defense against microbial threat.

\subsubsection{Mechanisms of action}

A common site of HDP expression is on the mucosal layer that covers epithelial cells in $\operatorname{animals}^{35}$. Initial HDP-mediated protection against bacteria, particularly of interest, gramnegative bacteria such as $E$. coli, relies on the electrostatic bonding of cationic peptides with negatively charged surfaces on bacterial membranes such as LPS. Once initial attraction towards the negatively charged surface is established, the peptide inserts into the bilayer and form transmembrane pores, disrupting the bacterial surface and ultimately leading to leakage of cellular content ${ }^{33,34,95-97}$. In addition to membrane rupture, there is also evidence of peptides having an intracellular mode of killing. After translocation into the cytoplasm, different HDPs can inhibit cell-wall, nucleic-acid, and protein synthesis and/or intracellular enzymatic activity ${ }^{34}$. Regardless of the specific mechanism of action, the net result is to reduce the bacterial load on the colonized mucosal surface, thereby contributing to host defense. The thinning of the mucosal layer after inflammatory flares of patients who suffer from IBD is associated with elevated production and localization of HDPs to the mucosal surface. In 2013, Meish et al. showed that there was increased expression of hBD3 in the biopsies from the terminal ileal of patients with CD compared to those from healthy controls ${ }^{98}$. In addition, another group showed that there was increase in LL-37 expression in both inflamed and non-inflamed patients with UC ${ }^{99}$. The host response in elevated production of antimicrobial peptides is critical in maintaining mucosal tolerance of a changing microbial community. However, bacteria with intrinsic HDP resistance could exploit survival in such harsh conditions produced by the host and help manifest the pathology of IBD.

\subsubsection{HDP resistance}

Bacteria have evolved various mechanisms to evade killing by HDPs. Staphylococcus aureus (S. aureus), a gram-positive species that is a common source of both nosocomial and community infections, secretes a protein called staphylokinase (SAK) which bind $\alpha$-defensins to render them inactive ${ }^{77,100}$. Jin and colleagues (2004) tested 19 S. aureus strains against the 
bactericidal properties of $\alpha$-defensins HNP1 and HNP2 and found that strains which produce SAK were effectively protected against the bactericidal activity of the peptides ${ }^{100}$. Other common bacterial resistance mechanism involves modifications to the cell membrane to reduce the overall negative charge. Lipid A, the bioactive component of LPS found on the gramnegative bacterial outer membrane contains anionic phosphate moieties. Several groups have shown that pathogens such as Salmenolla and Pseudomonas aeruginosa modify lipid A through the addition of positively charged aminoarabinose, altering the net membrane charge and enhancing the resistance of these microbes to cationic peptides ${ }^{77,101-103}$. Additional resistance mechanisms in Salmonella include using outer membrane proteases to cleave HDPs directly ${ }^{103}$. Guina et al. (2000) showed that strains expressing outer membrane protease PgtE had elevated resistance to $\alpha$-helical peptide $\mathrm{C} 18 \mathrm{G}$ through peptide degradation at one of the three putative $p g t E$ cleavage sites ${ }^{104}$. Further, several bacterial species use efflux pumps to protect against cationic antimicrobial peptides (CAMPs). Neisseria gonorrhoeae, the causative agent of the sexually transmitted disease gonorrhea, uses the MtrCDE efflux pump to actively export antibiotics, dyes, detergents, and HDP LL-3 $7^{102}$. The examples listed above are some of the many ways bacterial pathogens have evolved to escape killing from HDPs. The variety in resistance strategies highlights the need to better understand how these bacteria respond to antimicrobial threat.

\subsection{Two-component systems}

\subsubsection{Structure and function}

Two-component systems (TCSs) are common prokaryotic signaling systems that enable organisms to have an adaptive response to the microenvironments they reside in consists. They typically consist of two major players, a membrane-bound histidine kinase (HK) sensor and the cognate response regulator (RR). The former is traditionally known as the 'input' component of the pathway, where an appropriate stimulus interacts with the extracellular or periplasmic domain of the HK to cause an autophosphorylation reaction on a conserved histidine residue ${ }^{49,50,51}$. Typically, the cytoplasmic core of the HK consists of two distinct domains: the Cterminal catalytic and ATP-binding (CA) domain, and a dimerization and histidine 
phosphotransfer (DHp) domain ${ }^{51}$. The initial phosphorylation occurs through an ATP-dependent mechanism where the CA domain binds ATP and carries the catalytic reaction of transferring the phosphryl group from ATP to a conserved histidine residue located on the DHp domain ${ }^{50,51}$.

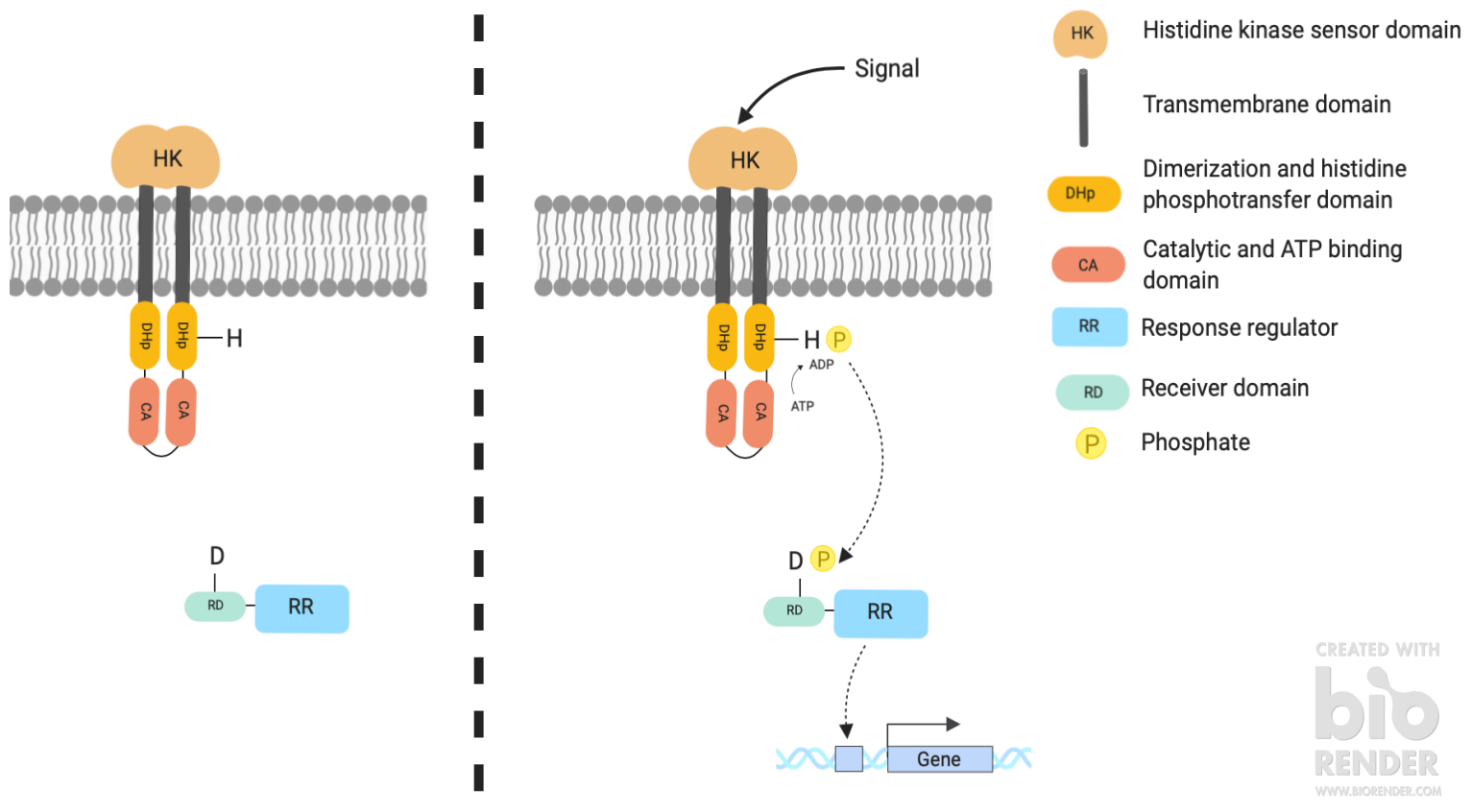

Figure 1. Visual representation of the classical two-component pathway.

Upon inducing stimulus, there is a phosphorylation of the conserved histidine residue on the DHp domain on the histidine kinase. Subsequently, there is a phosphor-transfer to the receiver domain on the response regulator, which activate the protein to regulate genes downstream.

Upon HK autophosphorylation at the histidine residue, two separate modes of action can occur to propagate the signal downstream to the RR, either a classical two-component pathway, or an unorthodox phosphorelay pathway depending on the structure of each respective system. In the classical pathway, upon autophosphorylation of the conserved histidine residue, there is a transfer of the phosphoryl group to the aspartate residue located on the receiver domain of the RR (Fig. 1) ${ }^{1}$. The latter phosphorelay pathway involves a hybrid HK which has a receiver domain of its own. It has been estimated that roughly $25 \%$ of HK have this additional receiver domain, suggesting that this 'unorthodox' pathway is actually rather common among TCS signaling pathways ${ }^{1,51}$. In this pathway, after autophosphorylation the phosphoryl group is 
transferred from phosphor-his to the receiver domain located on the C-terminus of the HK. Following this, a histidine phosphotransferase (HPt) domain receives the phosphoryl group from the HK receiver domain and shuttles the phosphoryl group to the receiver domain found on the cognate RR (Fig. 2) ${ }^{1}$. For TCSs, these HPt domains do not possess any kinase or phosphatase activity, therefore it is proposed to be involved as means of extra-regulatory measures ${ }^{51}$.

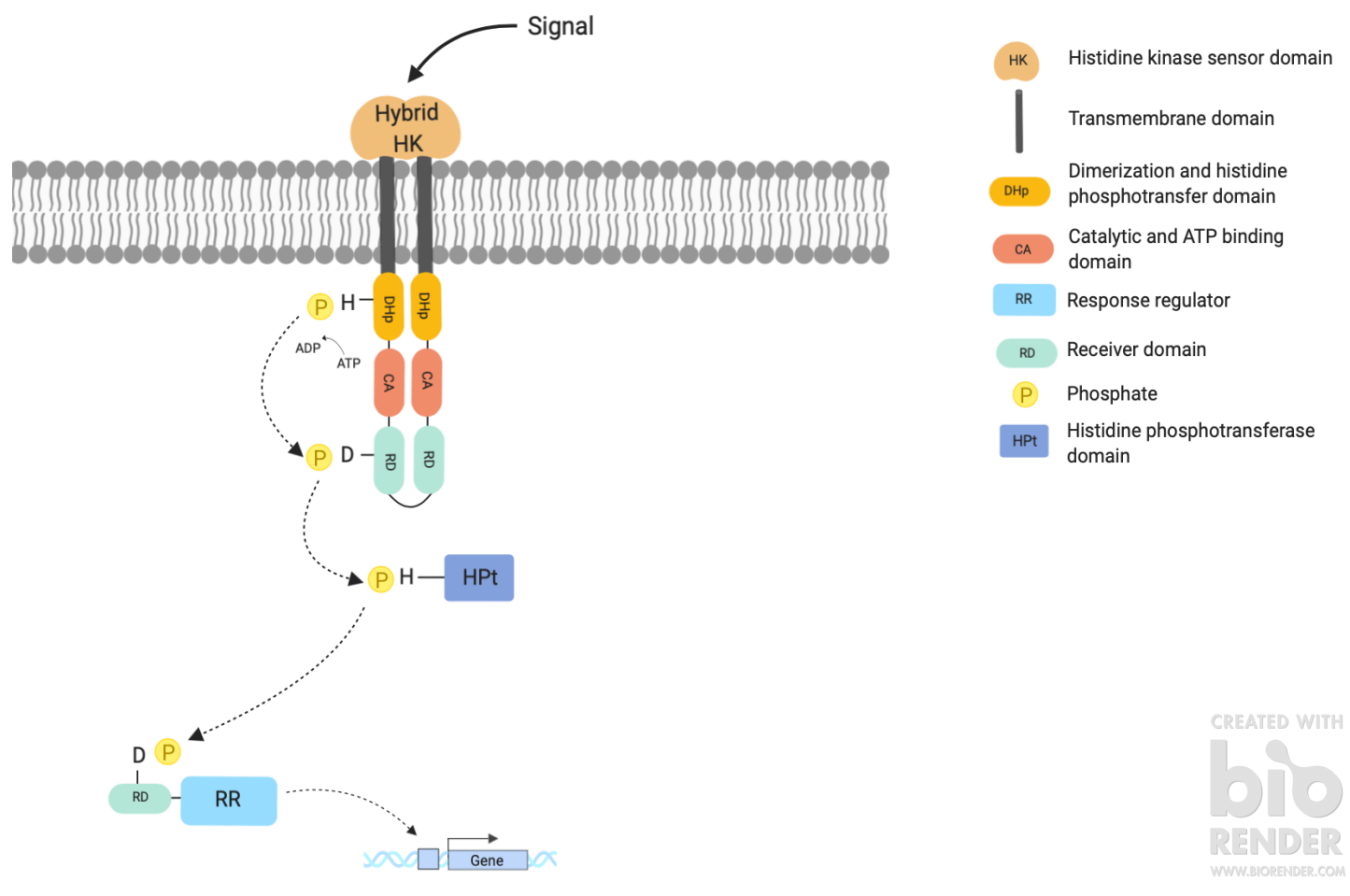

Figure 2. Visual representation of the unorthodox two-component pathway.

Upon inducing stimulus, the histidine kinase phosphorylates the histidine residue on the DHp domain, and subsequently transfers the phosphate to its own REC domain. The histidine phosphotransferase shuttles the phosphate to the REC domain on the response regulator, which activate the protein to regulate genes downstream.

The terminal RR is responsible for the 'output' response produced by a TCS, often leading to alterations in gene expression. Prototypical RR consist of two domains, an N-terminal receiver (REC) domain, and an effector domain ${ }^{51}$. The REC domain is approximately 120 residues which is bond with $\alpha / \beta$ folds and is found is two states, either active or inactive. The switch between the active or inactive state depends on phosphorylation from the HK. Upon 
phosphoryl transfer from the HK to the REC domain of the cognate RR, there is a conformational change in the RR that renders the REC domain active $\mathrm{e}^{1,50,51}$. The phosphorylation of this domain occurs at a conserved aspartate residue found on the loop that is after $\beta 3$ fold ${ }^{51}$. Following this, the active REC domain is able to modulate the effector domain, which elicits the output response often through regulating transcription via DNA binding. For instance, in the well-studied PhoPQ TCS, the RR PhoP binds a repeat of a two 7bp binding motifs spaced by a $4 \mathrm{bp}$ insert in-between them. This binding motif is called the pho box and is found on the promoters of many PhoP regulated genes ${ }^{52}$. Therefore, when the PhoP RR is phosphorylated, it directly binds, with high affinity, to the binding motif of the several downstream genes as a dimer to induce gene expression.

Despite the name, many HK have phosphatase activity their toward respective cognate RR's as well. When stimulating conditions are lost, the HK is able to effectively dephosphorylate the RR to rapidly stop the signaling pathway. A well-characterized example of this is within the EnvZ-OmpR TCS. This system, which is responsible for regulating responses to changing osmolarity, has a HK sensor (EnvZ) that is capable of autophosphorylation, phospho-transfer to its cognate RR OmpR, and subsequent dephosphorylation of phospho-OmpR (OmpR-P) ${ }^{53}$. As such, the output generated by such TCSs is generally controlled through the status of these bifunctional HK. Such bifunctionality is proposed to be used to avoid crosstalk by different TCSs. Down regulation of a cognate RR via phosphatase activity assures that there is no unintended phosphorylation from another a non-cognate $\mathrm{HK}$ and also allows rapid responses to changing environmental conditions. In addition, this allows for the suppression of non-cognate RR phosphorylation through constant phosphatase activity during unstimulated conditions, allowing for a more regulated mechanism of inducing each respective $\mathrm{TCS}^{54}$. One of the proposed phosphatase activities from HK is thought to occur on the DHp domain, with the conserved histidine residue playing an important role. One of the possible dephosphorylation mechanisms is through reversal of RR-phosphorylation to the His residue on the $\mathrm{HK}^{50,51}$. Conversely, several other dephosphorylation mechanisms must exist, as HK mutants that lack the histidine residue still possess phosphatase activity, insinuating another mode of action (Fig. 3) $)^{50,51}$. 
a)

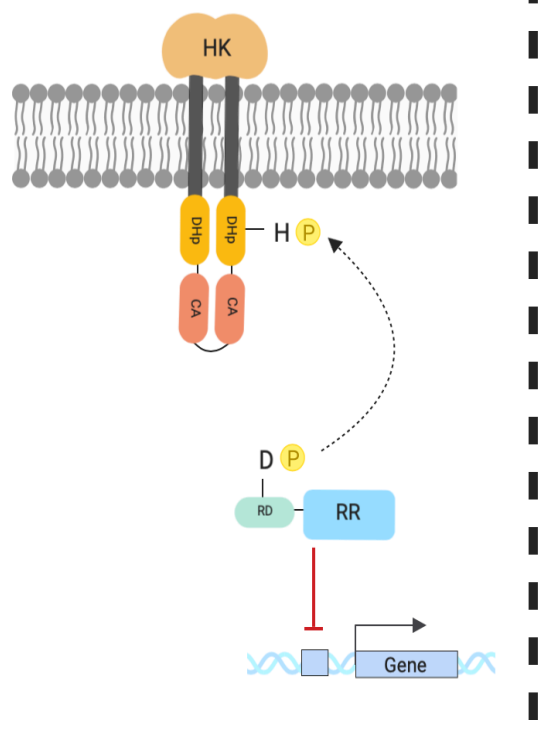

b)
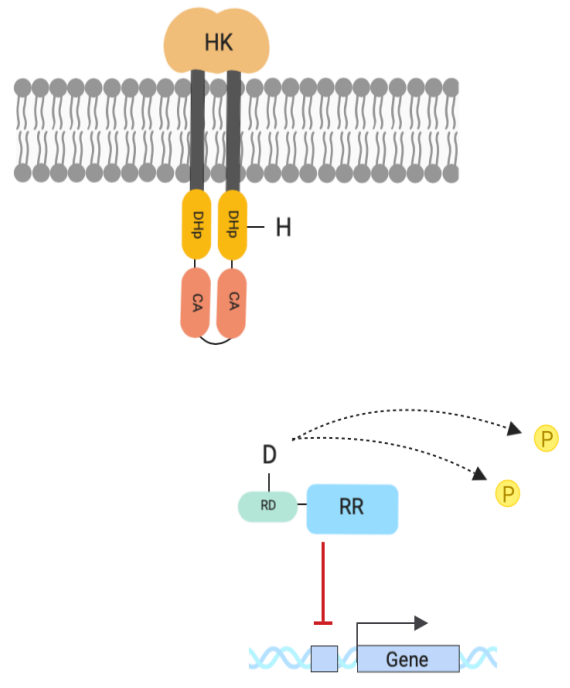

Histidine kinase sensor domain

Transmembrane domain

Dimerization and histidine phosphotransfer domain

Catalytic and ATP binding domain

RR Response regulator

RD Receiver domain

(P) Phosphate

Figure 3. Phosphatase activity from the histidine kinase sensor.

a) reverse phospho-transfer to the conserved histidine residue on the histidine kinase. b) reverse phospho-transfer independent method leading to dephosphorylation of the aspartate residue on response regulator.

Accessory proteins can play a role in the dephosphorylation of the RR. An example of such an interaction is a small 47 amino acid protein called MgrB with the PhoQ HK sensor. Upon sensing of antimicrobial peptides or low magnesium conditions by PhoQ HK sensor, there is an increase in PhoP phosphorylation, which leads to subsequent increase of PhoP regulated genes. This upregulation includes an increase in the transcription of $m g r B$. Goulian and colleagues (2009) demonstrated that after translation, MgrB localized to the inner membrane, orientating in a way where the $\mathrm{N}$-terminus is exposed to the cytoplasm and the $\mathrm{C}$-terminus is facing outwards towards the periplasm. To verify MgrB and PhoQ interaction, they performed a bacterial two-hybrid assay which showed for evidence of a physical interaction between MgrB and PhoQ. Deletion of $m g r B$ resulted in a dramatic increase in transcription of PhoP regulated genes, and conversely, over expression resulted in significantly lower transcription of PhoP regulated genes in both inducing and non-inducing conditions ${ }^{55}$, thus suggesting that MgrB plays a role in the regulation of PhoQ activity. 


\subsubsection{PhoPQ-PmrD-PmrAB signaling system}

Of interest to the McPhee lab are the PhoPQ and PmrAB TCSs. As briefly discussed above, within the PhoPQ TCS, PhoQ is the histidine sensor kinase that is involved in the detection of cationic peptides and is also induced in limiting conditions of divalent cations such as $\mathrm{Mg}^{2+}$. The PhoQ sensor has two transmembrane regions, a periplasmic sensor domain, and a cytosolic domain that is responsible for the catalytic output. Bader et al. (2005) examined the crystal structure of the Salmonella PhoQ sensor domain and demonstrated that there is an acidic surface on the sensor domain that closely interacts with the inner membrane. This acidic surface is negatively charged and requires divalent cations to form cationic bridges as means to interact with the negatively charged inner membrane. Divalent cations such as $\mathrm{Mg}^{2+}$ bind pockets within the acidic region of the periplasmic sensor domain, rendering PhoQ inactive, where it represses autophosphorylation of its own cytosolic catalytic domain. Antimicrobial peptides such as HDP LL-37 are small, positively charged molecules, and they therefore target the negatively charged head groups of phospholipids within the membrane. As such, these antimicrobial peptides come into close contact with the divalent cationic bridges resulting in competition for the negatively charged binding pocket on the acidic surface. This leads to the divalent cations being displaced, causing a conformation change that allows the autophosphorylation event on the catalytic domain to take place 55,56 . After activation, PhoQ phosphorylates the response regulator PhoP, which induces the expression of several genes downstream ${ }^{39}$. Two genes under the regulation of the PhoPQ TCS are pagP and pmrD. The PagP enzyme is involved in the transfer of palmitoyl groups from glycerophospholipids (GPL) to lipid A, the bioactive component of LPS that is recognized by the TLR4/MD2/CD14 innate immune receptor complex. This palmitoyl transfer increases the hydrophobicity of the outer membrane, which protects from HDPs ${ }^{39,40}$. PmrD is a protein downstream of the PhoPQ TCS which serves as a connector protein to another TCS

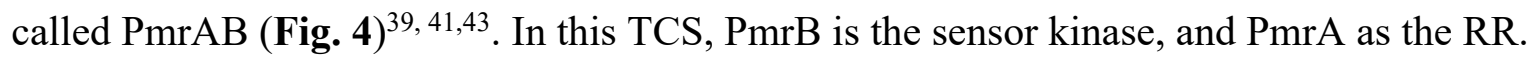
PmrAB responds to a variety of stimuli such as high $\mathrm{Fe}^{3+}$, low $\mathrm{pH}$ and bile salts ${ }^{115}$. After induction with such stimuli, PmrB phosphorylates PmrA, resulting in activation of several genes downstream. PmrB is also a bifunctional HK sensor, in that this protein has the ability to dephosphorylate PmrA to stop the signaling pathway. The PhoP regulated PmrD protein physically blocks phospho-PmrA from being dephosphorylated by PmrB, ultimately leading to 
robust activation of downstream genes that are involved in lipid A modification ${ }^{41}$. The net effect of this activation is addition of aminoarabinose to lipid A results in a lower overall negative charge on the LPS structure, allowing the bacteria to avoid killing via $\mathrm{HDPs}^{42,43}$.

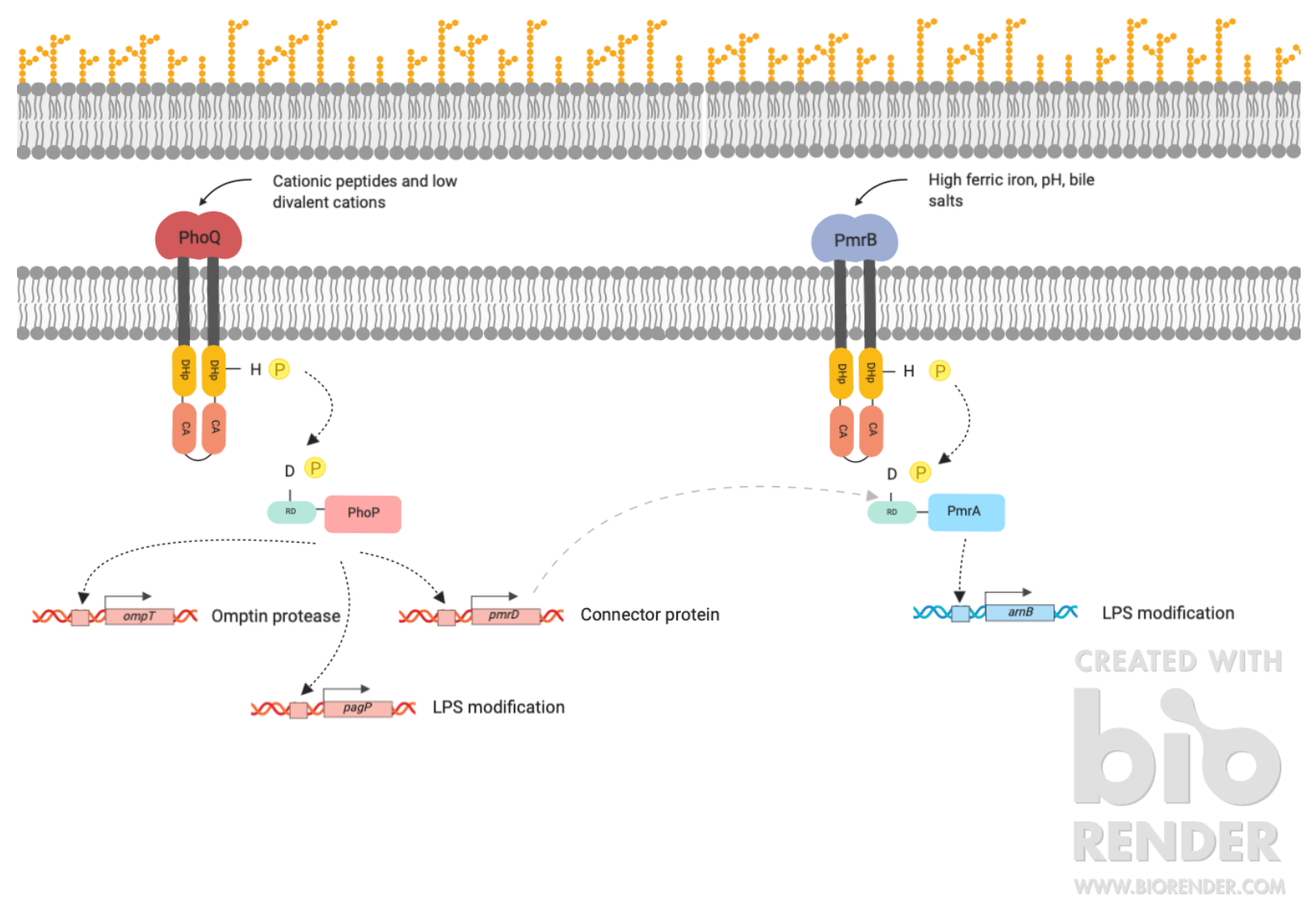

Figure 4. Schematic of the PhoPQ-PmrD-PmrAB two component system in E. coli.

As discussed above, HDPs commonly target the negative charge on bacterial membranes. As a result, bacteria have evolved intricate systems to avoid this peptide-mediated method of killing. These systems include either modifying the targets of HDPs, such as LPS on gramnegative outer membranes, or secreting outer membrane proteases involved in the degradation of HDPs (Unpublished data; Aziz, Cho and McPhee). In support of this, McPhee and colleagues illustrated in 2014 that AIEC strain NRG857c resist killing by HDPs through genes located on the plasmid-encoded genomic island (PI-6). Important to this effect are two proteins, arlA and arlC, encoding a Mig-14 family protein and an OmpT family outer membrane protease that is capable of cleaving LL-37, respectively ${ }^{47}$. While the role Mig-14 in resistance to HDPs is not yet 
well understood, the role of ompT in degrading $\alpha$-helical peptides is established, as was illustrated by Thomassin et al. in $2012^{48}$. These resistance outputs are under the regulation of a network of bacterial-sensing systems called two-component systems. In accordance to this, bacteria that display a broad range of metabolic diversity encode more TCSs in their genome than other bacteria that inhabit more of a uniform environment ${ }^{37}$. 


\section{Hypothesis and Objectives}

\subsection{Rationale}

Given the up-regulation of HDPs by the host and an increased presence of AIEC in patients with IBD, earlier work in the McPhee lab completed by graduate students Youn Hee Cho and Michael Renouf looked at resistance phenotypes of clinical strains of these IBDassociated E. coli (from now on, referred to as IBDEC) to HDPs LL-37 and hBD-3. Strains displayed a wide variety of resistance phenotypes, varying between completely susceptible to highly resistant for both LL-37 and hBD3 peptides (Fig. 5). In general, hBD-3 resistance is enriched in CD isolates, while LL-37 resistance is enriched in UC isolates. This variable phenotypic output forms the fundamental rationale behind my project: what is the underlying mechanism behind the heterogeneity in these resistance phenotypes among different strain of IBDEC?

The PhoPQ and PmrAB TCSs represent a mechanism by which IBDEC can respond and elicit resistance to HDPs. While a lot of previous work has been completed looking at TCS response to different concentrations of stimuli, insight into how genetically similar strains differentially responding to the same signal has yet to be determined. Most work in a laboratory setting using E. coli as a model organism is completed using K12 lab strains. These strains are experimentally evolved and well adapted to various growth and stressed conditions. As a result, they often yielding a consistent phenotypic output. Using non-lab adapted clinical strains allows for differentiation of a genetically similar bacterial groups into subpopulations with distinct phenotypes. Such distinct phenotypic outputs could provide insight as to how these different strains sense and respond to a fluctuating environment. Therefore, as a means to investigate the observed variation in HDP resistance, we hypothesize that the clinical isolates of IBDEC are able to differentially respond to the same stimulus of both the PhoPQ and PmrAB TCSs and that this difference may lead to elevated HDP resistance in those strains. 

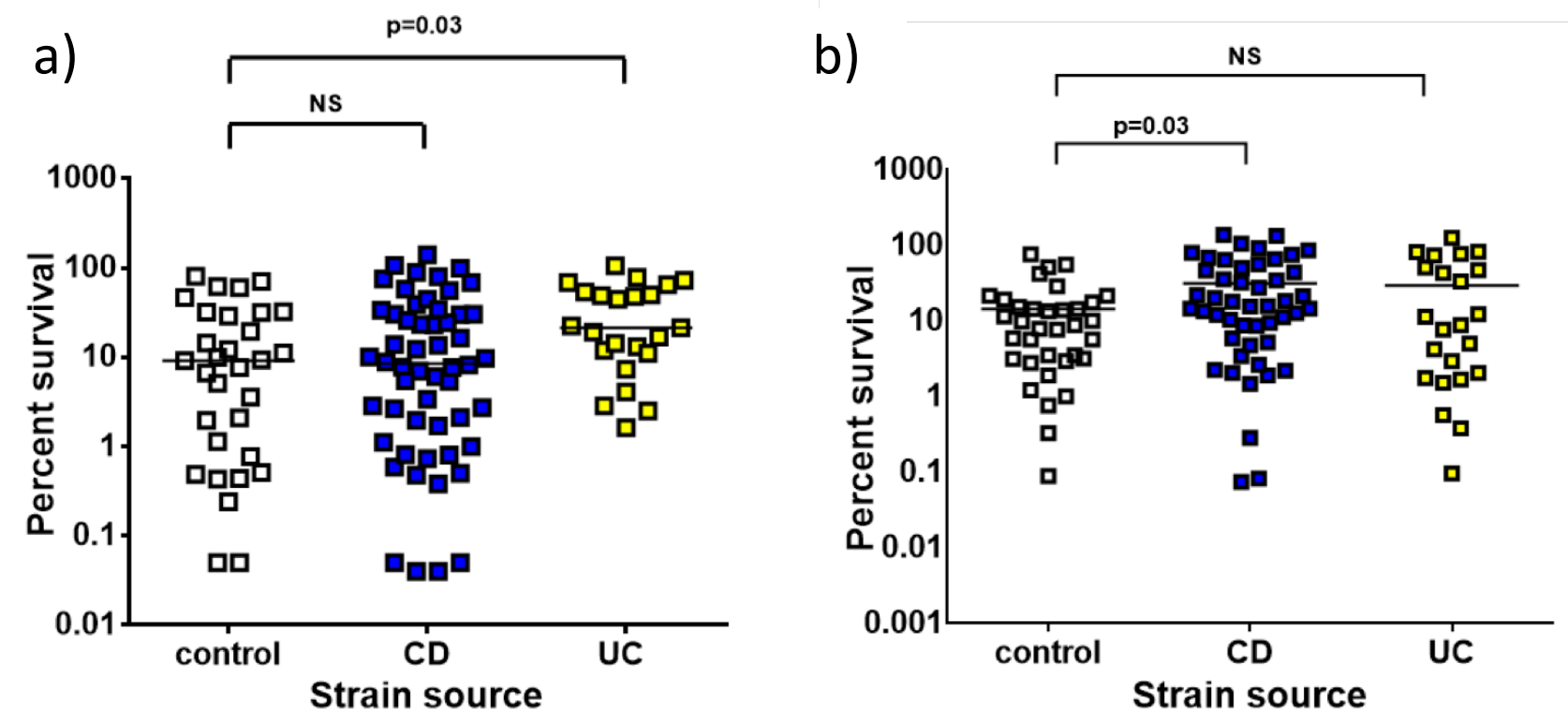

Figure 5. Resistance to LL-37 (a) or hBD3 (b) in IBDEC varies by the disease state of the patient from whom the strain was isolated.

\subsection{Hypothesis}

There is heterogeneity among IBDEC strains in the induction level of the PhoPQ and PmrAB TCS regulated genes using the same concentration of inducing stimulus and this heterogeneity contributes to HDP resistance.

\subsubsection{Objective I}

Fuse promoter regions of representative genes downstream of each TCS with a green fluorescent protein. Clone fusions into plasmid to serve as a toolbox for subsequent fluorescence assays. The promoter regions selected are arn operon, ompT and $p m r D$.

\subsubsection{Objective II}

Transform the constructs into a panel of clinical CD isolates for analysis of TCSs induction under stimulating conditions. The output will be measured using a fluorescence assay, 
measuring $\operatorname{arnB}$, ompT and $p m r D$ promoter activity. Here we will examine two distinct outputs of gene expression, absolute level of expression (measured in RFU/OD600) and fold-induction in response to a set of standardized inducing conditions.

\subsubsection{Objective III}

Measure polymyxin B resistance in IBDEC strains under varied $\mathrm{Mg}^{2+}$ concentrations to correlate any observed heterogeneity in $\mathrm{Mg}^{2+}$ dependent gene expression with a phenotypic output.

\subsubsection{Objective IV}

Perform western blots for HA-tagged PhoP in the panel of CD isolates and K12.

Following this, levels of PhoP phosphorylation for each strain will be determined by using phostag gels. 


\section{Methods}

\subsection{Amplification of $a r n B, o m p T$ and $p m r D$ promoters using polymerase chain reaction}

Using a BIO-RAD C1000 Touch ${ }^{\mathrm{TM}}$ Thermal Cycler, a polymerase chain reaction (PCR) was performed to amplify the upstream promoter regions of the $\operatorname{arn} B$, pagP and $p m r D$ genes using genomic DNA (gDNA) extracted from a K12 strain of E. coli BW25113. Primers were designed (Table. 1) and ordered from Sigma Aldrich ${ }^{\circledR}$ in dry form at $100 \mu \mathrm{M}$ stock for the forward (containing the XhoI restriction site) and reverse (containing the BamHI restriction site) strands in order to amplify the promoter region of each respective gene. Primers were resuspended in sterile milli-Q water (MQ- $\left.\mathrm{H}_{2} 0\right)$ to make $10 \mathrm{X}$ working stocks. A volume of $20 \mu \mathrm{L}$ PCR was prepared for each respective gene. The $20 \mu \mathrm{L}$ reaction contained the following: $10.2 \mu \mathrm{L}$ sterile MQ- $\mathrm{H}_{2} \mathrm{O}, 4 \mu \mathrm{L}$ High-Fidelity (HF) buffer, $0.4 \mu \mathrm{L} 10 \mathrm{mM}$ dNTPs, $0.25 \mu \mathrm{L}$ of Phusion ${ }^{\circledR}$ Hot Start II High-Fidelity DNA Polymerase, $4 \mu \mathrm{L}$ primer pair, and $0.5 \mu \mathrm{L}$ BW25113 gDNA. The reaction assembly was performed on ice. As a result, PCR tubes were also prechilled on ice to ensure that an optimal temperature was maintained throughout the process. As a general note, a master mix containing MQ- $\mathrm{H}_{2} \mathrm{O}, \mathrm{HF}-\mathrm{Buffer}, \mathrm{dNTPs}$ and Phusion ${ }^{\circledR}$ polymerase was made in a $1.5 \mathrm{~mL}$ microcentrifuge tube in that order. Subsequently, the master mix was aliquoted into an appropriate number prechilled PCR tubes. Once the master mix was evenly distributed, the primer pair for each respective gene and the gDNA was added. The PCR tubes were centrifuged for approximately 30 seconds before being placed in the thermocycler. The thermocycler was configured to an annealing temperature of $64^{\circ} \mathrm{C}$, extension temperature of $72^{\circ} \mathrm{C}$, and was run for 30 cycles (Table. 2 ).

Table 1. Primers designed for amplification of $\operatorname{arnB}$, pagP and $p m r D$ promoters from BW25113.

\begin{tabular}{|l|l|}
\hline PRIMER & SEQUENCE \\
\hline ArnB-Forward & CTCGAGGTAAACTCCACCTATAGACAAG \\
\hline ArnB-Reverse & $\underline{\text { GGATCCTGCTTTTCCTTCCGCCATTG }}$ \\
\hline PagP-Forward & $\underline{\text { CTCGAGCCCAATAAATTGGCGATG }}$ \\
\hline
\end{tabular}




\begin{tabular}{|l|l|}
\hline PagP-Reverse & GGATCCTTGTGACCATAAAACATTTATCAAAAATC \\
\hline PmrD-Forward & CTCGAGTCAGGCGCTAAAAGAGTGG \\
\hline PmrD-Reverse & $\underline{\text { GGATCCTGCATTATCCTGTTTGCTAAG }}$ \\
\hline
\end{tabular}

*Underlined sequence refers to restriction sites

Table 2. Thermocycler configuration for amplification of $\operatorname{arnB}, \operatorname{pag} P$ and $\operatorname{pmrD}$ promoters from BW25113.

\begin{tabular}{|l|l|l|}
\hline STEP & TEMPERATURE $^{\circ} \mathbf{C}^{\mathrm{C}}$ & TIME (in seconds) \\
\hline Initial & 96 & 60 \\
\hline Denaturing & 96 & 20 \\
\hline Annealing & 64 & 30 \\
\hline Extension & 72 & 30 \\
\hline Final Extension & 72 & 300 \\
\hline Infinite Hold & 4 & $\infty$ \\
\hline
\end{tabular}

\subsection{PCR validation using gel electrophoresis}

PCR products were verified using gel electrophoresis. In order to do this, a 1\% agarose small gel (6-8 wells) was created using $0.2 \mathrm{~g}$ of agarose powder, $20 \mathrm{~mL}$ of TAE buffer and $0.5 \mu \mathrm{L}$ of ethidium bromide. The agarose and TAE buffer was combined into a flask, after which the solution was microwaved to completely dissolve the agarose. Ethidium bromide was added once the solution was cooled to approximately $50-60^{\circ} \mathrm{C}$, or enough to be hand-held. Following this, the mixture was quickly transferred to a cast, and combs were placed inside before the mixture began to solidify. After solidification, the gel was submerged in TAE buffer inside the GE-100 MiniRun Gel Electrophoresis System. DNA ladder, either 1 kilobase (KB) or 100 base pair (BP) was added to the first lane for size references. Subsequent lanes were filled with $5 \mu \mathrm{L}$ of PCR product mixed with $0.5 \mu \mathrm{L}$ of Fast Digest (FD) Green Buffer. The gel was run at $100 \mathrm{~V}$ for approximately 15-18 mins. Following this, the gel was visualized with ultraviolet (UV) light using a Bio-Rad Gel Doc TM EZ Imager machine. 


\subsection{Amplification of $p a g P$ and $p m r D$ promoters using a temperature gradient PCR}

Based on the agarose gel results, successful amplification of the $\operatorname{arn} B$ promoter was completed based on the size of the band. The band for the pagP promoter was absent, therefore this amplification was not successful. It was suspected that the PCR product representing the pmrD promoter might be a hybridization of the forward and reverse primers due to the low brightness and molecular size. Therefore, in order to optimize the PCR for $p a g P$ and $p m r D$, a temperature gradient reaction was performed. This PCR protocol is identical to the one discussed above, with two differences: 1) a $50 \mu \mathrm{L}$ reaction size was used this time, which included: $32 \mu \mathrm{L}$ of MQ- $\mathrm{H}_{2} \mathrm{O}, 10 \mu \mathrm{L}$ HF buffer, $2 \mu \mathrm{L}$ dNTPs, $1 \mu \mathrm{L}$ Phusion ${ }^{\circledR}$ polymerase, $4 \mu \mathrm{L}$ primer pair and $1 \mu \mathrm{L}$ BW25113 gDNA, and 2) a panel of eight annealing temperatures were used for each respective promoter amplification. The temperature ranged from $60^{\circ}-70^{\circ} \mathrm{C}$. This temperature gradient efficiently determines the optimal annealing temperature for each PCR. Following the gradient PCR, validation through gel electrophoresis was completed as described above.

\subsection{PCR product purification}

Amplified DNA from the PCR described above were purified using a Geneaid $®$ Presto Gel/PCR DNA Fragments Kit. This high efficiency purification process removes any contaminants, enzymes, salts and unincorporated nucleotides, allowing up to $95 \%$ purification of a PCR product. Subsequently, the concentration of the eluted DNA was quantified using a Nanodrop ${ }^{\circledR} 2000$ Spectrophotometer.

\subsection{Cloning purified arnB, pagP and pmrD promoters into pCR2.1 TOPO Vector}

The nature of using high-fidelity polymerases such as Phusion ${ }^{\circledR}$ yields blunt-ends on the DNA being amplified. As a result, prior to inserting these vectors into pCR2.1 TOPO, purified DNA fragments were T-tailed to allow for effective ligation of the promoter inserts into the vector. Purified $a r n B$, pagP and $p m r D$ promoters, $5 \mu \mathrm{L}$ of $10 \mathrm{X}$ Taq buffer, $1 \mu \mathrm{L}$ of dNTPs, and $0.5 \mu \mathrm{L}$ of Taq polymerase were added to a $1.5 \mathrm{~mL}$ microcentrifuge tube. After all components had 
been combined, the mixture was centrifuged shortly prior to being incubated at $72^{\circ} \mathrm{C}$ for 10 minutes. Following incubation, the T-tailed DNA fragments were purified yet again, using the same protocol as described above. Once purified, the DNA fragments were cloned into pCR2.1 TOPO. In order to do this, $2 \mu \mathrm{L}$ of each respective T-tailed DNA fragments were combined with $0.5 \mu \mathrm{L}$ of $\mathrm{NaCl}$ solution and $0.5 \mu \mathrm{L}$ of $\mathrm{pCR} 2.1 \mathrm{TOPO}$ vector and centrifuged for a short time to ensure contents were mixed. The mixture was incubated at room temperature for approximately 15-20 minutes.

\subsection{Transformation of $\mathrm{pCR2.1}$ TOPO with arnB, pagP and $p m r D$ promoter inserts into MACH1 cells}

Chemically competent and fast growing MACH1 cells were used for initial transformations. To do so, MACH1 cells were thawed on ice for five minutes. After being thawed, each respective $3 \mu \mathrm{L}$ pCR2.1 TOPO reactions were added to MACH1 cells. The MACH1 cells + pCR2.1 TOPO went through a process of heat shock, where each tube containing the mixture was placed in a heating block set to $42^{\circ} \mathrm{C}$ for 30 seconds. Following this, all mixtures were placed on ice to recover for 5 minutes. $500 \mu \mathrm{L}$ of Super Optimal Broth (S.O.C) media was added to each tube, after which all tubes were placed in a shaking $37^{\circ} \mathrm{C}$ incubator for approximately two hours.

\subsection{X-gal screening of transformed MACH1 colonies}

The pCR2.1TOPO vector contains a lacZ $\alpha$ gene which encodes an enzyme called $\beta$ galactosidase that is capable of breaking the glyosidic bond of a sugar. Internally, the lacZ $\alpha$ gene has multiple cloning sites (MCS) that can be cut by restriction enzymes to insert fragments of DNA into. Therefore, if DNA is successfully inserted into the vector, the $\beta$-galactosidase enzyme will not be expressed. This reporter system can be utilized by using a substance called X-gal. Xgal is a clear liquid compound that contains galactose sugar linked to an indole molecule. $\beta$ -

galactosidase hydrolyzes the galactose in X-gal which yields a bright blue color bacterial colonies. A non-functional called $\beta$-galactosidase enzyme cannot breakdown the galactose, 
therefore will produce white bacterial colonies. Further, pCR2.1 TOPO also has kanamycin resistance as another mode of selection.

During two hours of recovery described above, lysogeny broth (LB) agar + kanamycin $(50 \mu \mathrm{g} / \mathrm{mL})$ plates were prewarmed in a $37^{\circ} \mathrm{C}$ incubator. After the recovery period was completed, LB + kanamycin plates were prepped for plating of the transformed MACH1 cells. First, each plate was treated with $25 \mu \mathrm{L}$ of X-gal. The X-gal solution was spread evenly using sterilized spreading beads. Once the X-gal solution had dried, each pCR2.1 TOPO transformed MACH1 strains were plated at two volumes, $50 \mu \mathrm{L}$ and $150 \mu \mathrm{L}$. Once the plates had dried, beads were removed, and all plates were incubated overnight at $37^{\circ} \mathrm{C}$.

\subsection{Confirmation of pCR2.1 TOPO with arnB, pagP and pmrD promoter inserts into MACH1 cells}

Following overnight incubation, plates were examined for blue and white colonies. 2-3 white colonies were picked and cultured overnight in $3 \mathrm{~mL}$ in $\mathrm{LB}+3 \mu \mathrm{L}$ of kanamycin. The following day, plasmids from overnight cultures were extracted using a Geneaid® High-Speed Plasmid Kit. After successful extraction, plasmids were double digested with an EcoRI restriction enzyme. This digestion separated the promoter inserts from the vector backbone. The digestion reaction included $5.5 \mu \mathrm{L}$ of $\mathrm{MQ}-\mathrm{H}_{2} \mathrm{O}, 0.5 \mu \mathrm{L}$ EcoRI, $1 \mu \mathrm{L}$ FD buffer, and $3 \mu \mathrm{L}$ of vector. The reaction was incubated at $37^{\circ} \mathrm{C}$ for 10 minutes. Once digestion was completed, a $1 \%$ agarose gel electrophoresis was performed. In addition, vectors containing the inserts were sent to an external sequencing facility for Sanger sequencing for verification.

\subsection{Subcloning into pCS26}

Upon sequence verification, the $\operatorname{arn} B$, pagP and $p m r D$ promoter inserts were subcloned from the pCR2.1 TOPO vector into a pCS26 plasmid. This plasmid contains a luxCDABE reporter system, which encodes for luciferase, an enzyme capable of producing luminescence. The pCS26 plasmid was extracted from using a Geneaid ${ }^{\circledR}$ Midi Plasmid Kit. In order to achieve the subcloning, another digestion reaction was performed using the XhoI and BamHI restriction 
enzymes. Purification of the digested vector was performed using the same PCR purification kit mentioned above, however, a gel extraction was completed instead of a PCR product purification. To do this, up to $300 \mathrm{mg}$ of the insert bands were excised from the $1 \%$ agarose gel under blue light to prevent DNA damage from UV light. The pCS26 plasmid was also digested with $\mathrm{XhoI}$ and $\mathrm{BamHI}$ and incubated at $37^{\circ} \mathrm{C}$ for 10 minutes. The digested plasmid and gel purified inserts were ligated together using the following reaction: $2 \mu \mathrm{L}$ of T4 ligase buffer, $2 \mu \mathrm{L}$ T4 DNA ligase, $2 \mu \mathrm{L}$ of double digested pCS26 plasmid, $10 \mu \mathrm{L}$ of gel purified respective promoter inserts and $4 \mu \mathrm{L}$ of $\mathrm{MQ}-\mathrm{H}_{2} \mathrm{O}$. The $20 \mu \mathrm{L}$ ligation reactions were incubated at room temperature for 1 hour. After the incubation period, all ligated plasmids were transformed in a DH5 $\alpha$ strain of E. coli using the same heat shock transformation protocol described above. After recovery, all strains were plated at two volumes of $50 \mu \mathrm{L}$ or $200 \mu \mathrm{L}$ on LB + kanamycin plates, as pCS26 also has kanamycin resistance.

\subsection{Verification of arnB, pagP and $p m r D$ promoters cloned into pCS26 plasmid using colony PCR}

Plates were examined for bacterial colonies the following day. Once there was visual confirmation of bacterial growth, colony PCR for each strain was performed to verify the promoter inserts. Colony PCR is an effective screening method to determine if the bacteria colonies have the plasmids of interest with the desired inserts. Plasmid specific primers are

needed for colony PCR, therefore, in this case, forward and reverse primers for pCS26 were used. Eight colonies were picked from each plate; therefore, a total 16 total colonies were picked from each individual strain. The colonies picked were used as a source of gDNA for the PCR. The reactions were $20 \mu \mathrm{L}$ and contained the following: $15.75 \mu \mathrm{L}$ MQ- $\mathrm{H}_{2} \mathrm{O}, 2 \mu \mathrm{L} 10 \mathrm{X}$ Taq buffer, $1 \mu \mathrm{L}$ dNTPs, $1 \mu \mathrm{L}$ pCS26 primer pair, $0.25 \mu \mathrm{L}$ Taq polymerase. The thermocycler was configured to an annealing temperature of $62^{\circ} \mathrm{C}$ (Table. 3). Following completion of PCR, the products were visualized through a $1 \%$ agarose gel described above. 
Table 3. Thermocycler configuration for colony PCR.

\begin{tabular}{|l|l|l|}
\hline STEP & TEMPERATURE $^{\circ} \mathbf{C}$ & TIME (in seconds) $^{-}$ \\
\hline Initial & 94 & 180 \\
\hline Denaturing & 94 & 30 \\
\hline Annealing & 62 & 20 \\
\hline Extension & 72 & 60 \\
\hline Final Extension & 72 & 600 \\
\hline Infinite Hold & 4 & $\infty$ \\
\hline
\end{tabular}

\subsection{Luciferase assay monitoring pagP and $p m r D$ upregulation in $B W 25113$ and $\triangle p h o P$ BW25113}

Following colony PCR verification of $\operatorname{arnB}$, $p a g P$ and $p m r D$ promoter inserts into pCS26, all plasmids were transformed into a collection of three $E$. coli strains: BW25113, $\Delta p h o P$ BW25113 and $\triangle p m r A$ BW25113 using the heat shock protocol described above. After successful transformations, freezer stocks of each strain were created. Luciferase based luminescence assays were performed using black-well, clear bottom 96 well plates. A total volume of $225 \mu \mathrm{L}$ was added to each well. Control wells included either $225 \mu \mathrm{L}$ of $\mathrm{N}$-minimal media with low $\mathrm{Mg}^{2+}$, N-Minimal media with high $\mathrm{Mg}^{2+}$, or LB. Overnight cultures of pCS26-pagP in BW25113 and $\triangle p h o P$ BW25113, and pCS26-pmrD in BW25113 and $\Delta p h o P$ BW25113 were prepared using $3 \mathrm{~mL}$ of $\mathrm{LB}+3 \mu \mathrm{L}$ of kanamycin. A 1:50 dilution of each overnight culture was used for the experiment. Three biological replicates of each combination of media and strain were arranged. Perimeter facing wells were filled with $250 \mu \mathrm{L}$ of $\mathrm{dH}_{2} \mathrm{O}$ to reduce the effect of evaporation during the experiment. After preparing the 96 well plates, a Biotek Synergy HTX Multi-Mode Reader was used to measure luminescence and bacterial growth. The luxCDABE bioreporter does not require any substrate or excitation to produce light, therefore the excitation wavelength was blocked, and emission filter was held at the 'hole' position. Luminescence and $\mathrm{OD}_{600}$ readings were measured every 15 mins for 12 hours under continuous shaking conditions at $37^{\circ} \mathrm{C}$. 


\subsection{Production of $a r n B, p a g P$ and $p m r D$ promoter + green fluorescent protein fusions}

In addition to utilizing luciferase activity as a measure for $\operatorname{arn} B$, $p a g P$ and $p m r D$ promoter regulation under inducing conditions using the pCS26 plasmid, arnB, pagP and $p m r D$ fusions with green fluorescent protein (GFP) were also constructed. GFPmut3, a more unstable version of GFP was used in order to more accurately track changes in gene expression levels. The protocol for creating these fusions involved a three step PCR, termed Single Overlap Extension PCR (SOE-PCR). Primers were generated for the promoter regions of arnB, pagP and pmrD. In addition, primers were also generated for GFP extracted from a p3174 plasmid. The primers were designed in a way where the end of the reverse primers for each respective promoter had the first 17 nucleotide sequences of GFP. Equally, the start of the forward primer designed for GFP contained approximately the last 20 nucleotides of each respective promoter region (Table. 4). Two separate PCRs were completed, one for each promoter region, and one for each promoter specific GFP region. This design enabled overhangs on each PCR product that allows the two products (promoter region and promoter specific GFP) to be 'stitched' together in the third PCR using the forward primer for the promoter, and the reverse primer for the promoter specific GFP.

The first two PCR were 50 $\mu \mathrm{L}$ reactions and contained the following: $32.5 \mu \mathrm{L}$ MQ- $\mathrm{H}_{2} \mathrm{O}$, $10 \mu \mathrm{L}$ HF buffer, $2 \mu \mathrm{L}$ dNTPs, $0.5 \mu \mathrm{L}$ Phusion ${ }^{\circledR}, 4 \mu \mathrm{L}$ appropriate primer pair, and $1 \mu \mathrm{L}$ of either BW25113 (promoters) or p3174 plasmid gDNA. Annealing temperature was set to $58^{\circ} \mathrm{C}$, and the reaction was run for 35 cycles. Optimization using gradient PCR was required for amplification of the $a r n B$ promoter region. Following successful amplification, all PCR products were purified as described above, and one last PCR was completed in order to fuse the promoter and GFP regions together. This was also a $50 \mu \mathrm{L}$ reaction, and included: $27.5 \mathrm{MQ}-\mathrm{H}_{2} \mathrm{O}, 10 \mu \mathrm{L} \mathrm{HF}$ buffer, $2 \mu \mathrm{L}$ dNTPs, $0.5 \mu \mathrm{L}$ Phusion ${ }^{\circledR}, 4 \mu \mathrm{L}$ appropriate primer pair, and $3 \mu \mathrm{L}$ of each respective purified promoter and purified GFP product as the gDNA. All PCRs were verified using a 1\% agarose gel, as described above. Subsequently, all products were purified as described above. 
Table 4. Primers designed for amplification of GFP and arnB, pagP, pmrD promoters.

\begin{tabular}{|l|l|}
\hline PRIMER & SEQUENCE \\
\hline ArnB-Forward -P1 & GAATCCGTAAACTCCACCTATAGACAAGCGC \\
\hline ArnB-Reverse -P2 & AGTTCTTCTCCTTTACGCATTGCTTTTCCTTCCGCCATTG \\
\hline $\begin{array}{l}\text { PrnB-GFP-Foward- } \\
\text { CAATGGCGGAAGGAAAAGCAATGCGTAAAGGAGAAGAACT } \\
\text { ArnB-GFP-Reverse- }\end{array}$ & AAGCTTTTATTTGTATAGTTCATCCATG \\
\hline PagP-Forward-P1 & GAATCCCCCAATAAATTGGCGATG \\
\hline PagP-Reverse-P2 & $\begin{array}{l}\text { AGTTCTTCTCCTTTACGCATTTGTGACCATAAAACATTTATCA } \\
\text { AAAATC }\end{array}$ \\
\hline $\begin{array}{l}\text { PagP-GFP-Forward- } \\
\text { P3 }\end{array}$ & $\begin{array}{l}\text { GATTTTTGATAAATGTTTTATGGTCACAAATGCGTAAAGGAG } \\
\text { AAGAACT }\end{array}$ \\
\hline $\begin{array}{l}\text { PagP-GFP-Reverse- } \\
\text { P4 }\end{array}$ & $\underline{\text { AAGCTTTTATTTGTATAGTTCATCCATG }}$ \\
\hline PmrD-Forward-P1 & $\underline{\text { GAATCCTCAGGCGCTAAAAGAGTGGG }}$ \\
\hline PmrD-Reverse-P2 & AGTTCTTCTCCTTTACGCATTGCATTATCCTGTTTGCTAAG \\
\hline $\begin{array}{l}\text { PmrD-GFP- } \\
\text { Forward-P3 }\end{array}$ & CTTAGCAAACAGGATAATGCAATGCGTAAAGGAGAAGAACT \\
\hline $\begin{array}{l}\text { PmrD-GFP-Reverse- } \\
\text { P4 }\end{array}$ & AAGCTTTTATTTGTATAGTTCATCCATG \\
\hline
\end{tabular}

*Underlined sequence refers to restriction sites

\subsection{Cloning purified $\operatorname{arn} B$, pagP and $p m r D$ promoter fusions with GFP into pCR2.1 TOPO Vector}

After the SOE-PCR protocol, identical steps were taken to clone the fusion constructs into the pCR2.1 TOPO vector. A concise summary is as follows: 1) T-tailing of fusion constructs prior to cloning into pCR2.1 TOPO; 2) cloning into the vector; 3) transform cloned vectors into MACH1 cells using the heat shock protocol; 4) X-gal screening for blue and white colonies; 5) overnight subculture of white colonies; 6) plasmid extraction from subculture; 7) EcoRI double 
digest of plasmid and sequence verification. The pagP-GFP fusion construct was unable to be produced. Therefore, we opted to use another PhoPQ regulated gene, ompT-GFP, of which we already had the construct made using the exact same protocol listed above.

\subsection{Transformation of $a r n B, o m p T$ and $p m r D$-GFP constructs into a panel of 8 clinical CD isolates using electroporation}

Electrocompetent cells were prepared using ice-cold deionized water washes, for a total of four washes. Electrocompetent cells were aseptically moved into prechilled cuvettes with each respective construct, for a total of 24 strains ( 8 x each construct). Using the Bio-Rad GenePusler Xcell machine, cells were electroporated at $2.5 \mathrm{~V}$, followed by immediate addition of S.O.C. media for recovery. Subsequently, cells were recovered for 2 hours in a shaking $37^{\circ} \mathrm{C}$ incubator. After recovery time, cells were plated on LB agar + kanamycin plates at two concentration, $50 \mu \mathrm{L}$ and $200 \mu \mathrm{L}$. The following day, successful plates were chosen, and colonies were picked to be sub-cultured in LB broth + kanamycin. If growth persisted the following day, freezer stocks were made for the respective strain.

\subsection{Fluorescence assay monitoring gene induction in panel of 8 clinical CD isolates}

Strains grown overnight are washed in HEPES buffer twice to assure no component of overnight media are carried over into the experiment. After washes, $\mathrm{OD}_{600}$ measurements are taken before assembling the plate. GFP assays were performed using black-well, clear bottom 96-well plates. To reduce error due to evaporation, the outer perimeter of the plate was filled with $225 \mu \mathrm{L}$ sterile $\mathrm{dH}_{2} \mathrm{O}$, which allows for insulation of the media inside. Two media conditions were tested per strain depending on the TCS construct. For ompT-GFP and pmrD-GFP, high magnesium $(10 \mathrm{mM})$ and low magnesium $(20 \mu \mathrm{M}) \mathrm{M} 9$ minimal media was used. For arnB-GFP, high iron $(100 \mu \mathrm{M})$ and low iron $(0-10 \mu \mathrm{M}) \mathrm{M} 9$ minimal media was used. In addition, to investigate a potential threshold concentration for stimulus of the PhoPQ system, a titration of $\mathrm{Mg}^{2+}$ concentrations were used. The concentrations used were: $20 \mu \mathrm{M}, 50 \mu \mathrm{M}, 100 \mu \mathrm{M}, 500 \mu \mathrm{M}$, $1 \mathrm{mM}, 2 \mathrm{mM}, 5 \mathrm{mM}$ and $10 \mathrm{mM}$. All strains were normalized to an $\mathrm{OD}_{600}$ reading of 0.1 and inoculated into wells that resulted in a final volume of $225 \mu \mathrm{L}$ (this included culture, media, and 
antibiotic). Following plate preparation, a Biotek Synergy HTX Multi-Mode Reader was used to measure fluorescence and bacterial growth for 16.5 hours, taking reads for both fluorescence and $\mathrm{OD}_{600}$ every 30 minutes. The system was configured with an excitation wavelength of $485 \mathrm{~nm}$ and emission wavelength of $530 \mathrm{~nm}$ for appropriate fluorescent readouts. A total of three technical replicates and six biological replicates were performed. Please refer to Figure 6 a visual representation of a typical plate layout.

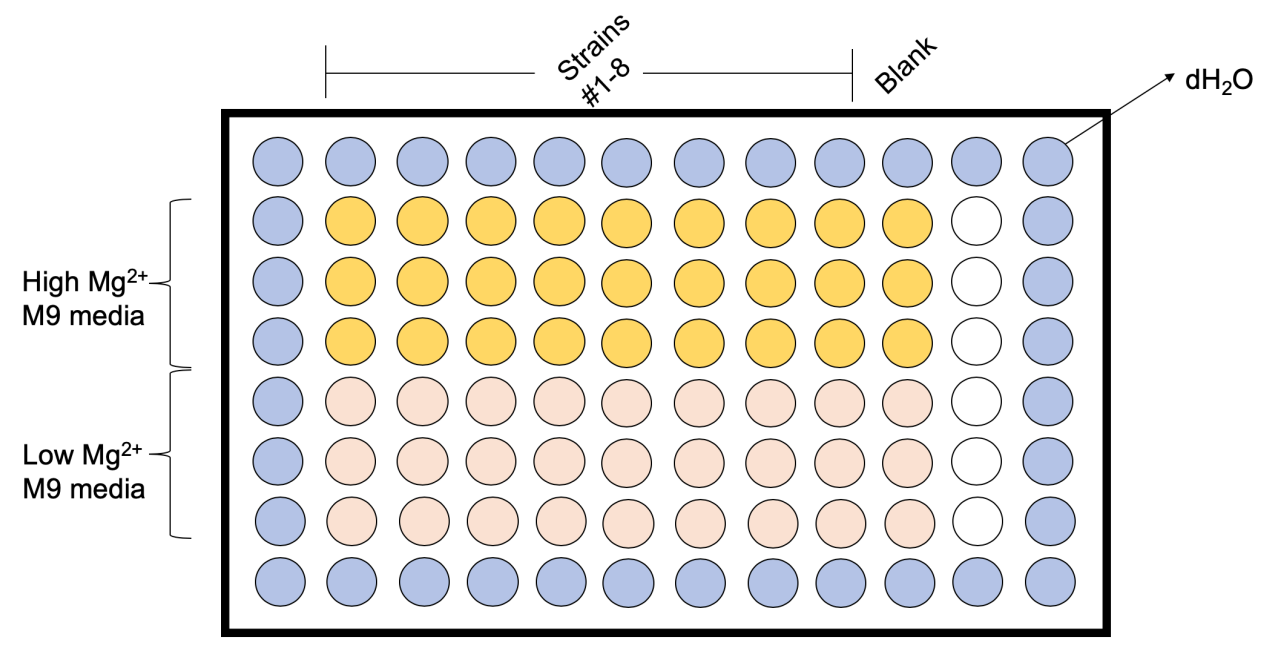

Figure 6. Example of 96-well plate layout for fluorescence assay testing for the PhoPQ TCS induction.

\subsection{Polymyxin B killing assay}

Killing assays were performed on the panel of 8 clinical CD isolates and a K12 strain to examine whether there are phenotypic changes associated with any altered signaling level. For killing assays, wild type $\mathrm{CD}$ isolates strains were grown overnight (without the GFP constructs). The following day, strains were washed once in HEPES buffer, and sub-cultured in high and low magnesium (10mM, $20 \mu \mathrm{M}$ respectively) M9 minimal media. The strains were grown to mid-log $\left(\mathrm{OD}_{600} \sim 0.6-0.8\right)$, at which point the cultured was washed in HEPES buffer one more time. After second HEPES wash, $\mathrm{OD}_{600}$ measurements were taken again. These $\mathrm{OD}_{600}$ readings were used to calculate how much of the culture was needed to reach a final concentration of $10^{8} \mathrm{CFU} / \mathrm{ml}$. After calculation, all strains + conditions were normalized to $10^{8} \mathrm{CFU} / \mathrm{ml}$. Normalized cells were subject to treatment with phosphate buffer saline (PBS) as a control, and various concentrations of polymyxin $\mathrm{B}(\mathrm{PMB})$ treatment. For the $\mathrm{CD}$ isolates, seven concentrations of polymyxin $\mathrm{B}$ 
were used; $1 \mu \mathrm{g} / \mathrm{ml}, 2 \mu \mathrm{g} / \mathrm{ml}, 5 \mu \mathrm{g} / \mathrm{ml}, 10 \mu \mathrm{g} / \mathrm{ml}, 25 \mu \mathrm{g} / \mathrm{ml}, 50 \mu \mathrm{g} / \mathrm{ml}$ and $100 \mu \mathrm{g} / \mathrm{ml}$. For K12, a lower range of polymyxin B was used; $0.1 \mu \mathrm{g} / \mathrm{ml}, 0.2 \mu \mathrm{g} / \mathrm{ml}, 0.5 \mu \mathrm{g} / \mathrm{ml}, 1 \mu \mathrm{g} / \mathrm{ml}, 2 \mu \mathrm{g} / \mathrm{ml}$, and $5 \mu \mathrm{g} / \mathrm{ml}$. Both control and polymyxin treated cells were transferred to titer tubes containing PBS to stop further killing from occurring at two time points, 0 minutes and 10 minutes. $2 \mu \mathrm{L}$ culture samples were taken and diluted 1:250 $\left(10^{0}\right)$ in PBS and further diluted 1:10 to generate 10 $0^{-1} .10$ $\mu \mathrm{L}$ samples of both dilutions were spot plated on LB agar plates and incubated at room temperature overnight until colonies could be counted. Minimum of four biological replicates were performed for each strain/condition and colony counts were the sum of four technical plating replicates.

\subsection{Construction of PhoP-HA-tag}

To monitor PhoP translation and phosphorylation via western blot analysis, HA was tagged to PhoP. Primers were designed to amplify PhoP, with the reverse primer containing the HA sequence to efficiently tag the C-terminus of PhoP (Table. 5). Similar protocols mentioned above were followed. A concise summary is as follows: 1) PCR amplification; 2) cloning into TOPO blunt vector; 3) transform cloned vectors into DH5a cells using the heat shock protocol; 4) X-gal screening for blue and white colonies; 5) overnight subculture of white colonies; 6) plasmid extraction from subculture; 7) EcoRI double digest of plasmid and sequence verification. Following sequence verification, constructs were subcloned into a low-copy plasmid pWSK129 using similar protocols as mentioned above. Once subcloning was verified, constructs were transformed into the panel of 8 electrocompetent CD isolates and K12 using the electroporation method.

Table 5. Primers designed for amplification of PhoP-HA-tag.

\begin{tabular}{|l|l|}
\hline PRIMER & SEQUENCE \\
\hline PhoP-Forward & GAATCCTTGGTCGAGCTATCACGATG \\
\hline PhoP-Reverse & $\begin{array}{l}\text { AAGCTTTCAAGCGTAATCTGGAACATCGTATGGGTAGCGCAAT } \\
\text { TCGAACAG }\end{array}$ \\
\hline
\end{tabular}

*Underlined sequence refers to restriction sites

*Blue refers to HA sequence 


\subsection{Subpopulation analysis}

A BD Accurit ${ }^{\mathrm{TM}}$ C6 Plus Flow Cytometer was used to observe the populations dynamic of all relevant strains at a single-cell level. Strains which contained the $p m r D$-GFP fusion were grown overnight in either low $\mathrm{Mg}^{2+}(20 \mu \mathrm{M})$ or high $\mathrm{Mg}^{2+}(10 \mathrm{mM}) \mathrm{M} 9$ media. The following day, cultures were washed once in 1X PBS. After the first wash, the cultures were centrifuged, and the supernatant was removed. Following this, cells were resuspended in approximately $100 \mu \mathrm{L}$ of $1 \mathrm{X}$ PBS and then mixed with $1 \mathrm{~mL}$ of $1: 1$ methanol acetone for fixing of cells. At this point the cells were incubated at room temperature for 10-15 minutes. After incubation, cells were centrifuged, the supernatant was completely removed, and cells were resuspended in $1 \mathrm{~mL}$ 1X PBS. The samples were run through the Flow Cytometer for single-cell analysis. The parameters used for differentiating inducing and non-induced populations were FITC-A (detecting green fluorescence), and FSC-A (detecting forward scatter). 10,000 cells were counted for each strain + condition (18 total samples). 


\section{Results}

\subsection{Differential regulation of $p m r D$ and $o m p T$ are observed in divergent strains of IBDEC}

Based on previous data collected from Youn Hee Cho and Michael Renouf which highlighted variation in resistance phenotypes of clinical IBDEC isolates to HDPs LL-37 and hBD3, we hypothesized that the altered signaling levels of downstream genes involved in HDP resistance could explain the observed pattern (Unpublished, Cho, Renouf and McPhee). To test this, we created reporter genes for PhoPQ signaling. We chose two PhoPQ regulated genes, $p m r D$ for its role in connecting to the PmrAB TCS, the master regulator of LPS modifications, and $\operatorname{ompT}$, a protease capable of cleaving HDP LL-37 (Unpublished, Cho, Fadle, and McPhee). We fused the promoter regions of these genes from a K12 strain, BW25113, to GFPmut3 and cloned the fused product into the pCR2.1 TOPO vector. We selected a panel of eight CD clinical isolates to conduct our reporter experiments. Strains were selected based on meeting one of four criteria: 1) have high level resistance to both LL-37 and hBD3, 2) have low level resistance to LL-37 and hBD3, 3) have high level resistance to LL-37 and low level resistance to hBD3, and 4) have low level resistance to LL-37 and high level resistance to hBD3. Of our eight selected strains, two belonged to each one of the criteria (Table. 6).

Table 6. Resistance profiles of selected clinical isolates against HDPs LL-37 and hBD3.

\begin{tabular}{|c|c|c|c|}
\hline Strain & LL-37 resistance (\%) & hBD3 resistance (\%) & $\begin{array}{c}\text { Resistance group } \\
\text { LL37/hBD3 }\end{array}$ \\
\hline DK3 & $0.74 \%$ & $2.22 \%$ & Low/Low \\
\hline DK26 & $0.80 \%$ & $1.92 \%$ & Low/Low \\
\hline DK89 & $0.69 \%$ & $80.26 \%$ & Low/High \\
\hline DK136 & $79.36 \%$ & $75.87 \%$ & High/High \\
\hline DK236 & $75.12 \%$ & $0.08 \%$ & High/High \\
\hline UM146 & $106.55 \%$ & $86.99 \%$ & Low/High \\
\hline DF-06 & $1.68 \%$ & $106.15 \%$ & High/Low \\
\hline PP-26 & $140.44 \%$ & $46.80 \%$ & \\
\hline
\end{tabular}


To measure PhoPQ signaling, we conducted overnight experiments measuring the promoter activity of each construct in $\mathrm{K} 12$ and the selected $\mathrm{CD}$ isolates. To repress and induce PhoPQ, we used high $(10 \mathrm{mM})$ and low $(20 \mu \mathrm{M})$ magnesium M9 minimal media respectively during the experiment. As expected, we saw significantly altered signaling levels in both noninducing and inducing conditions for the $p m r D$-GFP and ompT-GFP constructs in our panel of CD isolates (Fig. 7). While there are numerous ways to analyze this data set, we initially focused on measuring the difference of induced PhoPQ signaling of our clinical isolates to our K12 strain. Of particular interest were two IBDEC strains, DK89 and UM146. DK89, a CD isolate with high resistance to hBD3 and low resistance to LL-37, was one of the highest $p m r D$ signaling strains we tested. Interestingly, when measuring oтрT signaling in this background, we found DK89 had one of the lowest expressions among the all strains tested. UM146, on the hand, showed the exact opposite, where it was the lowest $p m r D$ signaling strains, but the highest ompT signaling strain among the clinical CD strains. When compared to a K12 strain, there is consistently a lower and tightly regulated fold-change between non-inducing to inducing conditions. For instance, for $\operatorname{pmrD}$, all $\mathrm{CD}$ isolates hover tightly around a 2-fold change, while the K12 strain exhibits a 5-fold change from non-inducing to inducing conditions (Fig. 7 b).

a)

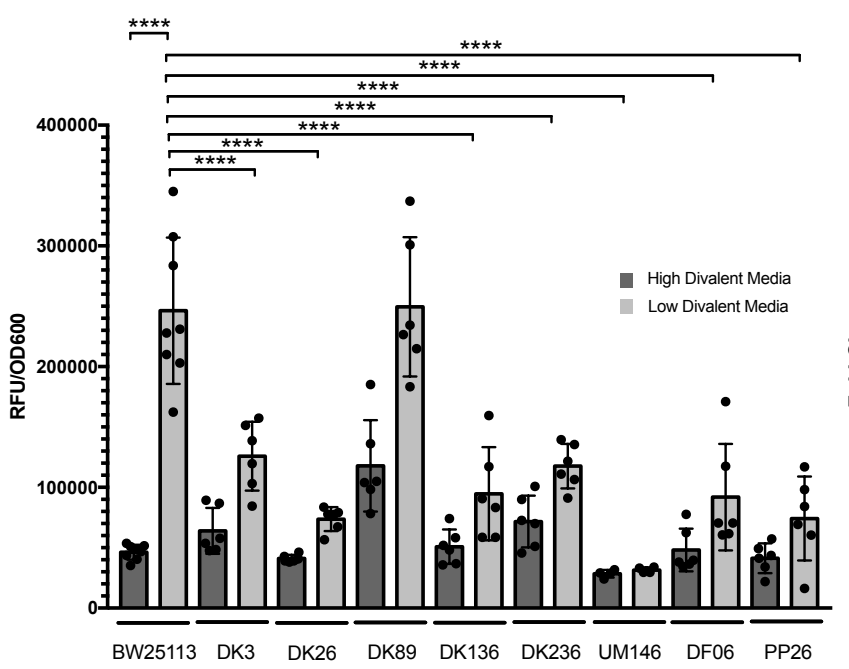

b)

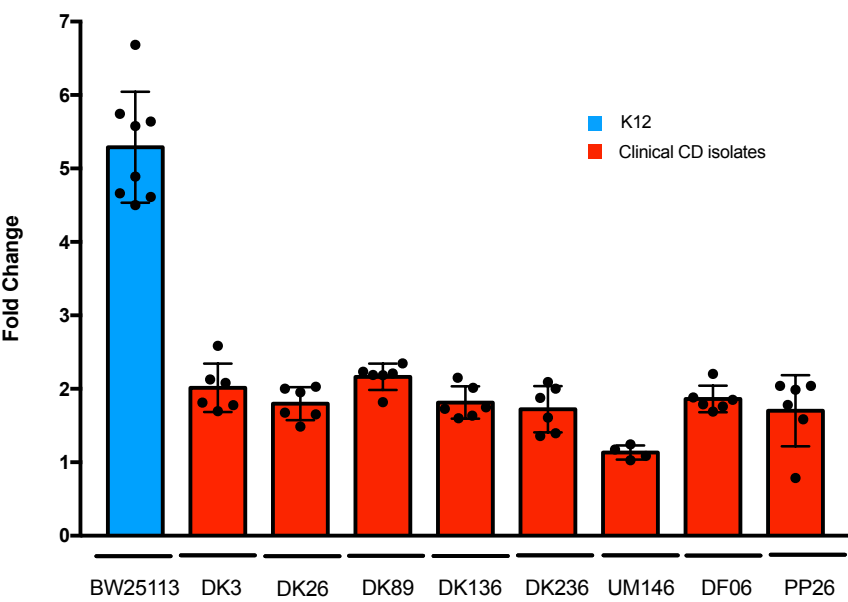


C) ompT-GFP

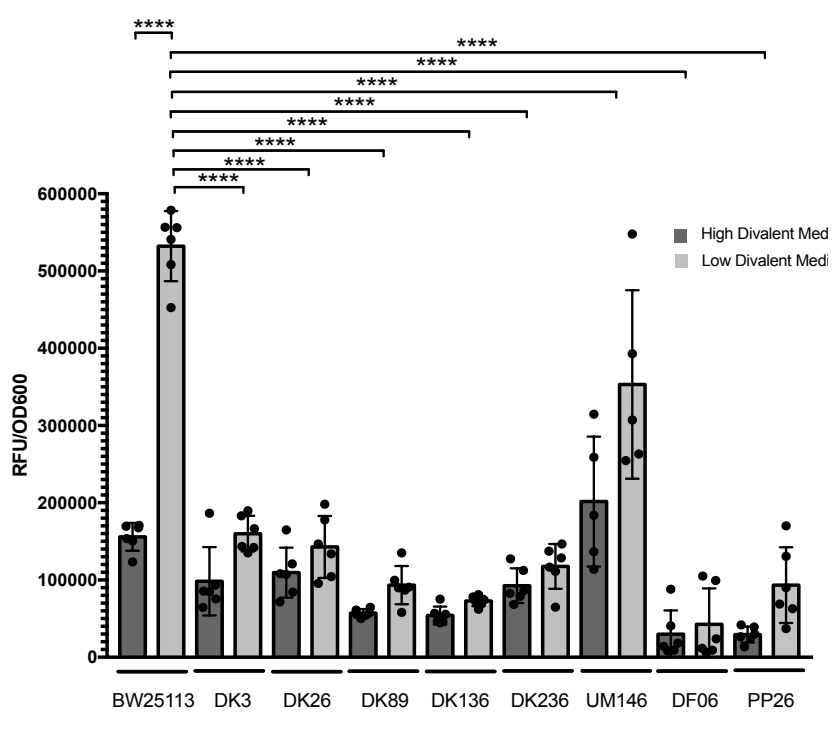

d)

ompT-GFP

Figure 7. Measuring PhoPQ signaling in $\mathrm{K} 12$ and $\mathrm{CD}$ isolates under fixed $\mathrm{Mg}^{2+}$ concentrations.

a) Expression from a pmrD-GFP fusion construct in different clinical CD isolates grown in M9 minimal medium containing PhoP-inducing levels of $\mathrm{Mg}^{2+}(20 \mu \mathrm{M})$ or PhoP-repressing levels of $\mathrm{Mg}^{2+}(10 \mathrm{mM})$. b) Relative fold change in $p m r D$-GFP expression from non-inducing to inducing conditions. c) Expression from an ompT-GFP fusion construct in the same clinical isolates and media. d) Relative fold change in $p m r D$-GFP expression from noninducing to inducing conditions. Compared to WT K12 strain of E. coli (BW25113), majority of clinical isolates of AIEC exhibit differential regulation of genes associated with HDP resistance $(* \mathrm{p}<0.05 ; * * * \mathrm{p}<0.001 ; * * * *$ $\mathrm{p}<0.0001)$. Each dot represents one biological replicate.

\subsection{Strain-to-strain differences in the relationship between $\mathrm{Mg}^{2+}$ concentrations and PhoPQ signaling}

While induction of the PhoPQ system under limiting magnesium conditions is well established, to date there has not been much insight of the systems response to a gradient of magnesium conditions. Given the differences in the absolute signaling potential between our IBDEC strains, we wanted to test how these strains respond to increasing concentrations of $\mathrm{Mg}^{2+}$ to elucidate a potential strain-specific inducing threshold concentration of $\mathrm{Mg}^{2+}$ for PhoPQ activation. To assess this, we completed fluorescence assays using the $p m r D$-GFP construct exposed to eight different increasing concentrations of magnesium in M9 minimal media. Our selected $\mathrm{Mg}^{2+}$ concentration gradient for these experiments was $20 \mu \mathrm{M}, 50 \mu \mathrm{M}, 100 \mu \mathrm{M}, 500 \mu \mathrm{M}$, $1 \mathrm{mM}, 2 \mathrm{mM}, 5 \mathrm{mM}$ and $10 \mathrm{mM}$. 
Our results confirmed the inverse relationship between $\mathrm{Mg}^{2+}$ concentration and PhoPQ activation, consistent with literature and previous experiments. However, while all strains follow the same general pattern, long-term response to the $\mathrm{Mg}^{2+}$ differs substantially from strain-tostrain. For instance, in our K12 strain, we see an exponential signaling response to $\mathrm{Mg}^{2+}$ concentrations (Fig. 8 b), while strain DK89 exhibits a relatively consistent signaling output throughout all concentrations (Fig. 8 e). Another interesting observation was the potential of strains DK3, DK26, DK136 and DF-06 to respond robustly to our lowest, most inducing concentration of $\mathrm{Mg}^{2+}$, and then show a steep decline in $p m r D$ expression when cultured in higher $\mathrm{Mg}^{+}$concentrations (Fig. 8 c, d, f and j). This phenomenon might reflect differences in PhoPQ sensitivity in these strain to an inducing stimulus. To view the signaling data on the same figure, we plotted the average of the peak expression from each strain at each concentration of $\mathrm{Mg}^{2+}$ (Fig. 8 a). 

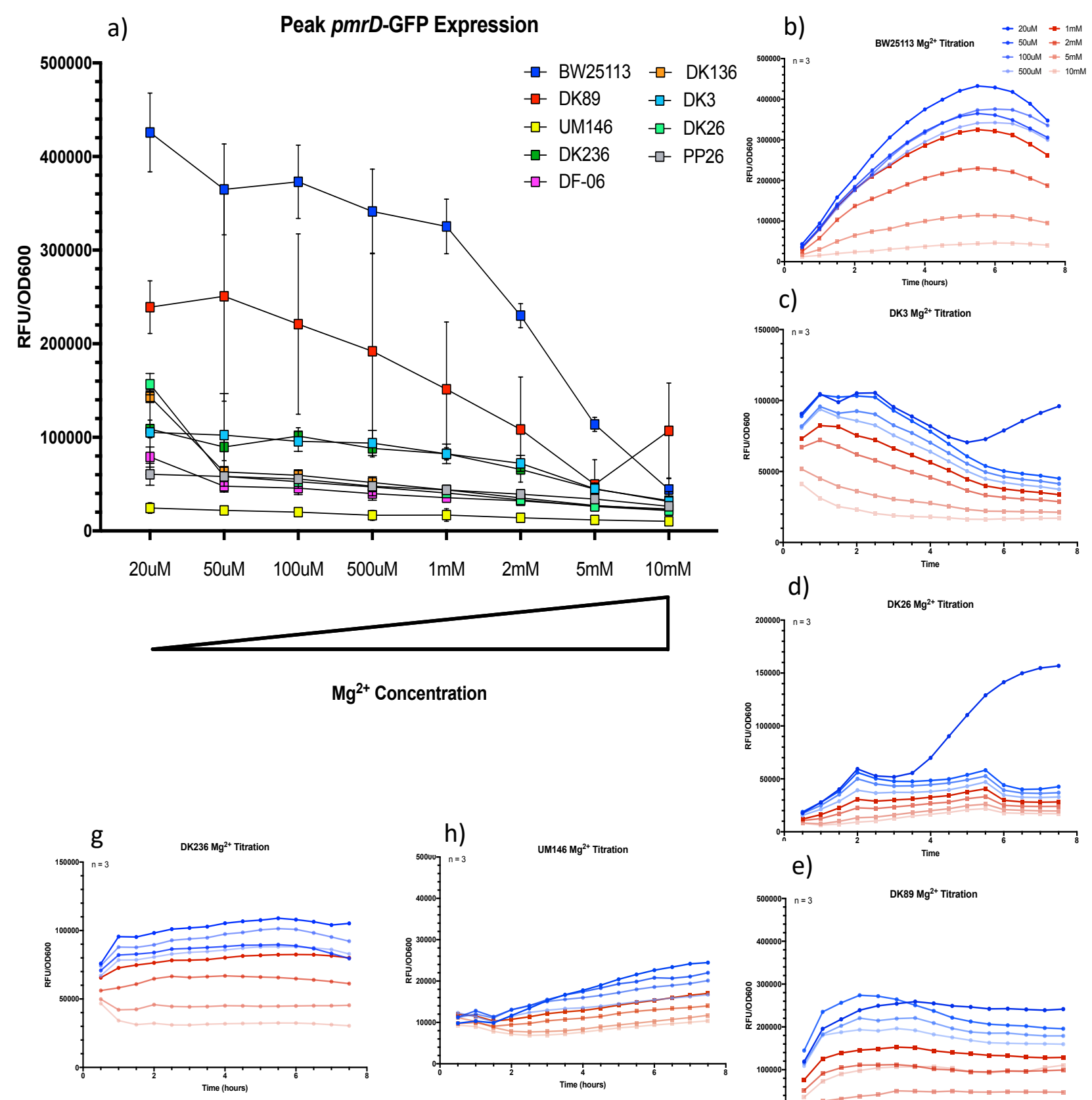

d)
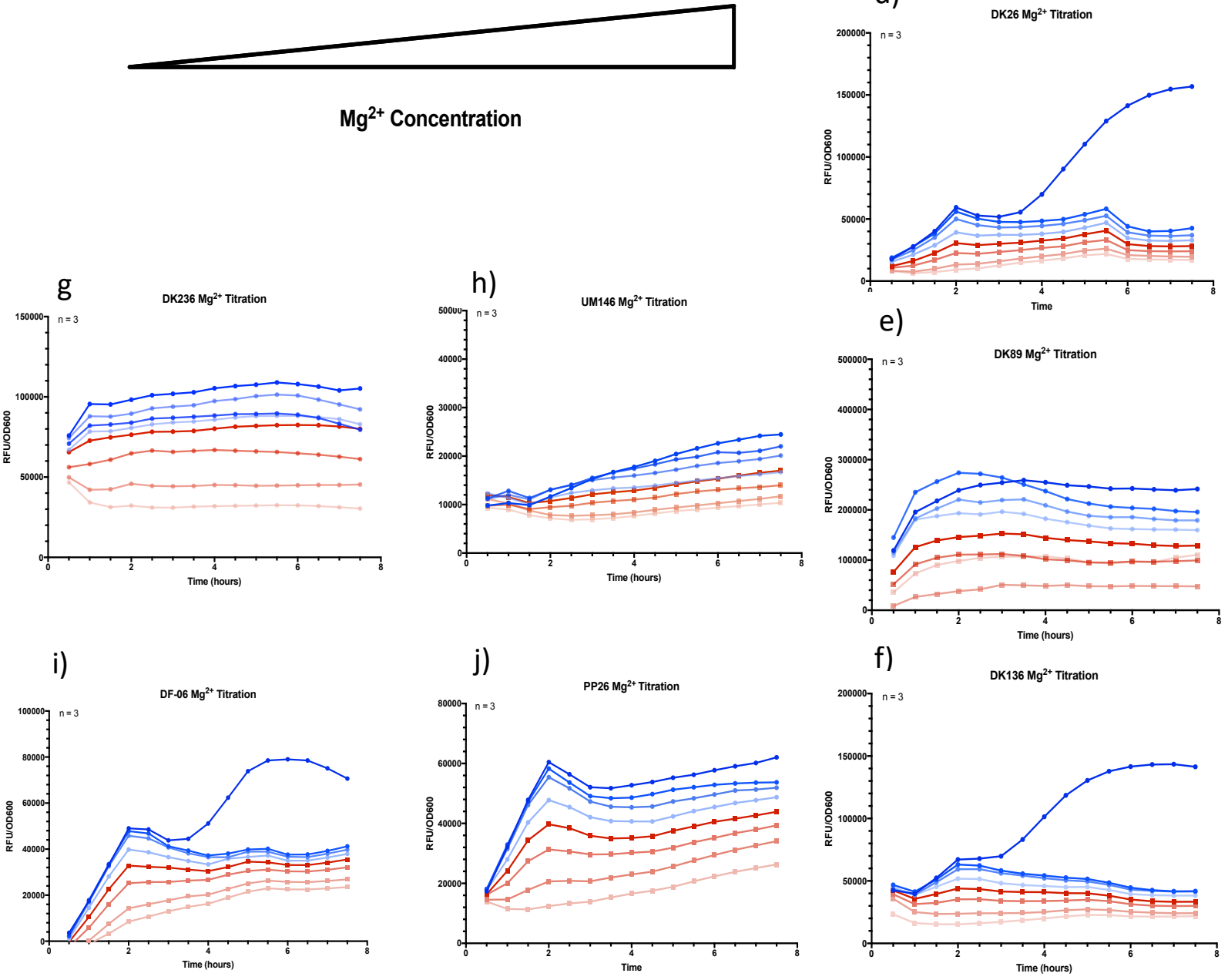
Figure 8. PhoPQ signaling response to increasing $\mathrm{Mg}^{2+}$ concentrations.

a) Snapshot of peak pmrD-GFP expression at set concentrations of $\mathrm{Mg}^{2+}$ in the panel of CD isolates and $\mathrm{K} 12 . \mathrm{b}-\mathrm{j}$ )

Kinetic expression of $p m r D$-GFP in all relevant strains when exposed to increasing concentrations of $\mathrm{Mg}^{2+}$; data points represent the average of 3 biological replicates.

\subsection{PMB resistance of IBDEC strains differs due PhoPQ signaling potential}

To assess if there are phenotypic differences associated with the altered signaling levels among strains, we performed polymyxin B killing assays to analyze if signaling potential can predict bacterial resistance. To test this, we challenged our panel of isolates with increasing concentrations of drug to uncover strain-to-strain differences in resistance. In this model, we would predict that a high PhoPQ signaling strain would result in resistance at higher concentrations of PMB. In addition, we also wanted to establish that resistance phenotypes change when bacteria are cultured in non-inducing vs. inducing media. Here, we would predict

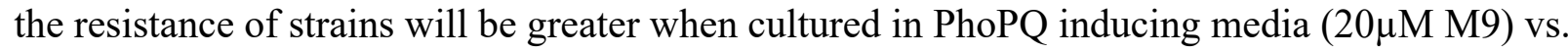
being cultured in non-inducing media (10mM M9). The concentrations we chose to test were $1 \mu \mathrm{g} / \mathrm{ml}, 2 \mu \mathrm{g} / \mathrm{ml}, 5 \mu \mathrm{g} / \mathrm{ml}, 10 \mu \mathrm{g} / \mathrm{ml}, 25 \mu \mathrm{g} / \mathrm{ml}, 50 \mu \mathrm{g} / \mathrm{ml}$ and $100 \mu \mathrm{g} / \mathrm{ml}$ for our clinical isolates, and $0.1 \mu \mathrm{g} / \mathrm{ml}, 0.2 \mu \mathrm{g} / \mathrm{ml}, 0.5 \mu \mathrm{g} / \mathrm{ml}, 1 \mu \mathrm{g} / \mathrm{ml}, 2 \mu \mathrm{g} / \mathrm{ml}$, and $5 \mu \mathrm{g} / \mathrm{ml}$ for our $\mathrm{K} 12$ strain.

We found the resistance patterns of some strains align with the altered signaling levels for each respective strain. For instance, DK89, a clinical isolate that exhibited the most absolute induction of $\mathrm{pmrD}$ shows the highest resistance profile and substantial difference in resistance phenotypes when grown in either inducing or non-inducing conditions (Fig. 9 d). Other strains, on the other hand, show a rather surprising phenotype of elevated resistance when grown in noninducing media vs. inducing media. For example, strains DK26 and DK236, both of which had low to medium level of $p m r D$ induction, appear to be more resistant in non-inducing conditions. This observation is also noted in the K12 background, where we see higher levels of resistance when cultured in non-inducing media. We want to investigate potential explanations for some of the observations seen here by conducting single-cell analysis, inductively coupled plasma (ICP) analysis looking at $\mathrm{Mg}^{2+}$ sequestration by the strains, screening for resistance sub-populations among isogenic cultures, and also sequencing the genomes. 

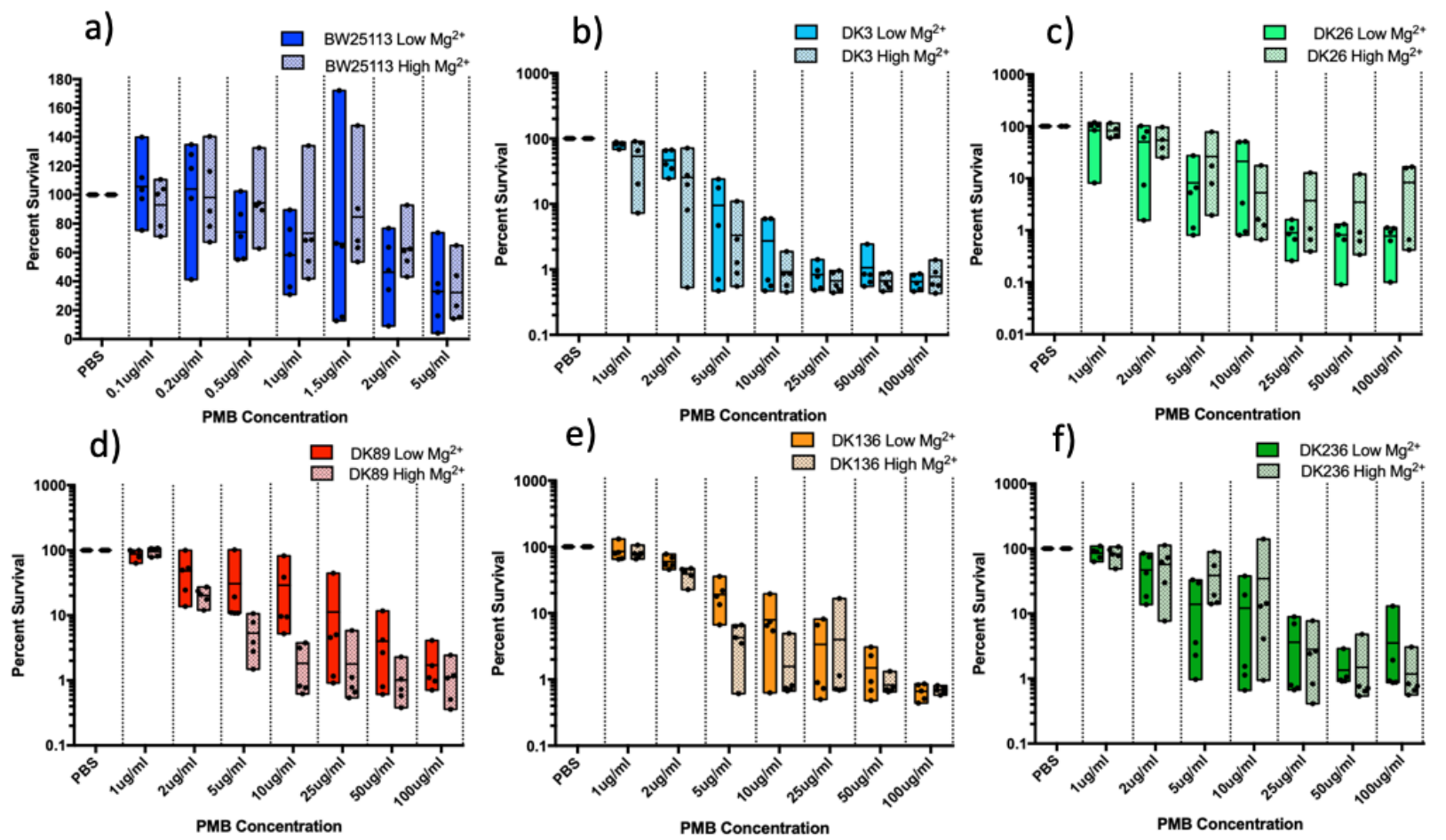

e)
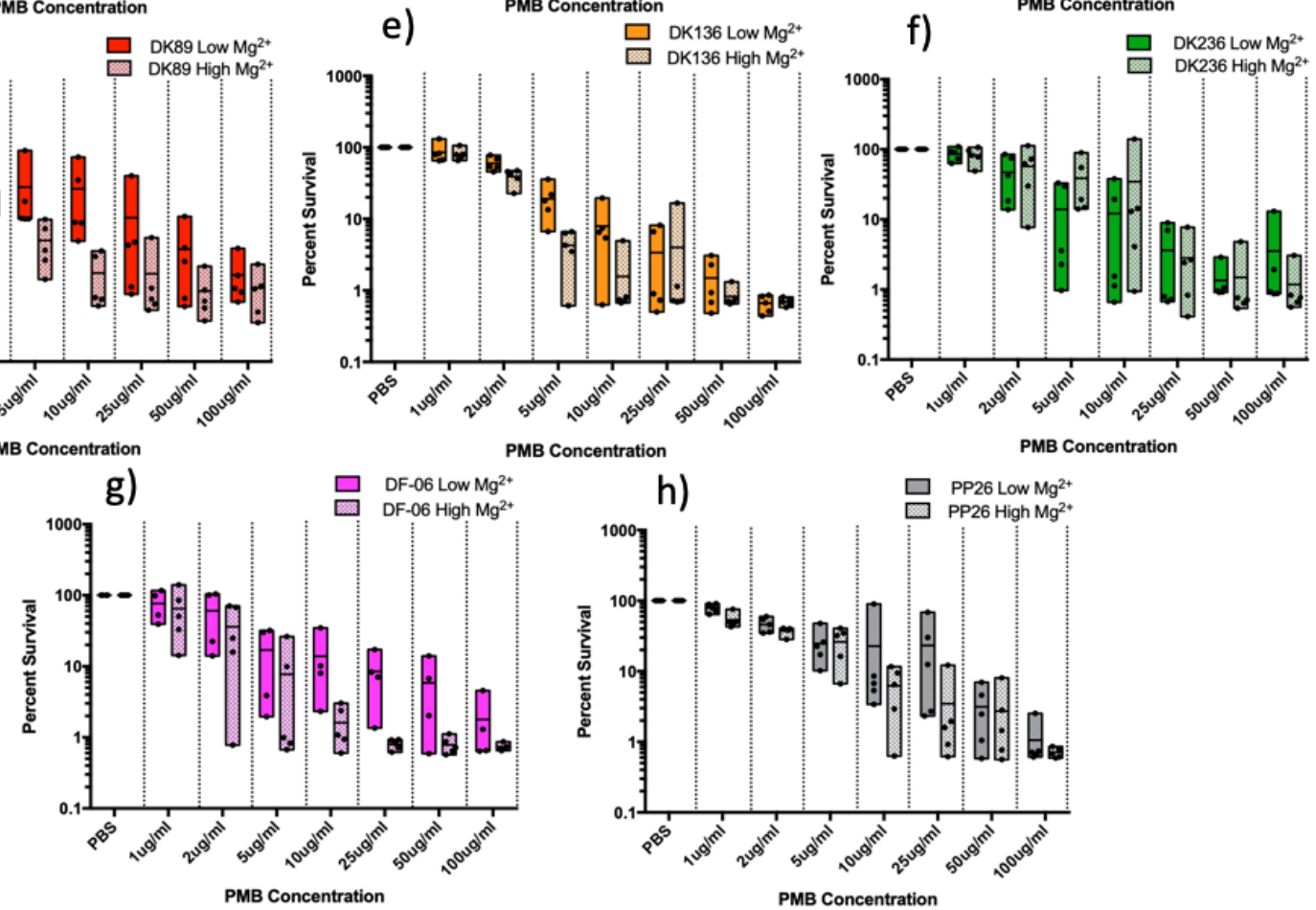

Figure 9. Polymyxin B resistance of K12 and CD isolates to increasing drug concentrations.

a-h.) Resistance of K12 clinical CD isolates to seven concentrations of polymyxin B shows phenotypic differences among each strain when grown in inducing $\left(20 \mu \mathrm{M} \mathrm{Mg}^{2+}\right)$ or non-inducing conditions $\left(10 \mathrm{mM} \mathrm{Mg}^{2+}\right)$. Each dot represents one biological replicate. Boxes represent spread of data (minimum to maximum).

\subsection{PmrA transcriptional feedback repression results in reduced $p m r D$ expression in IBDEC strain DK89}

Upregulation of $p m r D$ results in the induction of PmrA-activated genes under $\mathrm{Fe}^{3+}$ replete conditions. Previous work by Kato et. al in 2003 showed that the PmrA protein footprinted on the $p m r D$ promoter, therefore giving evidence of direct regulation of $p m r D$ by PmrA post transcriptionally ${ }^{65}$. This interaction occurs when the PmrAB system is activated independently 
from the PhoPQ system. Therefore, we wanted to determine if under PmrA inducing conditions via PmrB (high $\mathrm{Fe}^{3+}$ ) we saw repression of the $p m r D$-GFP construct in our panel of selected strains. To do this, we conducted a fluorescence assays measuring $p m r D$ expression using two minimal media types, low $\mathrm{Mg}^{2+}(20 \mu \mathrm{M})$, and low $\mathrm{Mg}^{2+}(20 \mu \mathrm{M})+$ high $\mathrm{Fe}^{3+}(100 \mu \mathrm{M})$. Here, we see that strain DK89, a highly induced strain, seems to have active repression of $p m r D$ under PmrAB inducing conditions (Fig. 10).

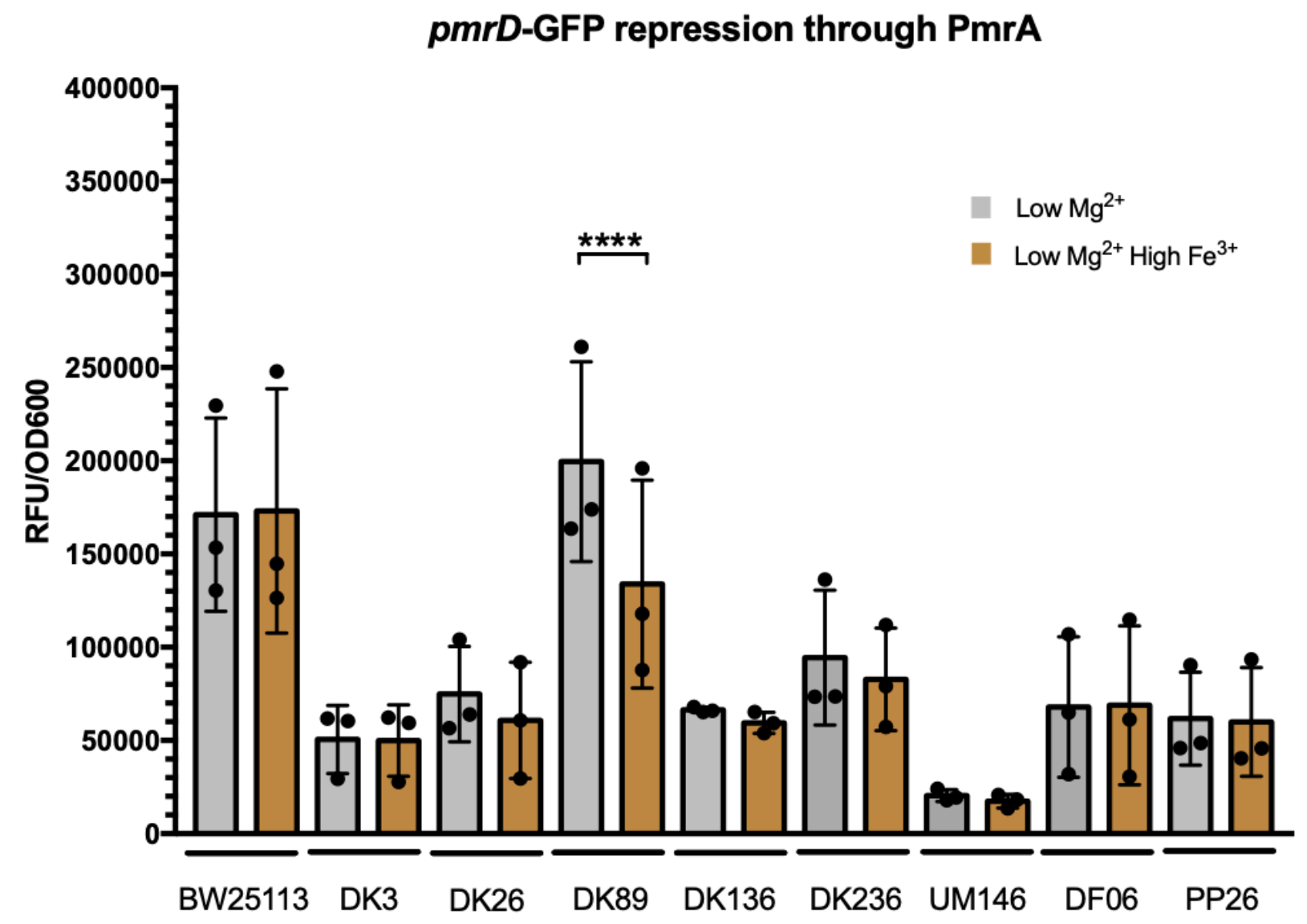

Figure 10. $p m r D$ repression through the PmrAB TCS.

Expression from a pmrD-GFP fusion construct in $\mathrm{K} 12$ and $\mathrm{CD}$ isolates grown in M9 minimal medium containing PhoPQ-inducing levels of $\mathrm{Mg}^{2+}(20 \mu \mathrm{M})$ or PhoPQ and PmrAB induing conditions, low $\mathrm{Mg}^{2+}(20 \mu \mathrm{M})+$ high Fe $(100 \mu \mathrm{M}) .(* * * * \mathrm{p}<0.0001)$. Each dot represents one biological replicate. Error bars represent standard deviation. 


\subsection{Differential pmrD and ompT signaling in other pathogenic $E$. coli strains}

Due to the observed heterogeneity in signaling levels downstream of the PhoPQ TCS in a subset of IBDEC, we probed the question whether a same trend could be seen in other pathogen strains of E. coli. We chose to screen four well-characterized pathogenic strains of E. coli: EHEC strains DK O157:H7 and 86-24, UPEC strain NU-14, and EPEC strain E2348/64. To monitor PhoPQ signaling in these strains, we used both of our ompT-GFP and $p m r D$-GFP constructs to perform fluorescence assays to measure the induction of these genes. The same parameters were used as mentioned above, where we measured signaling in both PhoPQ repressing $\left(10 \mathrm{mM} \mathrm{Mg}^{2+}\right)$ and inducing $\left(20 \mu \mathrm{M} \mathrm{Mg}^{2+}\right) \mathrm{M} 9$ media.

Highly virulent EHEC strain O157:H7 exhibited a high and robust level of induction for both ompT and $p m r D$, irrespective of whether inducing or non-inducing media was used (Fig. 11). In fact, $\mathrm{PhoPQ}$ signaling under non-inducing conditions for $\mathrm{O} 157: \mathrm{H} 7$ rivaled the induced signaling of our highest $p m r D$ signaling strain DK89. In addition, there was a slight fold-change in both ompT and $p m r D$ expression from non-inducing to inducing conditions in this EHEC background. Therefore, we sought to address whether regulation of both ompT and $p m r D$ was still PhoPQ dependent in EHEC. To test for this, we conducted the same experiment using another EHEC strain called 86-24, where we had a PhoP KO in the same background. Firstly, we wanted to establish the same signaling trend in this EHEC background. Albeit to a much lower magnitude, EHEC strain 86-24 also shows small to no differences in signaling when cultured in non-inducing vs. inducing conditions. However, when we used a PhoP KO in this background, we saw complete loss of signaling of both ompT and $p m r D$, suggesting that gene expression is still contingent upon PhoPQ signaling despite the low fold change between inducing and noninducing conditions. While strains UPEC NU-14 and EPEC E2348/64 showed lower overall induction of oтрT compared to O157:H7, the fold change between non-inducing and inducing conditions was higher ( $\sim 2$ fold). Interestingly, strains UPEC NU-14 and EPEC E2348/64 showed little induction of $p m r D$, with almost no difference in fold change between inducing and noninducing conditions. These observations highlight two things, 1) the altered PhoPQ signaling between IBDEC strains also occurs between different strains of EHEC, and 2) despite both being 
regulated by PhoPQ, ompT and $p m r D$ show different levels of signaling under identical conditions.

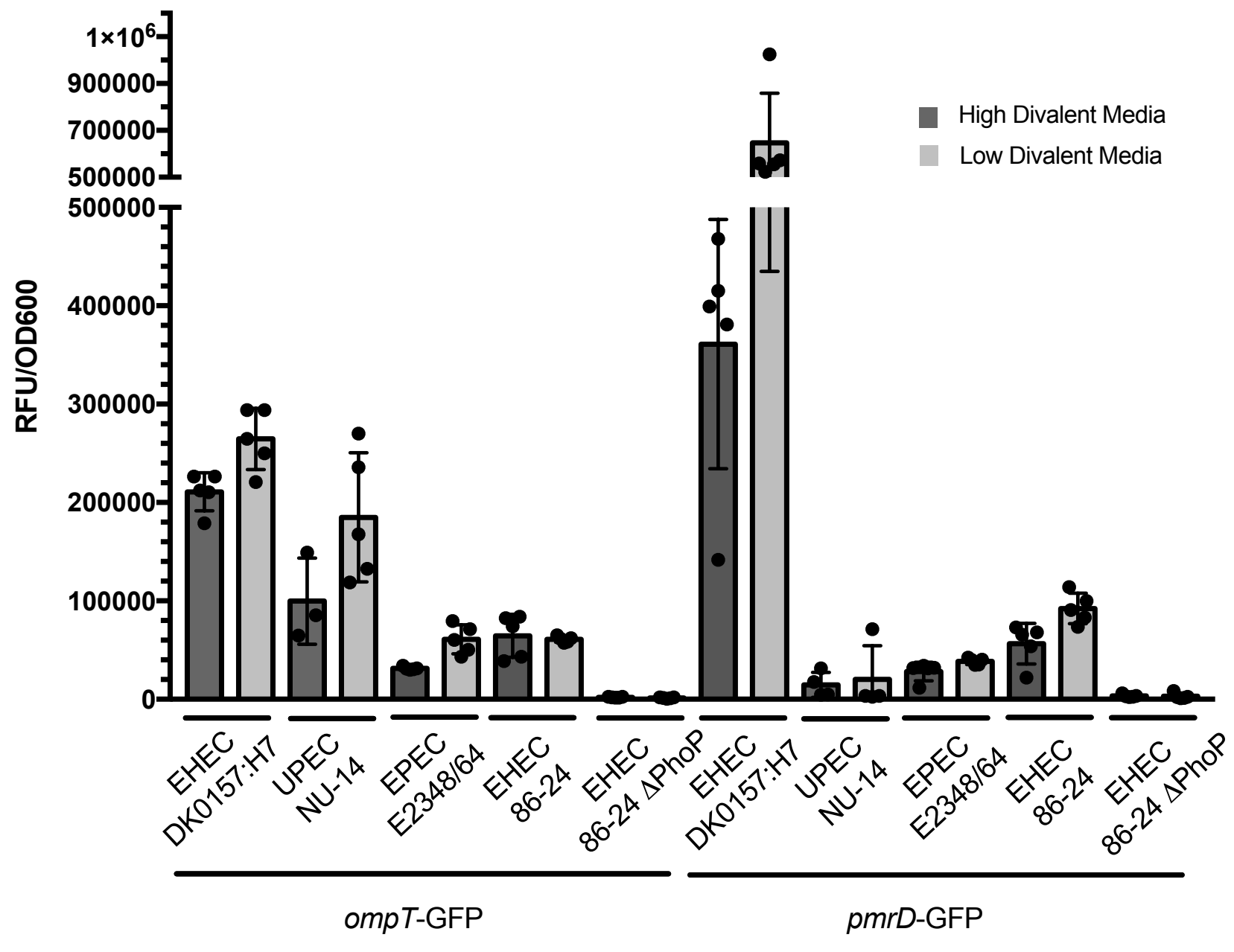

Strain

Figure 11. PhoPQ signaling in non-IBDEC pathovars of E. coli.

Expression from the ompT and $p m r D$-GFP fusion construct in clinical isolates of EHEC DK O157:H7, UPEC isolate NU-14, EPEC E2348/64, EHEC 86-24, and EHEC 86-24 with a PhoP KO. All strains were grown in M9 minimal medium containing PhoP-inducing levels of $\mathrm{Mg}^{2+}(20 \mu \mathrm{M})$ or PhoP-repressing levels of $\mathrm{Mg}^{2+}(10 \mathrm{mM})$. Each dot represents one biological replicate. Error bars represent standard deviation. 


\subsection{Subpopulation analysis highlights differential signaling potential and morphology among IBDEC strains}

Given the broad range of PMB resistance phenotypes observed, we wanted to analyze the strains at a single-cell level to uncover any insight into heterogeneity within isogenic cultures that might be driving the population dynamics as a whole ${ }^{66}$. The end product of our PMB killing assays select for cells that survived exposure to a set concentration of drug. What can go unnoticed in these experiments is a subpopulation of resistant cells within an isogenic culture that could be pushing the resistance phenotypes we measure. For instance, strains that showed higher resistance to PMB when cultured in PhoPQ repressing media vs. inducing media could have a large portion of intrinsically resistant cells. Therefore, when we measure PMB resistance of these strains, we are also indirectly measuring potentially hetero-resistant subpopulations within the strains (Fig. 12). This phenomenon, called heteroresistance or heterogenous resistance, is emerging topic in the field of microbiology.

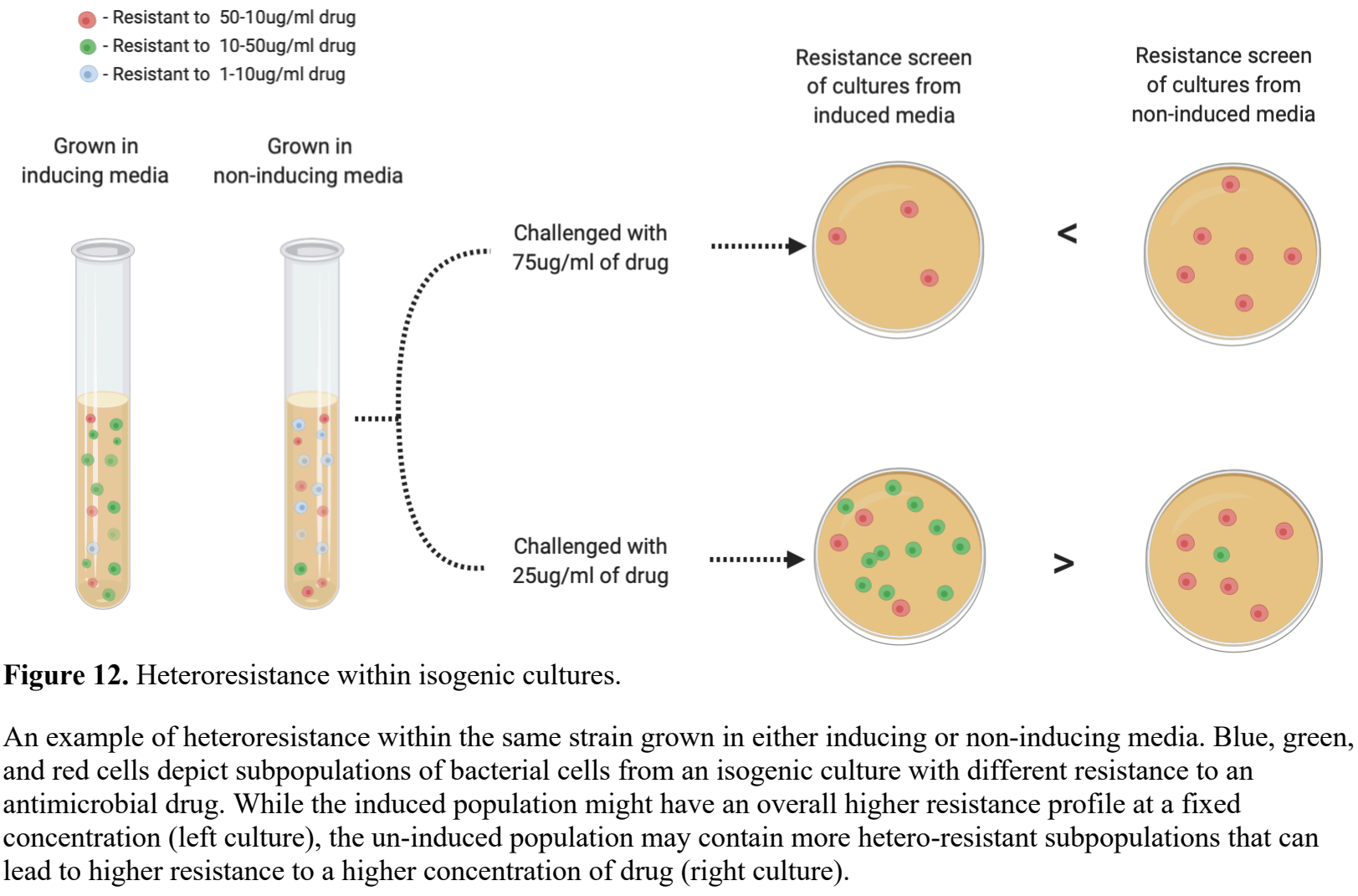


To assess the heteroresistance profiles of our selected strains, we used flow cytometry to measure $p m r D$-GFP activity. We grew all our strains overnight in either PhoPQ inducing $(20 \mu \mathrm{M}$ $\left.\mathrm{Mg}^{2+}\right)$ or PhoPQ repressing $\left(10 \mathrm{mM} \mathrm{Mg}^{2+}\right) \mathrm{M} 9$ media. The following day, we fixed the cells, and resuspended the cultures in PBS, after which they were run through the flow cytometer to measure two primary parameters; green fluorescence and forward scatter. According to our PMB killing data, we would predict that strains which showed higher resistance when cultured in noninducing media would have a larger spread in $p m r D$ signaling (e.g. GFP signal intensity) that overlaps with the induced cultures. As a whole, the results from this experiment support our previous data showing up-regulation of $p m r D$ expression in PhoPQ inducing conditions when compared to PhoPQ repressing conditions. Additionally, we found strains to differ in their spread of $p m r D$-GFP activation in either media condition. For instance, strains DK236 and DK136 show tight and distinct clustering of cells for either media condition, while strains DF-06 and DK3 show more variability in the spread of data with quite a lot of overlap between the two media types. Interestingly, there seems to be a relationship between non-induced cells with higher forward scatter, which for our purposes represents bacterial cell size. This suggests that a potential downstream target of PhoPQ system is/are gene(s) associated with altering overall cell morphology.

a)

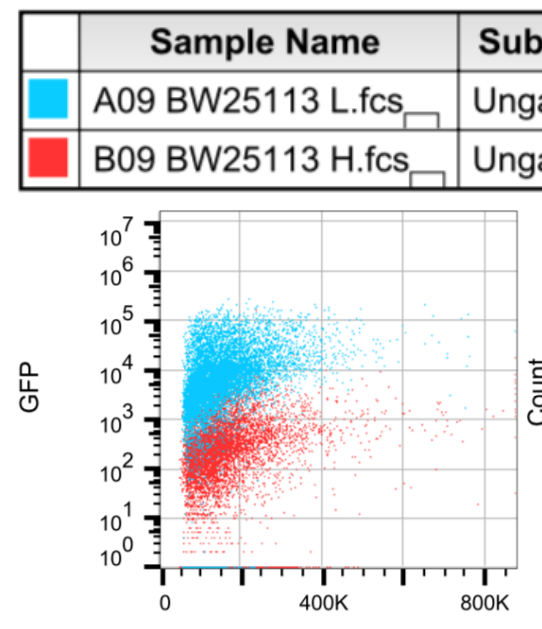

Forward Scatter

\begin{tabular}{|c|c|c|c|}
\hline \multicolumn{4}{|c|}{ Strain: BW25113 } \\
\hline \multicolumn{2}{|c|}{ Low Mg2+ } & \multicolumn{2}{c|}{ High Mg2+ } \\
\hline Mean (GFP) & 13709 & Mean (GFP) & 548 \\
\hline Mean (FSC) & 149723 & Mean (FSC) & 48500 \\
\hline Median (GFP) & 6224 & Median (GFP) & 189 \\
\hline Median (FSC) & 129745 & Median (FSC) & 128251 \\
\hline Robust CV (GFP) & 169 & Robust CV (GFP) & 316 \\
\hline Robust CV (FSC) & 49.4 & Robust CV (FSC) & 48.2 \\
\hline
\end{tabular}

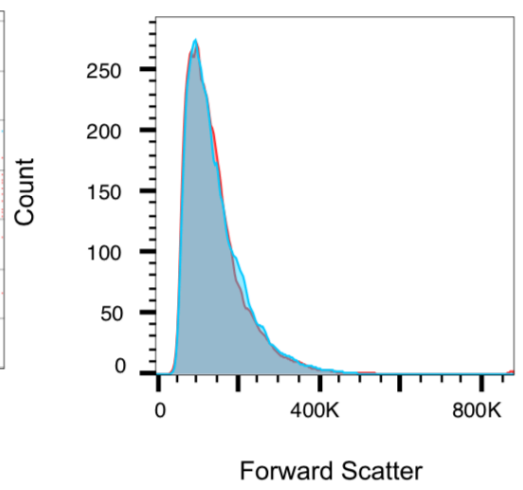

Forward Scatter

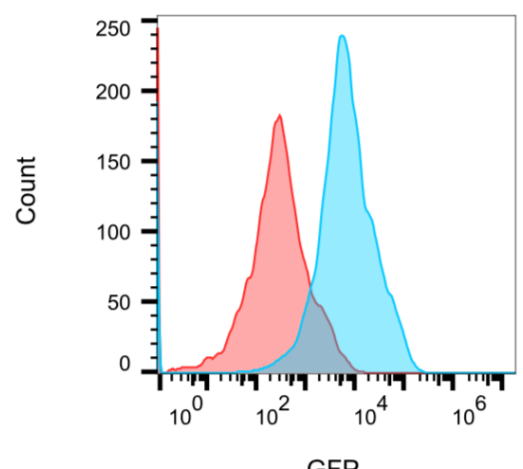

GFP 
b)

\begin{tabular}{|c|c|c|c|c|c|c|c|}
\hline & \multicolumn{2}{|c|}{ Low Mg2+ } & \multicolumn{2}{|c|}{ High Mg2+ } \\
\hline & & & & Mean (GFP) & 4147 & ean (GFP) & 323 \\
\hline & Sample Name & Subset Name & Count & Mean (FSC) & 114348 & Mean (FSC) & 141514 \\
\hline & & & 100 & Median (GFP) & 2209 & Median (GFP) & 149 \\
\hline & & U & & Median (FSC) & 95815 & Median (FSC) & 121422 \\
\hline & B03 DK89 H.fcs & Ungated & 10000 & Robust CV (GFP) & 107 & Robust CV (GFP) & 249 \\
\hline & & & & Robust CV (FSC) & 38.6 & Robust CV (FSC) & 44.4 \\
\hline
\end{tabular}

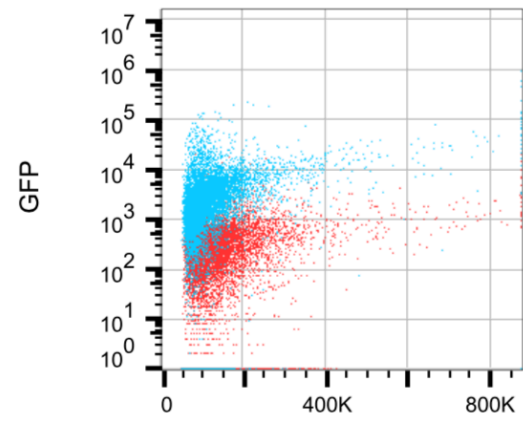

Forward Scatter

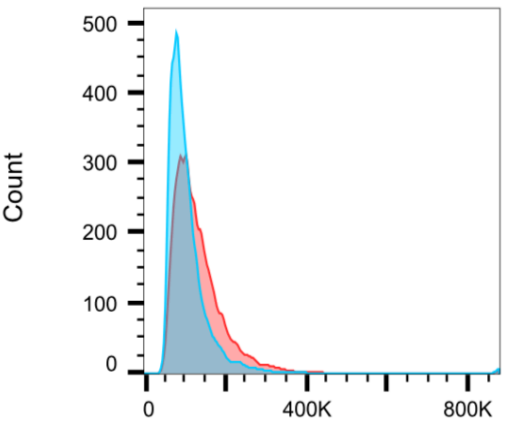

Forward Scatter

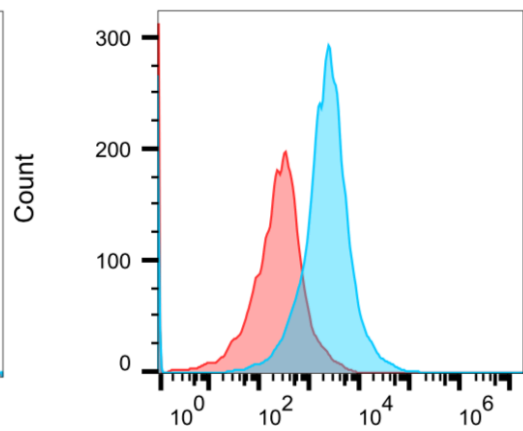

GFP

c)

\begin{tabular}{|c|c|l|c|}
\hline & \multicolumn{1}{|c|}{ Sample Name } & Subset Name & Count \\
\hline \hline & A06 UM146 L.fcs & Ungated & 10000 \\
\hline \hline & B06 UM146 H.fcs & Ungated & 10000 \\
\hline
\end{tabular}

\begin{tabular}{|c|c|c|c|}
\hline \multicolumn{4}{|c|}{ Strain: UM146 } \\
\hline \multicolumn{2}{|c|}{ Low Mg2+ } & \multicolumn{2}{c|}{ High Mg2+ } \\
\hline Mean (GFP) & 846 & Mean (GFP) & 225 \\
\hline Mean (FSC) & 115551 & Mean (FSC) & 169411 \\
\hline Median (GFP) & 238 & Median (GFP) & 94.1 \\
\hline Median (FSC) & 88773 & Median (FSC) & 89413 \\
\hline Robust CV (GFP) & 226 & Robust CV (GFP) & 136 \\
\hline Robust CV (FSC) & 40.4 & Robust CV (FSC) & 107 \\
\hline
\end{tabular}

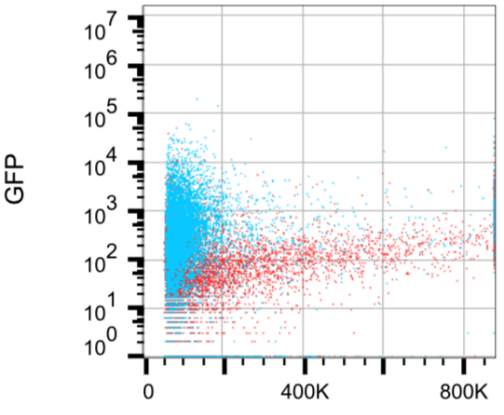

Forward Scatter

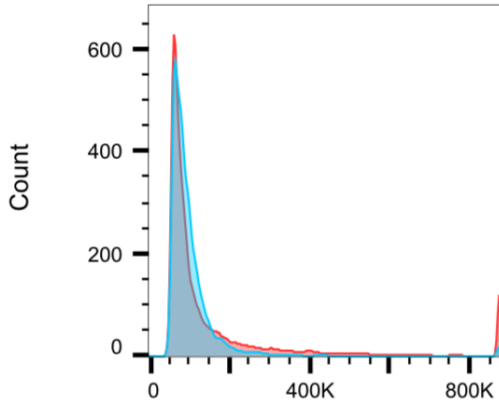

Forward Scatter

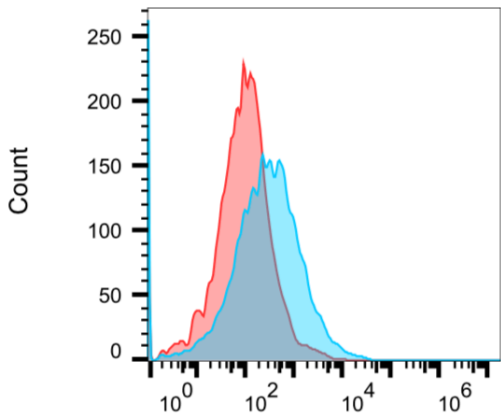

GFP

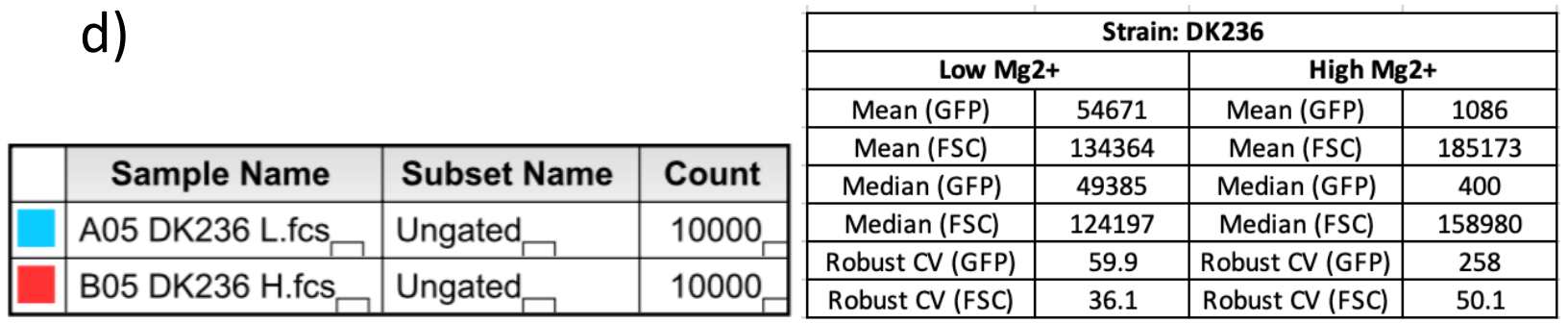



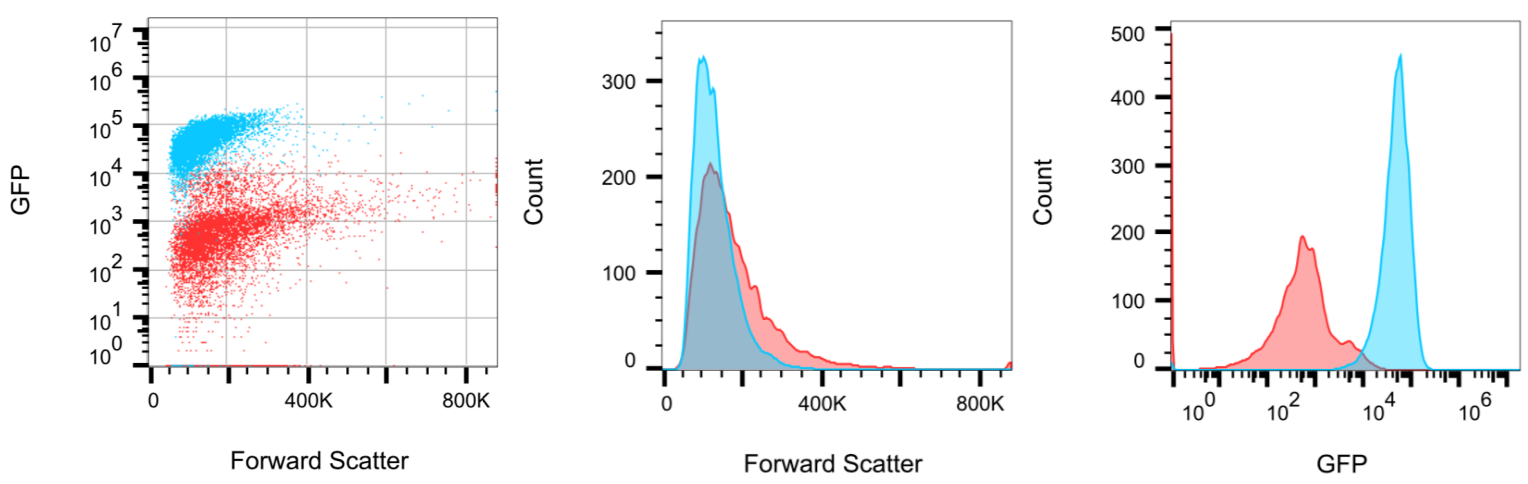

e)

\begin{tabular}{|c|c|l|c|}
\hline & Sample Name & Subset Name & Count \\
\hline & A07 DF-06 L.fcs $\square$ & Ungated & 10000 \\
\hline$\square$ & B07 DF-06 H.fcs & Ungated & 10000 \\
\hline
\end{tabular}

\begin{tabular}{|c|c|c|c|}
\hline \multicolumn{4}{|c|}{ Strain: DF-06 } \\
\hline \multicolumn{2}{|c|}{ Low Mg2+ } & \multicolumn{2}{c|}{ High Mg2+ } \\
\hline Mean (GFP) & 2522 & Mean (GFP) & 256 \\
\hline Mean (FSC) & 145739 & Mean (FSC) & 155841 \\
\hline Median (GFP) & 794 & Median (GFP) & 147 \\
\hline Median (FSC) & 132946 & Median (FSC) & 141908 \\
\hline Robust CV (GFP) & 517 & Robust CV (GFP) & 229 \\
\hline Robust CV (FSC) & 38.5 & Robust CV (FSC) & 42.7 \\
\hline
\end{tabular}

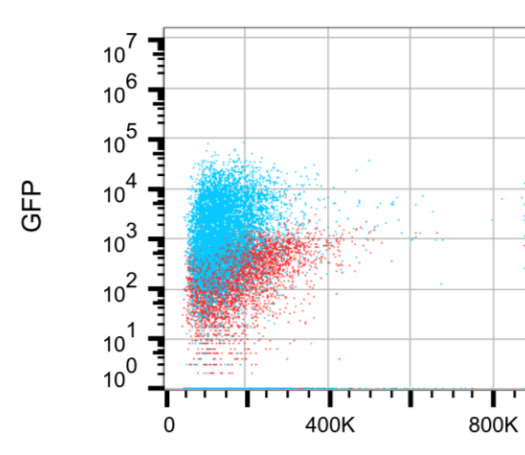

Forward Scatter
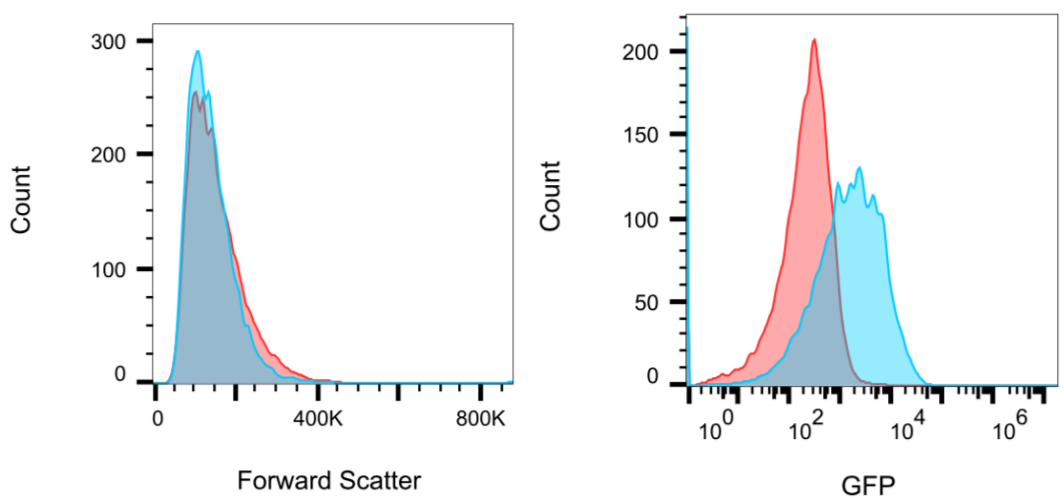

f)

\begin{tabular}{|l|l|l|c|}
\hline & \multicolumn{1}{|c|}{ Sample Name } & Subset Name & Count \\
\hline & A04 DK136 L.fcs & Ungated & 10000 \\
\hline$\square$ & B04 DK136 H.fcs & Ungated & 10000 \\
\hline
\end{tabular}

\begin{tabular}{|c|c|c|c|}
\hline \multicolumn{4}{|c|}{ Strain: DK136 } \\
\hline \multicolumn{2}{|c|}{ Low Mg2+ } & \multicolumn{2}{c|}{ High Mg2+ } \\
\hline Mean (GFP) & 18925 & Mean (GFP) & 800 \\
\hline Mean (FSC) & 137392 & Mean (FSC) & 169616 \\
\hline Median (GFP) & 17319 & Median (GFP) & 500 \\
\hline Median (FSC) & 126757 & Median (FSC) & 152151 \\
\hline Robust CV (GFP) & 56.6 & Robust CV (GFP) & 201 \\
\hline Robust CV (FSC) & 36.1 & Robust CV (FSC) & 47 \\
\hline
\end{tabular}



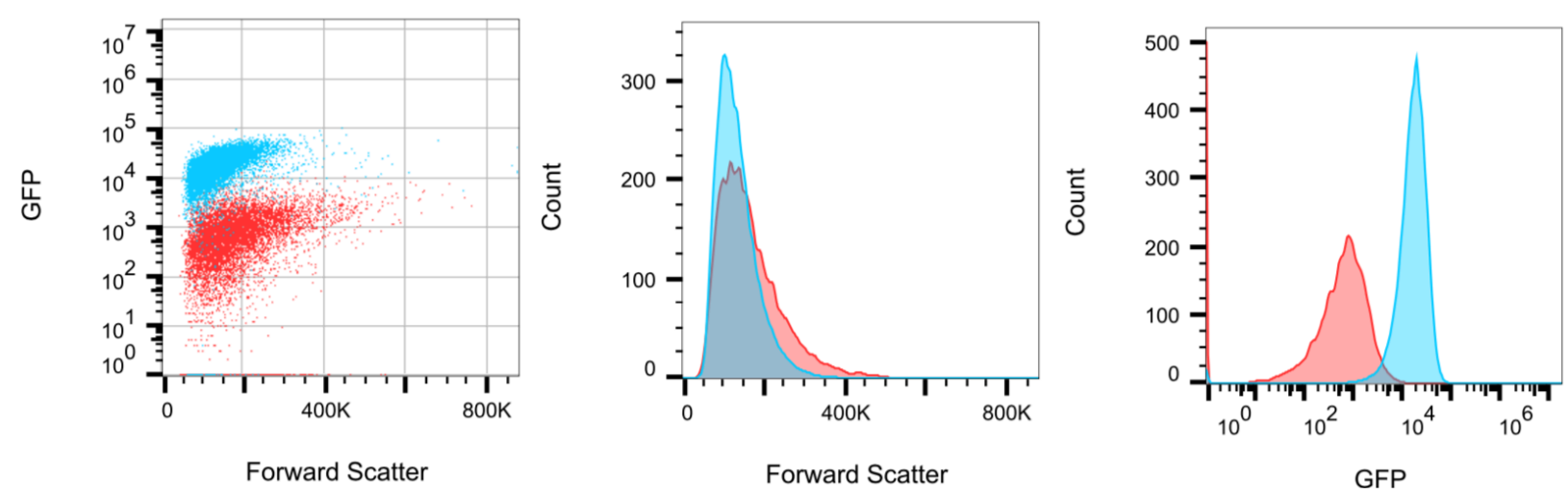

g)

\begin{tabular}{|l|l|l|c|}
\hline & Sample Name & Subset Name & Count \\
\hline$\square$ & A01 DK3 L.fcs & Ungated & 10000 \\
\hline$\square$ & B01 DK3 H.fcs & Ungated & 10000 \\
\hline
\end{tabular}

\begin{tabular}{|c|c|c|c|}
\hline \multicolumn{4}{|c|}{ Strain: DK3 } \\
\hline \multicolumn{2}{|c|}{ Low Mg2+ } & \multicolumn{2}{c|}{ High Mg2+ } \\
\hline Mean (GFP) & 21752 & Mean (GFP) & 780 \\
\hline Mean (FSC) & 120320 & Mean (FSC) & 176813 \\
\hline Median (GFP) & 11585 & Median (GFP) & 137 \\
\hline Median (FSC) & 106912 & Median (FSC) & 151298 \\
\hline Robust CV (GFP) & 169 & Robust CV (GFP) & 860 \\
\hline Robust CV (FSC) & 37.5 & Robust CV (FSC) & 52 \\
\hline
\end{tabular}

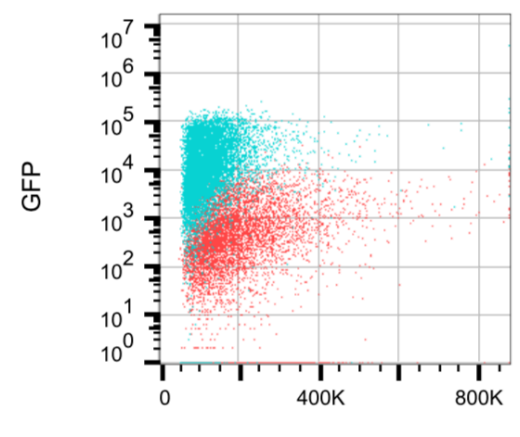

Forward Scatter

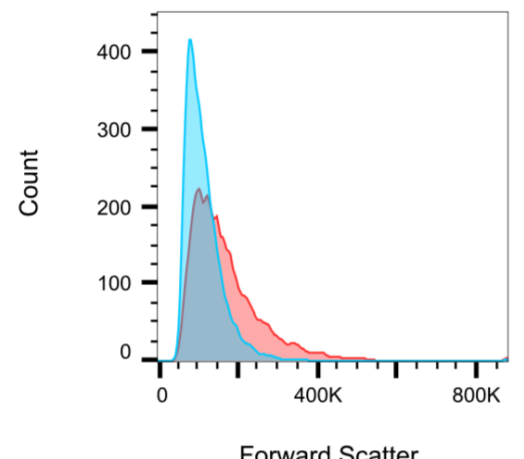

Forward Scatter

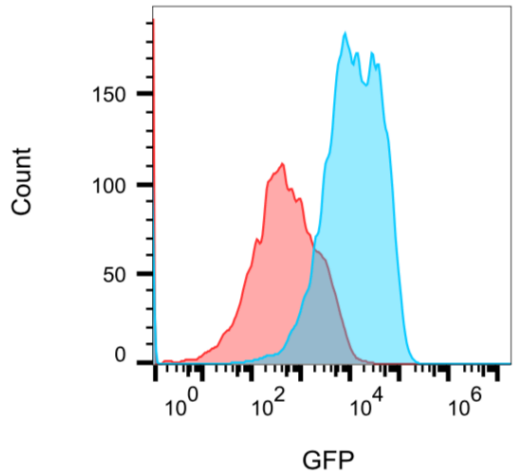

GFP

h)
\begin{tabular}{|c|c|l|c|}
\hline & Sample Name & Subset Name & Count \\
\hline & A02 DK26 L.fcs $_{\square}$ & Ungated \\
\hline & B $_{\square}$ DK26 H.fcs & & 10000 \\
\hline & Ungated \\
\hline
\end{tabular}

\begin{tabular}{|c|c|c|c|}
\hline \multicolumn{4}{|c|}{ Strain: DK26 } \\
\hline \multicolumn{2}{|c|}{ Low Mg2+ } & \multicolumn{2}{c|}{ High Mg2+ } \\
\hline Mean (GFP) & 14721 & Mean (GFP) & 323 \\
\hline Mean (FSC) & 141107 & Mean (FSC) & 167426 \\
\hline Median (GFP) & 12313 & Median (GFP) & 125 \\
\hline Median (FSC) & 122276 & Median (FSC) & 149804 \\
\hline Robust CV (GFP) & 81.8 & Robust CV (GFP) & 276 \\
\hline Robust CV (FSC) & 39.4 & Robust CV (FSC) & 45.7 \\
\hline
\end{tabular}




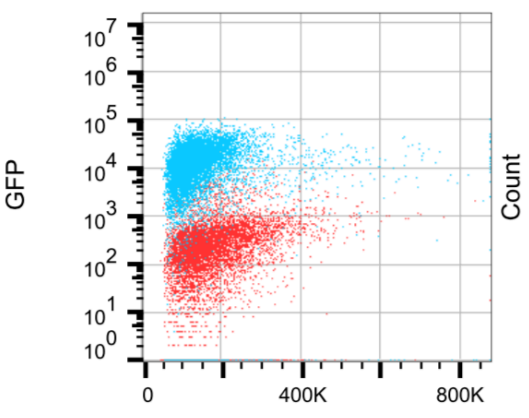

Forward Scatter

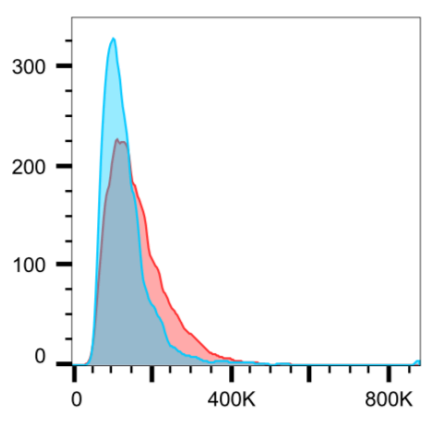

Forward Scatter

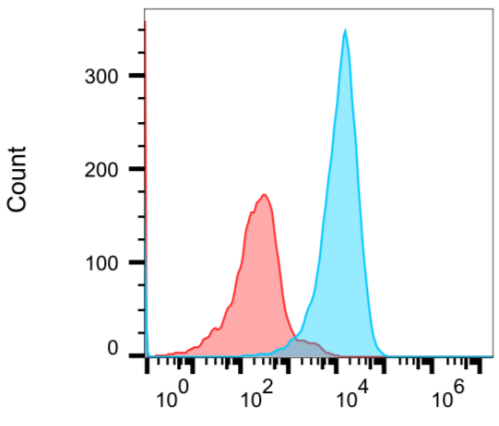

GFP

i)

\begin{tabular}{|l|l|l|l|}
\hline & Sample Name & Subset Name & Count \\
\hline & A08 PP26 L.fcs & Ungated & 10000 \\
\hline & B08 PP26 H.fcs & Ungated & 10000 \\
\hline
\end{tabular}

\begin{tabular}{|c|c|c|c|}
\hline \multicolumn{4}{|c|}{ Strain: PP26 } \\
\hline \multicolumn{2}{|c|}{ Low Mg2+ } & \multicolumn{2}{c|}{ High Mg2+ } \\
\hline Mean (GFP) & 596 & Mean (GFP) & 283 \\
\hline Mean (FSC) & 255643 & Mean (FSC) & 261133 \\
\hline Median (GFP) & 71.1 & Median (GFP) & 77.1 \\
\hline Median (FSC) & 155352 & Median (FSC) & 153645 \\
\hline Robust CV (GFP) & 572 & Robust CV (GFP) & 290 \\
\hline Robust CV (FSC) & 123 & Robust CV (FSC) & 129 \\
\hline
\end{tabular}

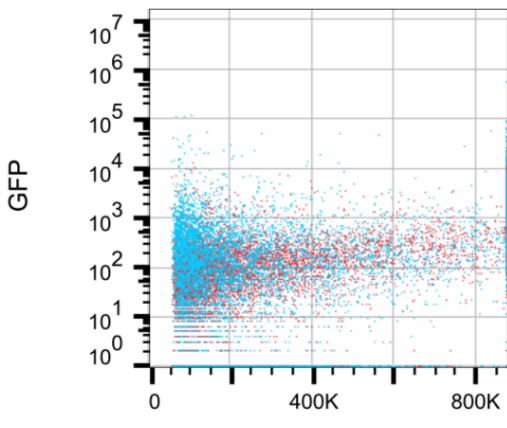

Forward Scatter
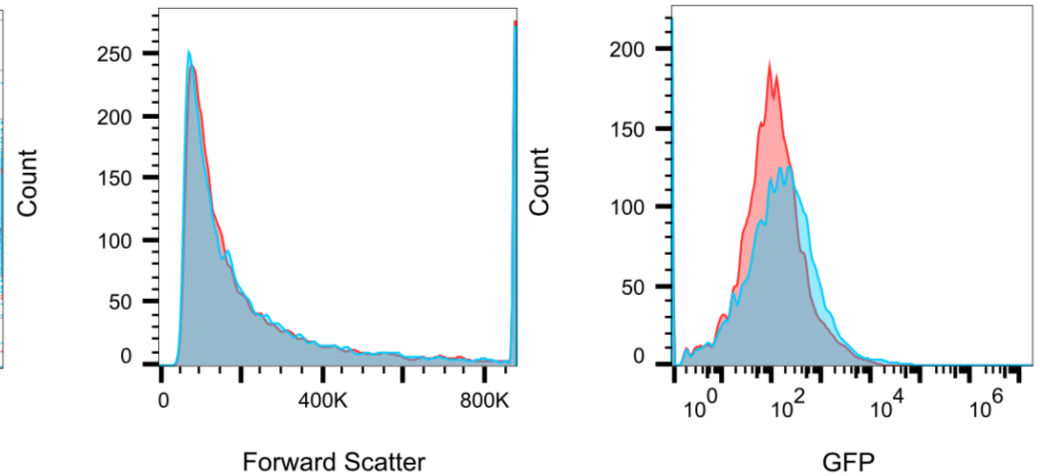

Figure 13. Single-cell analysis of $p m r D$ expression and cell size.

a-i) Single-cell analysis of $p m r D$-GFP construct in K12 and CD isolates using a Flow Cytometer. Parameters shown are Forward Scatter (FSC) and GFP, with primary statistics being mean, median, and robust CV for both FSC and GFP. Strains were grown overnight in either low $\mathrm{Mg}^{2+}(20 \mu \mathrm{M})$ or high $\mathrm{Mg}^{2+}(10 \mathrm{mM})$ prior to fixing with 1:1 methanol acetone. 


\section{Discussion}

IBD is complex, multifactorial disorder that affects 1 in 50 people in Canada ${ }^{11}$. While several treatment options exist for those that suffer from IBD, there is a need to better understand the etiology of this disease. The human gut microbiome, which plays a critical role in maintaining host health, is altered in those that suffer from either CD or $\mathrm{UC}^{27}$. Within this altered community is the increased prevalence IBDEC, a pathogen that has shown the ability to successfully colonize the HDP abundant epithelial surface of the gut ${ }^{28,29,98}$. IBDEC's survival against these peptides relies heavily on intricate bacterial signaling through conserved pathways that ultimately lead to increased expression of genes involved in cationic peptide resistance. Previous work in the McPhee lab has characterized disease specific HDP resistance among a large collection of IBDEC isolates. However, while resistance exists, there is large strain-tostrain variation in resistance phenotypes, ranging from completely susceptible to completely resistant. Here, we show evidence that this strain-to-strain variation is through differential PhoPQ signaling, a TCS critical for HDP resistance, in a panel of eight CD clinical isolates when induced using the same concentration of stimulus. Furthermore, the magnitude of strain-specific signaling might be used to predict the resistance profiles of these strains to cationic antimicrobial peptides.

To measure the transcriptional regulation of PhoPQ regulated genes, we sought to use a GFP reporter system. This system has been widely employed in E. coli models over the last two decades, with several different successful examples of studies looking at expression of genes involved in DNA repair, amino-acid synthesis pathways, flagella synthesis and much more ${ }^{105}$. Remarkable work from the Bren group in 2006 made significant progress at using this system in E. coli by making GFP transcriptional fusions to $75 \%$ of promoters found in the organism, creating a powerful resource for those exploring E. coli gene systems ${ }^{105}$. Our PhoPQ reporters included fusing the promoters of two PhoPQ regulated genes, $p m r D$ and $o m p T$, from a $\mathrm{K} 12$ strain BW25513 to GFP, bringing the transcription of GFP under the control of these promoters. We transformed these constructs into a K12 background and a panel of eight clinical CD isolates, where we induced or repressed the PhoPQ system and measured the activity of these promoters independently. 


\subsection{Heterogeneity in PhoPQ signaling among IBDEC isolates}

Our work shows that there are significant differences in the expression of both $p m r D$ and ompT under both PhoPQ inducing and repressing conditions among our clinical isolates (Fig. 7). While there are a number of ways to analyze this data set, we first opted to focus on looking at strain-to-strain differences in signaling when the system was induced using low $\mathrm{Mg}^{2+}$ minimal media $(20 \mu \mathrm{M})$. When we compared the induced signal from our CD isolates to our K12 control strain BW25113, we found, rather surprisingly, that BW25113 showed the highest signaling potential for both of our reporter genes. As these genes are involved in resistance to HDP, we anticipated the expression to be higher in our clinical isolates. The high signaling potential of BW25113 also correlated with a higher fold-change from non-inducing to inducing conditions ( $\sim 5$-fold for $p m r D$ and $\sim 3.5$-fold for omp $T$ ) when compared to the clinical isolates ( $\sim 2$-fold for pmrD and $\sim 1.7$-fold for $o m p T$ ).

\subsubsection{IBDEC strains differ in long-term signaling dynamics}

To study the intermediate dynamics of PhoPQ activation or repression, we used increasing concentrations of $\mathrm{Mg}^{2+}$ in our media to determine if we could reveal a strain-specific $\mathrm{Mg}^{2+}$ dependent threshold that switches PhoPQ from its repressive state to activating (Fig. 8). Consistent with our understanding of the PhoPQ system, all strains exhibited an inverse relationship between extracellular $\mathrm{Mg}^{2+}$ concentration and PhoPQ signaling. While we were not able to see an activation threshold for all of our strains, we were able to see interesting subtleties in the PhoPQ response in a subset of our strains. BW25113 showed significant response in signal as we transiently switch from repressive to inducing media. The biggest clustering of PhoPQ response we detected was at the $20 \mu \mathrm{M}$ to $1 \mathrm{mM} \mathrm{Mg}^{2+}$ range, suggesting a possible activation threshold range in this K12 background (Fig. 8b). On the other hand, other clinically isolated strains had varied responses. For instance, strain DK89, our highest $p m r D$ signaling strain, did not show exponential signaling potential over time, but rather a steady, plateaued signaling increase depending on the concentration (Fig. 8e). Strains DK3, DK26, DK136 and DF-06 respond well to the most inducing (lowest) concentrations of $\mathrm{Mg}^{2+}$ but have a steep decline in signaling at any $\mathrm{Mg}^{2+}$ concentrations greater than that $($ Fig. $\mathbf{8} \mathbf{c}, \mathbf{d}, \mathbf{f}, \mathbf{i})$. This could be attributed 
to one of two things, 1) lack of bacterial growth at the lowest $\mathrm{Mg}^{2+}$ concentration, or 2) a more robust response of these strains to the lowest $\mathrm{Mg}^{2+}$ concentration. In order to normalize for bacterial growth, we divide the fluorescence units generated from our reporter genes by the $\mathrm{OD}_{600}$. Therefore, if they same two strains emit the same fluorescence, but grow at different rates, the slower growing strain will generate a higher signaling value. When looking at the raw $\mathrm{OD}_{600}$ reads at the lowest $\mathrm{Mg}^{2+}$ concentration for DK3, DK26, DK136, DF-06, we see that the strains are actively growing and dividing. Therefore, option 2) from above seems like a more probable scenario of what is occurring in these four strains. They are primed to robustly respond at the lowest concentration of $\mathrm{Mg}^{2+}$ and have a steep decline in signaling potential at any concentrations higher than that.

\subsubsection{The role of $O$-antigen in $P h o P Q$ response}

To find a possible explanation for why our K12 background was our highest signaling strain, we looked for differences in the outer membrane between K12 and our clinical isolates. LPS found on the outer leaflet of the outer membrane in gram negatives has three distinct moieties, 1) an outer membrane embedded lipid A portion, 2) an oligosaccharide core region, and 3 ) and a highly variable $\mathrm{O}$-antigen region ${ }^{106,107}$. The lipid A portion is widely known as the most conserved and bioactive component within LPS, connecting to the oligosaccharide core. This core can be further divided into a highly conserved inner oligosaccharide region, and an outer oligosaccharide region that connects to the $\mathrm{O}$-antigen ${ }^{106}$. The $\mathrm{O}$-antigen region, which varies greatly in length and density between strains, is not an essential part of LPS and usually not found in E. coli $\mathrm{K} 12$ due to an insertion sequence (IS) in the $w b b L$ gene coding for rhamnosyltransferase, an enzyme critical for O-antigen synthesis ${ }^{107,108}$. We hypothesize that this $\mathrm{O}$-antigen defect in K12 is involved in the higher-fold increase we see in K12 signaling compared to our clinical isolates. In this working model, we believe that the O-antigen of our clinical strains modulates extracellular $\mathrm{Mg}^{2+}$ levels, creating a divalent cation microenvironment of its own. As an analogy, the O-antigen serves as 'sponges' that are able to sequester $\mathrm{Mg}^{2+}$ ions. Therefore, even in low $\mathrm{Mg}^{2+}$ concentrations, the PhoPQ response of these clinical strains are tainted with $\mathrm{O}$-antigen associated divalent cations, thus generating a consistent 2 -fold increase for PhoPQ signaling. K12 lacks these 'sponges', therefore response to $\mathrm{Mg}^{2+}$ levels reflect $\mathrm{Mg}^{2+}$ 
concentration within the media. To test this hypothesis, we plan to proceed with two separate experiments. Firstly, we want to conduct ICP analysis to measure a $\mathrm{Mg}^{2+}$ coefficient for each strain that measures bacterial cell-associated $\mathrm{Mg}^{2+}$ vs. supernatant $\mathrm{Mg}^{2+}$ concentrations. We would predict that our clinical isolates will have a higher portion of membrane-associated $\mathrm{Mg}^{2+}$ compared to our K12. And secondly, we want to fix the mutated $w b b L$ gene in our K12 strain, and test for PhoPQ signaling under the same conditions again. If our hypothesis holds true, we should see a reduction in the fold-change from non-inducing to inducing conditions in our 'fixed' K12 strain.

\subsection{PhoPQ signaling as a predictive marker for resistance}

We wanted to determine if the altered PhoPQ signaling among our clinical isolates correlated with a phenotypic output. Here, we hypothesized that high PhoPQ signaling strains would have elevated resistance to PMB, a small cationic antimicrobial that targets the negatively charged bacterial cell membrane. We elected to use the $p m r D$ signaling as a predictive model for resistance phenotype for three primary reasons: 1) there is no evidence that PMB can be cleaved by OmpT, 2) parallel work in McPhee lab has discovered a novel PhoPQ-independent way that ompT is regulated, and 3) the role of $p m r D$ in LPS modifications. As mentioned above, PmrD is a connector protein to the PmrAB TCS. This system is widely known as the master regulator of LPS modification, resulting in an overall negative charge on the bacterial membrane. This modification represents a direct mechanism by which bacteria are able to evade killing through PMB.

Results from our PMB resistance screens highlighted several interesting observations. Firstly, strain DK89, the highest pmrD, signaling strain, showed highest resistance phenotypes in most of the PMB concentrations tested, supporting our hypothesis. In addition, there was a clear distinction between the strains enhanced ability to resist PMB challenge after being cultured in PhoPQ-inducing vs. repressing media prior to PMB exposure (Fig. 9d). We also found evidence of active repression of $p m r D$ by PmrB-activated PmrA in strain DK89 (Fig. 10). First shown by Kato et al. in 2003, PmrB-activated PmrA has shown the ability to directly reduce pmrD transcription by binding to the promoter in a repressive manner. When we measured this 
phenomenon in our panel of isolates, we found evidence of this negative regulation only in DK89. Therefore, something we plan to do is perform PMB susceptibility assays of DK89 grown in both PhoPQ and PmrAB inducing media $\left(20 \mu \mathrm{M} \mathrm{Mg}^{2+}, 100 \mu \mathrm{M} \mathrm{Fe}^{3+}\right)$ to see if we can reduce the resistance phenotypes, as suggested by $p m r D$ expression levels in Figure 10. The results of the remaining isolates were not what was expected. According to our model, the lowest $p m r D$ signaling strain should exhibit the lowest resistance phenotype, and the remaining strains would follow the same sequential pattern. However, this is not what we observed. For example, PP26, a low signaling strain, actually displayed quite high PMB resistance phenotypes among the isolates (Fig. 10h). Additionally, we would expect to measure higher PMB resistance when strains were cultured in PhoPQ-inducing vs. repressive media. Strains DK26, DK236 and BW25113 showed elevated PMB resistance when grown in PhoPQ-repressing vs. inducing media, opposite of what we anticipated. This suggests that although PhoPQ-mediated signaling may be necessary for high level resistance to HDPs, it is not sufficient to explain it. To rationalize these results, the remaining portion of this section will discuss these two observations.

\subsubsection{Heteroresistance within isogenic cultures causes unusual resistance patterns}

Heteroresistance is broadly defined as subpopulations of cells within isogenic cultures that have different susceptibilities to antimicrobials drugs ${ }^{109,110}$. This phenomenon, which is becoming an increasingly prevalent topic in the scientific community, is an ambiguous mechanism where usually susceptible bacteria have subpopulations of antimicrobial resistant cells that can replicate after drug exposure. We wanted to screen our panel of strains to detect if heteroresistant subpopulations were driving the unusual PMB resistance we measured. To do this, we measured $p m r D$ activity at the single-cell level using flow cytometry for all our strains grown in either PhoPQ-inducing or repressing media (Fig. 12). If $p m r D$ transcription varied more in our cells grown in PhoPQ-repressive conditions, where a subpopulation of cells displayed pmrD signaling levels higher then when grown in PhoPQ-inducing conditions, it would give us confidence that heteroresistance could be the driving force behind the unusual PMB resistance measured. Strain UM146, a low pmrD signaling strain showed significant overlap between of $p m r D$ signaling when grown in either PhoPQ-inducing or repressive media (blue dots vs. red dots, Fig. 12c). Unfortunately, due the poor growing nature of UM146, we 
were unable to perform PMB killing assays on this strain. We were not able to detect significant overlap between the two media-types among the other strains tested. Of note, these single-cell analysis tests were completed using overnight cultures. The sample preparation of our cultures is different than what we do for our PMB resistance screens, where strains are subcultured and grown to mid-log in PhoPQ-inducing or repressing media. Bacteria display different metabolic activity in the different growth phases; therefore, we plan to complete this experiment again, but this time preparing our samples as we would for PMB killing assays. Another separate way we plan to screen for heteroresistant subpopulations within our strains is to plate cultures on nutrient agar plates with set concentrations of PMB, as was demonstrated by Napier et al. in 2014. In this screen, cultures would be grown to mid-log, and then be plated on nutrient agar with or without $\mathrm{PMB}^{110}$. The frequency of heteroresistant subpopulations would be measured by dividing the number of colonies present on PMB plates by PMB-free plates.

\subsubsection{Exploring strain-specific structural PhoQ variation}

The PhoQ histidine kinase contains a periplasmic domain (PD) comprised of an $\alpha / \beta$ core that senses for divalent cation concentration and the presence of CAMPs ${ }^{112}$. Within this PD are acidic patches that interact with the negatively charged inner membrane phospholipids through divalent cation bridges, with a particularly high affinity for $\mathrm{Mg}^{2+}$ ions. When bound to $\mathrm{Mg}^{2+}$, the PD retains a certain conformation that prevents autophosphorylation on $\mathrm{C}$-terminal catalytic domain $^{112}$. Traditionally, it has been thought that CAMPs activate PhoQ by out competing and displacing the $\mathrm{Mg}^{2+}$ from the acidic surface on the PD, thus disrupting the divalent cation bridges. However, recent work in 2015 showed evidence of a Salmonella PhoQ variant that was impaired for $\mathrm{Mg}^{2+}$ sensing but able to respond to CAMPs, suggesting independent recognition mechanisms ${ }^{111}$. This was achieved by mutating the PD through insertion of cysteine residues at positions W104 (located on the $\alpha 2$ helix) and A128 (located on the $\alpha 4$ helix), creating a disulphide bond between the two helices. The structure of the PhoQ ${ }^{\mathrm{W} 104 \mathrm{C}-\mathrm{A} 128 \mathrm{C}}$ mutant highly resembled both WT PhoQ PDs from Salmonella and E. coli backgrounds ${ }^{111}$, and in general, Salmonella PhoQ PD shares an $80.5 \%$ sequence similarity with the E. coli PhoQ PD ${ }^{112}$. To test for the virulence of this mutant, the authors infected BALB/c mice with WT Salmonella, the pho $Q^{W 104 C-A 128 C}$ strain, and a $\triangle p h o Q$ strain and measured splenic bacterial burden. The pho $Q^{W 104 C-A 128 C}$ mutant had increased bacterial burden compared to mice infected with the 
$\triangle p h o Q$ strain, and exhibited a higher splenic bacterial competitive index compared to the WT strain, highlighting its ability to be a virulent pathogen in vivo ${ }^{111}$.

We want to examine the PhoPQ sequences from our clinical isolates to screen for possible similar mutations mentioned above. If some of our strains hold a mutation that reduce its ability to respond to $\mathrm{Mg}^{2+}$ concentrations while maintaining its capacity to sense cationic peptides like PMB, it would explain why we see high PMB resistance in strains that were low $\mathrm{Mg}^{2+}$-dependent PhoPQ signalers (e.g. for strain PP26, Fig. 7a, Fig. 10h). In this circumstance, strains would have a higher propensity to signal through the PhoPQ system after being challenged by $\mathrm{PMB}$ rather than induced with $\mathrm{Mg}^{2+}$ replete conditions. Therefore, we also plan to measure PhoPQ signaling through our $p m r D$-GFP reporter using a CAMP as a stimulant to determine if we can recapitulate our $\mathrm{Mg}^{2+}$ induced results. If the signaling patterns between the two stimuli differ, it would suggest of independent mechanisms of PhoQ sensing in the respective strains.

\subsection{Novel insight of conserved signaling systems}

Bacteria rely on highly organized signaling through conserved systems to increase their fitness in competitive environments. Here, we have shown the ability of IBDEC strains to differentially signal through the PhoPQ signaling system to survive against antimicrobial threat. Interestingly, we were also able to see the same pattern of differential signaling in two EHEC strains, suggesting that this altered signaling response might exist among strains of other enteric pathogens as well (Fig. 11). Recent work from the Coombes showed that AIEC strain NRG857c gains hypermotility and metabolic advantages after mouse colonization, suggesting the adaptive role of these strains in $v i v o^{114}$. It is possible that our tested strains rapidly and independently evolved across the different gut environments they originally resided in and are now primed to respond a certain way. Due to the known interaction between the host immune system and microbial community in IBD, the signaling and HDP resistance profile of our IBDEC strains could provide insight into the host-specific environment they once colonized. 


\section{Future Directions}

We have two future projects planned that stem from the work uncovered during this thesis project. Firstly, two necessary experiments needed to validate this project directly are: 1) to complete western blots measuring PhoP phosphorylation per strain, and 2) confirm our transcriptional regulation data with qPCR. In the former, we plan to use our PhoP-HA tagged construct in the low copy pWSK129 vector to measure strain-specific PhoP phosphorylation via phos-tag gels. We hope to see the level of PhoP phosphorylation match the level of PhoPQ signaling from our $\mathrm{pmrD}$ reporter screen. In addition, we plan to use use qPCR on a subset of interesting strains (e.g. DK89) to verify the transcriptional regulation data produced by our $p m r D$ reporter screens. Two separate projects will be discussed below.

\subsection{Exploring the role of $\mathrm{O}$-antigen}

As previously mentioned, there are several planned experiments to look at the role of Oantigen in modulating PhoPQ signaling. ICP analysis of membrane associated $\mathrm{Mg}^{2+}$ in BW25113 and our panel of clinical isolates will be completed as an initial screen to determine a strainspecific $\mathrm{Mg}^{2+}$ coefficient. In parallel, 'fixing' the broken $w b b L$ gene in the $\mathrm{K} 12$ background and repeating the $p m r D$-GFP induction assays will give critical insight into the role of O-antigen in PhoPQ signaling. Following the induction assays, PMB resistance screens will be completed to determine if the presence of O-antigen in BW25113 enhances antimicrobial resistance, as suggested in literature ${ }^{107,113}$.

\subsection{Cloning and sequencing strain-specific PhoPQ}

Given the heterogeneity in PhoPQ signaling among IBDEC strains, future projects will attempt to establish a basis for this altered signaling. This will include cloning strain-specific PhoPQ proteins from IBDEC isolates for sequencing and transformation into a $\triangle$ phoPQ K12 strain. The sequencing results will be analyzed for potential important mutations. Further, the various strain-specific PhoPQ proteins in a $\triangle \mathrm{phoPQ}$ K12 background will be screened by completing $p m r D$-GFP induction assays to determine if the signaling heterogeneity is a product 
of these two proteins, or from accessory genes feeding back into the system. If the PhoPQ proteins themselves are the sole reason behind the heterogenous signaling, then the signaling from these experiments would match previous signaling data (Fig. 7a). If not, it gives as solid evidence of accessory genes involved in the altered signaling levels among strains. 


\section{References:}

1. Erb, A., et al. Prevalence of Antibiotic Resistance in Escherichia Coli: Overview of Geographical, Temporal, and Methodological Variations. Eur J Clin Microbiol Infect Dis, 2007, doi:10.1007/s10096-006-0248-2.

2. Rasko, David A., et al. "The Pangenome Structure of Escherichia Coli: Comparative Genomic Analysis of E. Coli Commensal and Pathogenic Isolates." Journal of Bacteriology, vol. 190, no. 20, American Society for Microbiology, Oct. 2008, pp. 6881-93, doi:10.1128/JB.00619-08.

3. Goldfine, H. "Bacterial Membranes and Lipid Packing Theory." Journal of Lipid Research, vol. 25, no. 13, 1984, pp. 1501-07, http://www.ncbi.nlm.nih.gov/pubmed/6530599.

4. Tlaskalová-Hogenová, Helena, et al. "The Role of Gut Microbiota (Commensal Bacteria) and the Mucosal Barrier in the Pathogenesis of Inflammatory and Autoimmune Diseases and Cancer: Contribution of Germ-Free and Gnotobiotic Animal Models of Human Diseases." Cellular \& Molecular Immunology, vol. 867, no. 10, 2011, pp. 110-20, doi:10.1038/cmi.2010.67.

5. Kostic, Aleksandar D., et al. The Microbiome in Inflammatory Bowel Diseases: Current Status and the Future Ahead. doi:10.1053/j.gastro.2014.02.009. Accessed 10 May 2018.

6. Conway, Tyrrell, and Paul S. Cohen. Commensal and Pathogenic Escherichia Coli Metabolism in the Gut. doi:10.1128/microbiolspec.MBP-0006-2014. Accessed 10 May 2018.

7. Rocchi Msc, Angela, et al. "Inflammatory Bowel Disease: A Canadian Burden of Illness Review." Can J Gastroenterol, vol. 26, no. 11, 2012, https:/www.ncbi.nlm.nih.gov/pmc/articles/PMC3495699/pdf/cjg26811.pdf.

8. Ulcerative Colitis - Crohn's and Colitis Canada. http://www.crohnsandcolitis.ca/About-Crohn-sColitis/What-are-Crohns-and-Colitis/ulcerativecolitis?gclid=Cj0KCQjwodrXBRCzARIsAIU59TIi0Yaoc1uw2zq7TuQw0qZmSvRCBsgGNB1 DtyhjcXkwPbEsBXHW9RsaAr9OEALw_wcB. Accessed 12 May 2018.

9. Gecse, Krisztina B., and Péter L. Lakatos. "Biologicals and Biosimilars in IBD — the Road to Personalized Treatment." Nature Reviews Gastroenterology \& Hepatology, vol. 14, no. 2, Nature Publishing Group, Feb. 2017, pp. 74-76, doi:10.1038/nrgastro.2016.206.

10. Louis, Edouard. "Stopping Biologics in IBD_-What Is the Evidence?" Inflamm Bowel Dis, vol. 24, no. 4, 2018, https://academic.oup.com/ibdjournal/article-abstract/24/4/725/4934202.

11. Kaplan, Gilaad G. "The Global Burden of IBD from 2015 to 2025 Nature Reviews Gastroenterology \& Hepatology Nature Publishing Group.” Nature Publishing Group, vol. 12, no. 12, 2015, pp. 720-27, https:/www.nature.com/articles/nrgastro.2015.150.

12. Frolkis, Alexandra, et al. "Environment and the Inflammatory Bowel Diseases." Canadian Journal of Gastroenterology, vol. 27, no. 3, Hindawi, 2013, pp. e18-24, doi:10.1155/2013/102859.

13. Molodecky, Natalie A., et al. "Increasing Incidence and Prevalence of the Inflammatory Bowel Diseases With Time, Based on Systematic Review." YGAST, vol. 142, 2012, pp. 46-54.e42, doi:10.1053/j.gastro.2011.10.001.

14. Calkins, Beverly M. "A Meta-Analysis of the Role of Smoking in Inflammatory Bowel Disease." Digestive Diseases and Sciences, vol. 34, no. 12, Kluwer Academic Publishers-Plenum Publishers, Dec. 1989, pp. 1841-54, doi:10.1007/BF01536701.

15. Harries, A. D., et al. "Non-Smoking: A Feature of Ulcerative Colitis." British Medical Journal (Clinical Research Ed.), vol. 284, no. 6317, 1982, p. 706, http://www.ncbi.nlm.nih.gov/pubmed/6802296\%0Ahttp:/www.pubmedcentral.nih.gov/articlere nder.fcgi?artid=PMC1496690. 
16. Stagg, Andrew J., et al. "Smokers with Active Crohn's Disease Have a Clinically Relevant Dysbiosis of the Gastrointestinal Microbiota*." Inflammatory Bowel Diseases, vol. 18, no. 6, 2011, pp. 1092-100, doi:10.1002/ibd.21864.

17. Boyko, Edward J., et al. "Risk of Ulcerative Colitis among Former and Current Cigarette Smokers." New England Journal of Medicine, vol. 316, no. 12, Mar. 1987, pp. 707-10, doi:10.1056/NEJM198703193161202.

18. Xavier, RJ, et al. "Unravelling the Pathogenesis of Inflammatory Bowel Disease R. J. Xavier1,2\& D. K. Podolsky1." Nature.Com, http://immunologie.charite.de/fileadmin/user_upload/microsites/m_cc12/immunologie/Lehre/rev iew-IBD-nature.pdf. Accessed 15 May 2018.

19. Jostins, Luke, et al. "Host-Microbe Interactions Have Shaped the Genetic Architecture of Inflammatory Bowel Disease." Nature, vol. 491, no. 7422, NIH Public Access, Nov. 2012, pp. 119-24, doi:10.1038/nature11582.

20. Ogura, Yasunori, et al. "A Frameshift Mutation in NOD2 Associated with Susceptibility to Crohn's Disease1. Ogura Y, Bonen DK, Inohara N, et Al. A Frameshift Mutation in NOD2 Associated with Susceptibility to Crohn's Disease. Nature. 2001;411(6837):603-606. Doi:10.1038/35079114." Nature, vol. 411, no. 6837, 2001, pp. 603-06, doi:10.1038/35079114.

21. Pidasheva, Svetlana, et al. "Functional Studies on the IBD Susceptibility Gene IL23R Implicate Reduced Receptor Function in the Protective Genetic Variant R381Q." PLoS ONE, edited by Sunil K. Ahuja, vol. 6, no. 10, Public Library of Science, Oct. 2011, p. e25038, doi:10.1371/journal.pone.0025038.

22. Cummings, Fraser J. R., et al. "Confirmation of the Role of ATG1611 as a Crohn's Disease Susceptibility Gene.” Inflammatory Bowel Diseases, vol. 13, no. 8, Aug. 2007, pp. 941-46, doi:10.1002/ibd.20162.

23. Weersma, Rinse K., et al. "ATG16L1 and IL23R Are Associated With Inflammatory Bowel Diseases but Not With Celiac Disease in The Netherlands." American Journal of Gastroenterology, 2008, doi:10.1111/j.1572-0241.2007.01660.x.

24. Hampe, Jochen, et al. "A Genome-Wide Association Scan of Nonsynonymous SNPs Identifies a Susceptibility Variant for Crohn Disease in ATG16L1." Nature Genetics, vol. 39, no. 2, 2007, pp. 207-11, doi:10.1038/ng1954.

25. Fava, Francesca, and Silvio Danese. "Intestinal Microbiota in Inflammatory Bowel Disease: Friend of Foe?" World Journal of Gastroenterology, vol. 17, no. 5, Baishideng Publishing Group Inc, Feb. 2011, pp. 557-66, doi:10.3748/wjg.v17.i5.557.

26. Frank, Daniel N., et al. "Disease Phenotype and Genotype Are Associated with Shifts in Intestinal-Associated Microbiota in Inflammatory Bowel Diseases." Inflammatory Bowel Diseases, vol. 17, no. 1, NIH Public Access, Jan. 2011, pp. 179-84, doi:10.1002/ibd.21339.

27. Gevers, Dirk, et al. "The Treatment-Naive Microbiome in New-Onset Crohn's Disease." Cell Host \& Microbe, vol. 15, no. 3, Cell Press, Mar. 2014, pp. 382-92, doi:10.1016/J.CHOM.2014.02.005.

28. Darfeuille-Michaud, Arlette, et al. "High Prevalence of Adherent-Invasive Escherichia Coli Associated with Ileal Mucosa in Crohn's Disease." Gastroenterology, vol. 127, no. 2, Elsevier, Aug. 2004, pp. 412-21, doi:10.1053/j.gastro.2004.04.061.

29. Darfeuille-Michaud, A., et al. "Presence of Adherent Escherichia Coli Strains in Ileal Mucosa of Patients with Crohn's Disease." Gastroenterology, vol. 115, no. 6, 1998, pp. 1405-13, doi:10.1016/S0016-5085(98)70019-8. 
30. Carvalho, Frédéric A., et al. "Crohn's Disease Adherent-Invasive Escherichia Coli Colonize and Induce Strong Gut Inflammation in Transgenic Mice Expressing Human CEACAM.” The Journal of Experimental Medicine, vol. 206, no. 10, Rockefeller University Press, Sept. 2009, pp. 2179-89, doi:10.1084/jem.20090741.

31. Barnich, Nicolas, et al. "CEACAM6 Acts as a Receptor for Adherent-Invasive E. Coli, Supporting Ileal Mucosa Colonization in Crohn Disease." The Journal of Clinical Investigation, vol. 117, no. 6, American Society for Clinical Investigation, June 2007, pp. 1566-74, doi:10.1172/JCI30504.

32. Small, Cherrie-Lee N., et al. "Persistent Infection with Crohn's Disease-Associated AdherentInvasive Escherichia Coli Leads to Chronic Inflammation and Intestinal Fibrosis." Nature Communications, vol. 4, Nature Publishing Group, June 2013, p. 1957, doi:10.1038/ncomms2957.

33. Hancock, Robert E. W., and Hans Georg Sahl. "Antimicrobial and Host-Defense Peptides as New Anti-Infective Therapeutic Strategies.” Nature Biotechnology, vol. 24, no. 12, 2006, pp. 1551-57, doi:10.1038/nbt1267.

34. Brodgen KA. "Antimicrobial Peptides: Pore Formers or Metabolic Inhibitors in Bacteria?" Nature Reviews. Microbiology, vol. 3, no. 3, 2005, pp. 238-50, doi:10.1038/nrmicro1098.

35. Hancock, R. E., and M. G. Scott. "The Role of Antimicrobial Peptides in Animal Defenses." Proceedings of the National Academy of Sciences of the United States of America, vol. 97, no. 16, 2000, pp. 8856-61, http://www.ncbi.nlm.nih.gov/pubmed/10922046\%0Ahttp:/www.pubmedcentral.nih.gov/articler ender.fcgi?artid=PMC34023.

36. Hancock, Robert E. W., et al. "The Immunology of Host Defence Peptides: Beyond Antimicrobial Activity." Nature Reviews Immunology, vol. 16, no. 5, 2016, pp. 321-34, doi:10.1038/nri.2016.29.

37. Beier, Dagmar, and Roy Gross. "Regulation of Bacterial Virulence by Two-Component Systems." Current Opinion in Microbiology, vol. 9, no. 2, 2006, pp. 143-52, doi:10.1016/j.mib.2006.01.005.

38. Breland, Erin J., et al. "An Overview of Two-Component Signal Transduction Systems Implicated in Extra-Intestinal Pathogenic E. Coli Infections." Frontiers in Cellular and Infection Microbiology, vol. 7, May 2017, doi:10.3389/fcimb.2017.00162.

39. Dalebroux, Zachary D., and Samuel I. Miller. "Salmonellae PhoPQ Regulation of the Outer Membrane to Resist Innate Immunity." Current Opinion in Microbiology, vol. 17, NIH Public Access, Feb. 2014, pp. 106-13, doi:10.1016/j.mib.2013.12.005.

40. Hwang, Peter M., et al. "Solution Structure and Dynamics of the Outer Membrane Enzyme PagP by NMR." Proceedings of the National Academy of Sciences of the United States of America, vol. 99, no. 21, National Academy of Sciences, Oct. 2002, pp. 13560-65, doi:10.1073/pnas.212344499.

41. Rubin, Erica J., et al. "PmrD Is Required for Modifications to Escherichia Coli Endotoxin That Promote Antimicrobial Resistance." Antimicrobial Agents and Chemotherapy, vol. 59, no. 4, American Society for Microbiology, Apr. 2015, pp. 2051-61, doi:10.1128/AAC.05052-14.

42. Schurek, Kristen N., et al. "Involvement of PmrAB and PhoPQ in Polymyxin B Adaptation and Inducible Resistance in Non-Cystic Fibrosis Clinical Isolates of Pseudomonas Aeruginosa." Antimicrobial Agents and Chemotherapy, vol. 53, no. 10, American Society for Microbiology, Oct. 2009, pp. 4345-51, doi:10.1128/AAC.01267-08. 
43. Farizano, Juan V, et al. "The PmrAB System-Inducing Conditions Control Both Lipid A Remodeling and O-Antigen Length Distribution, Influencing the Salmonella Typhimurium-Host Interactions." The Journal of Biological Chemistry, vol. 287, no. 46, American Society for Biochemistry and Molecular Biology, Nov. 2012, pp. 38778-89, doi:10.1074/jbc.M112.397414.

44. Blount, Zachary D. "The Unexhausted Potential of E. Coli." ELife, vol. 4, eLife Sciences Publications, Ltd, Mar. 2015, doi:10.7554/eLife.05826.

45. Randal Bollinger, R., et al. "Human Secretory Immunoglobulin A May Contribute to Biofilm Formation in the Gut." Immunology, vol. 109, no. 4, Wiley/Blackwell (10.1111), Aug. 2003, pp. 580-87, doi:10.1046/j.1365-2567.2003.01700.x.

46. Murthy, Aditya, et al. "A Crohn's Disease Variant in Atg1611 Enhances Its Degradation by Caspase 3." Nature, vol. 506, no. 7489, Feb. 2014, pp. 456-62, doi:10.1038/nature13044.

47. McPhee, Joseph B., et al. "Host Defense Peptide Resistance Contributes to Colonization and Maximal Intestinal Pathology by Crohn's Disease-Associated Adherent-Invasive Escherichia Coli." Infection and Immunity, vol. 82, no. 8, American Society for Microbiology, Aug. 2014, pp. 3383-93, doi:10.1128/IAI.01888-14.

48. Thomassin, Jenny-Lee, et al. "OmpT Outer Membrane Proteases of Enterohemorrhagic and Enteropathogenic Escherichia Coli Contribute Differently to the Degradation of Human LL-37." Infection and Immunity, vol. 80, no. 2, American Society for Microbiology, Feb. 2012, pp. 48392, doi:10.1128/IAI.05674-11.

49. Capra, Emily J., and Michael T. Laub. "Evolution of Two-Component Signal Transduction Systems.” Annual Review of Microbiology, vol. 66, no. 1, Oct. 2012, pp. 325-47, doi:10.1146/annurev-micro-092611-150039.

50. Casino, et al. "The Mechanism of Signal Transduction by Two-Component Systems." Current Opinion in Structural Biology, vol. 20, no. 6, 2010, pp. 763-71, doi:10.1016/j.sbi.2010.09.010.

51. Gao, Rong, and Ann M. Stock. "Biological Insights from Structures of Two-Component Proteins." Annual Review of Microbiology, vol. 63, no. 1, Oct. 2009, pp. 133-54, doi:10.1146/annurev.micro.091208.073214.

52. He, Xiaoyuan, and Shuishu Wang. "DNA Consensus Sequence Motif for Binding Response Regulator PhoP, a Virulence Regulator of Mycobacterium Tuberculosis.” Biochemistry, vol. 53, no. 51, 2014, pp. 8008-20, doi:10.1021/bi501019u.

53. Goulian, Mark. "Two-Component Signaling Circuit Structure and Properties." Current Opinion in Microbiology, vol. 13, no. 2, 2010, pp. 184-89, doi:10.1016/j.mib.2010.01.009.

54. Russo, Frank D., and Thomas J. Silhavy. "The Essential Tension: Opposed Reactions in Bacterial Two-Component Regulatory Systems." Trends in Microbiology, vol. 1, no. 8, 1 Nov. 1993, pp. 306-10, doi:10.1016/0966-842X(93)90007-E.

55. Batchelor, E., and M. Goulian. "Robustness and the Cycle of Phosphorylation and Dephosphorylation in a Two-Component Regulatory System." Proceedings of the National Academy of Sciences, vol. 100, no. 2, 2003, pp. 691-96, doi:10.1073/pnas.0234782100.

56. Miyashiro, T., and M. Goulian. "High Stimulus Unmasks Positive Feedback in an Autoregulated Bacterial Signaling Circuit." Proceedings of the National Academy of Sciences, vol. 105, no. 45, 2008, pp. 17457-62, doi:10.1073/pnas.0807278105.

57. Lippa, Andrew M., and Mark Goulian. "Feedback Inhibition in the PhoQ/PhoP Signaling System by a Membrane Peptide." PLoS Genetics, vol. 5, no. 12, 2009, p. 1000788, doi:10.1371/journal.pgen.1000788. 
58. Lippa, Andrew M., and Mark Goulian. "Perturbation of the Oxidizing Environment of the Periplasm Stimulates the PhoQ/PhoP System in Escherichia Coli." Journal of Bacteriology, vol. 194, no. 6, 2012, pp. 1457-63, doi:10.1128/JB.06055-11.

59. Herrera, Carmen M., et al. "Activation of PmrA Inhibits LpxT-Dependent Phosphorylation of Lipid A Promoting Resistance to Antimicrobial Peptides.” Molecular Microbiology, vol. 76, no. 6, 2010, pp. 1444-60, doi:10.1111/j.1365-2958.2010.07150.x.

60. Bader, Martin W., et al. "Recognition of Antimicrobial Peptides by a Bacterial Sensor Kinase." Cell, vol. 122, no. 3, 2005, pp. 461-72, doi:10.1016/j.cell.2005.05.030.

61. Girardin, Stephen E., et al. "Nod2 Is a General Sensor of Peptidoglycan through Muramyl Dipeptide (MDP) Detection." Journal of Biological Chemistry, vol. 278, no. 11, American Society for Biochemistry and Molecular Biology, Mar. 2003, pp. 8869-72, doi:10.1074/jbc.C200651200.

62. Cadwell, Ken, et al. "Virus-Plus-Susceptibility Gene Interaction Determines Crohn's Disease Gene Atg16L1 Phenotypes in Intestine." Cell, vol. 141, no. 7, NIH Public Access, June 2010, pp. 1135-45, doi:10.1016/j.cell.2010.05.009.

63. Cadwell, Ken, et al. "A Key Role for Autophagy and the Autophagy Gene Atg1611 in Mouse and Human Intestinal Paneth Cells." Nature, vol. 456, no. 7219, NIH Public Access, Nov. 2008, pp. 259-63, doi:10.1038/nature07416.

64. Elhenawy, Wael, et al. "A Polymicrobial View of Disease Potential in Crohn's-Associated Adherent-Invasive E. Coli.” Gut Microbes, vol. 9, no. 2, Taylor \& Francis, 4 Mar. 2017, pp. 1-9, doi:10.1080/19490976.2017.1378291.

65. Kato, A., et al. "Closing the Loop: The PmrA/PmrB Two-Component System Negatively Controls Expression of Its Posttranscriptional Activator PmrD." Proceedings of the National Academy of Sciences, vol. 100, no. 8, 2003, pp. 4706-11, doi:10.1073/pnas.0836837100.

66. El-Halfawy, Omar M., and Miguel A. Valvano. "Antimicrobial Heteroresistance: An Emerging Field in Need of Clarity." Clinical Microbiology Reviews, vol. 28, no. 1, 2015, pp. 191-207, doi:10.1128/CMR.00058-14.

67. Ricciuto, Amanda, et al. "Diagnostic Delay in Canadian Children with Inflammatory Bowel Disease Is More Common in Crohn's Disease and Associated with Decreased Height." Archives of Disease in Childhood, vol. 103, no. 4, 2018, pp. 319-26, doi:10.1136/archdischild-2017313060.

68. Benchimol, Eric I., et al. "Changing Age Demographics of Inflammatory Bowel Disease in Ontario, Canada.” Inflammatory Bowel Diseases, vol. 20, no. 10, 2014, pp. 1761-69, doi:10.1097/mib.0000000000000103.

69. Benchimol, E. I., et al. "Increasing Incidence of Paediatric Inflammatory Bowel Disease in Ontario, Canada: Evidence from Health Administrative Data." Gut, vol. 58, 2009, pp. 1490-97, doi:10.1136/gut.2009.188383.

70. N., Gupta, et al. "Presentation and Disease Course in Early- Compared to Later-Onset Pediatric Crohn's Disease." American Journal of Gastroenterology, vol. 103, no. 8, 2008, pp. 2092-98, https://www.nature.com/articles/ajg2008407.

71. De Ridder, Lissy, et al. "Genetic Susceptibility Has a More Important Role in Pediatric-Onset Crohn's Disease than in Adult-Onset Crohn's Disease.” Inflammatory Bowel Diseases, vol. 13, no. 9, Sept. 2007, pp. 1083-92, doi:10.1002/ibd.20171.

72. Iida, Tomoya, et al. "Impact of Autophagy of Innate Immune Cells on Inflammatory Bowel Disease." Cells, vol. 8, no. 1, 2018, p. 7, doi:10.3390/cells8010007. 
73. Plantinga, Theo S., et al. 'Crohn's Disease-Associated ATG16L1 Polymorphism Modulates proInflammatory Cytokine Responses Selectively upon Activation of NOD2.” Gut, vol. 60, no. 9, 2011, pp. 1229-35, doi:10.1136/gut.2010.228908.

74. Baümler, Andreas J., and Vanessa Sperandio. "Interactions between the Microbiota and Pathogenic Bacteria in the Gut.” Nature, vol. 535, no. 7610, NIH Public Access, 2016, pp. 8593, doi:10.1038/nature18849.

75. Keeney, Kristie M., and B. Brett Finlay. "Enteric Pathogen Exploitation of the MicrobiotaGenerated Nutrient Environment of the Gut." Current Opinion in Microbiology, vol. 14, no. 1, NIH Public Access, Feb. 2011, pp. 92-98, doi:10.1016/j.mib.2010.12.012.

76. Stecher, Bärbel. "The Roles of Inflammation, Nutrient Availability and the Commensal Microbiota in Enteric Pathogen Infection." Metabolism and Bacterial Pathogenesis, vol. 3, no. 3, American Society of Microbiology, 2015, pp. 297-320, doi:10.1128/microbiolspec.mbp-00082014.

77. Peschel, A., et al. "The Co-Evolution of Host Cationic Antimicrobial Peptides and Microbial Resi...: University of Liverpool Library." Nature.Com, https://www.nature.com/articles/nrmicro1441. Accessed 20 June 2019.

78. Netea-Maier, Romana T., et al. "Modulation of Inflammation by Autophagy: Consequences for Human Disease." Autophagy, vol. 12, no. 2, 2016, pp. 245-60, doi:10.1080/15548627.2015.1071759.

79. Conway, Tyrrell, and Paul S. Cohen. "Commensal and Pathogenic Escherichia Coli Metabolism in the Gut.” Microbiology Spectrum, vol. 3, no. 3, NIH Public Access, June 2015, doi:10.1128/microbiolspec.mbp-0006-2014.

80. Matic, I., et al. "Highly Variable Mutation Rates in Commensal and Pathogenic Escherichia Coli." Science, vol. 277, no. 5333, 1997, pp. 1833-34, doi:10.1126/science.277.5333.1833.

81. Tenaillon, Olivier, et al. "The Population Genetics of Commensal Escherichia Coli." Nature Reviews Microbiology, vol. 8, no. 3, 2010, pp. 207-17, doi:10.1038/nrmicro2298.

82. Rasko, David A., et al. "The Pangenome Structure of Escherichia Coli: Comparative Genomic Analysis of E. Coli Commensal and Pathogenic Isolates." Journal of Bacteriology, vol. 190, no. 20, 2008, pp. 6881-93, doi:10.1128/JB.00619-08.

83. McDaniel, T. K., et al. "A Genetic Locus of Enterocyte Effacement Conserved among Diverse Enterobacterial Pathogens." Proceedings of the National Academy of Sciences, vol. 92, no. 5, 2006, pp. 1664-68, doi:10.1073/pnas.92.5.1664.

84. Cepeda-Molero, Massiel, et al. "Attaching and Effacing (A/E) Lesion Formation by Enteropathogenic E. Coli on Human Intestinal Mucosa Is Dependent on Non-LEE Effectors." PLoS Pathogens, edited by Brian K. Coombes, vol. 13, no. 10, Oct. 2017, p. e1006706, doi:10.1371/journal.ppat.1006706.

85. Franzin, Fernanda M., and Marcelo P. Sircili. "Locus of Enterocyte Effacement: A Pathogenicity Island Involved in the Virulence of Enteropathogenic and Enterohemorragic Escherichia Coli Subjected to a Complex Network of Gene Regulation.” BioMed Research International, vol. 2015, Hindawi Limited, 2015, pp. 1-10, doi:10.1155/2015/534738.

86. Snyder, Jennifer A., et al. "Transcriptome of Uropathogenic Escherichia Coli during Urinary Tract Infection." Infection and Immunity, vol. 72, no. 11, 2004, pp. 6373-81, doi:10.1128/IAI.72.11.6373-6381.2004.

87. Tabaqchali, S., et al. "Escherichia Coli Antibodies in Patients with Inflammatory Bowel Disease." Gut, vol. 19, no. 2, 1978, pp. 108-13, doi:10.1136/gut.19.2.108. 
88. J., Boudeau, et al. "Invasive Ability of an Escherichia Coli Strain Isolated from the Ileal Mucosa of a Patient with Crohn's Disease.” Infection and Immunity, vol. 67, no. 9, 1999, pp. 4499-509, https://iai.asm.org/content/67/9/4499.short.

89. Boudeau, Jérôme, et al. "Type 1 Pili-Mediated Adherence of Escherichia Coli Strain LF82 Isolated from Crohn's Disease Is Involved in Bacterial Invasion of Intestinal Epithelial Cells." Molecular Microbiology, vol. 39, no. 5, Feb. 2001, pp. 1272-84, doi:10.1046/j.13652958.2001.02315.x.

90. Glasser, A. L., et al. “Adherent Invasive Escherichia Coli Strains from Patients with Crohn's Disease Survive and Replicate within Macrophages without Inducing Host Cell Death." Infection and Immunity, vol. 69, no. 9, 2001, pp. 5529-37, https://iai.asm.org/content/69/9/5529.short.

91. Delmas, Julien, et al. "Metabolic Adaptation of Adherent-Invasive Escherichia Coli to Exposure to Bile Salts." Scientific Reports, vol. 9, no. 1, 2019, doi:10.1038/s41598-019-38628-1.

92. Shaler, Christopher R., et al. "The Unique Lifestyle of Crohn's Disease-Associated AdherentInvasive Escherichia Coli." Journal of Molecular Biology, 2019, doi:10.1016/j.jmb.2019.04.023.

93. Dogan, Belgin, et al. "Inflammation-Associated Adherent-Invasive Escherichia Coli Are Enriched in Pathways for Use of Propanediol and Iron and M-Cell Translocation." Inflammatory Bowel Diseases, vol. 20, no. 11, Narnia, Nov. 2014, pp. 1919-32, doi:10.1097/MIB.0000000000000183.

94. Carvalho, Frédéric A., et al. "Crohn's Disease Adherent-Invasive Escherichia Coli Colonize and Induce Strong Gut Inflammation in Transgenic Mice Expressing Human CEACAM.” The Journal of Experimental Medicine, vol. 206, no. 10, 2009, pp. 2179-89, doi:10.1084/jem.20090741.

95. Mookherjee, N., and R. E. W. Hancock. "Cationic Host Defence Peptides: Innate Immune Regulatory Peptides as a Novel Approach for Treating Infections." Cellular and Molecular Life Sciences, vol. 64, no. 7-8, 19 Apr. 2007, pp. 922-33, doi:10.1007/s00018-007-6475-6.

96. Bevins, C. I., et al. "Defensins and Innate Host Defence of the Gastrointestinal Tract." Gut, vol. 45, no. 6, 1999, pp. 911-15, doi:10.1136/gut.45.6.911.

97. De Smet, Kris, and Roland Contreras. "Human Antimicrobial Peptides: Defensins, Cathelicidins and Histatins." Biotechnology Letters, vol. 27, no. 18, Sept. 2005, pp. 1337-47, doi:10.1007/s 10529-005-0936-5.

98. J.P., Meisch, et al. "Human -Defensin 3 Peptide Is Increased and Redistributed in Crohn's Ileitis.” Inflammatory Bowel Diseases, vol. 19, no. 5, 2013, pp. 942-53, https://academic.oup.com/ibdjournal/article-abstract/19/5/942/4603083.

99. Schauber, Jürgen, et al. "Heterogeneous Expression of Human Cathelicidin HCAP18/LL-37 in Inflammatory Bowel Diseases." European Journal of Gastroenterology and Hepatology, vol. 18, no. 6, 2006, pp. 615-21, doi:10.1097/00042737-200606000-00007.

100. Jin, T., et al. "Staphylococcus Aureus Resists Human Defensins by Production of Staphylokinase, a Novel Bacterial Evasion Mechanism." The Journal of Immunology, vol. 172, no. 2, 2014, pp. 1169-76, doi:10.4049/jimmunol.172.2.1169.

101. Ernst, Robert K., et al. "Salmonella Typhimurium Outer Membrane Remodeling: Role in Resistance to Host Innate Immunity." Microbes and Infection, vol. 3, no. 14-15, 2001, pp. 1327-34, doi:10.1016/S1286-4579(01)01494-0.

102. McPhee, Joseph B., et al. "Cationic Antimicrobial Peptides Activate a Two-Component Regulatory System, PmrA-PmrB, That Regulates Resistance to Polymyxin B and Cationic 
Antimicrobial Peptides in Pseudomonas Aeruginosa." Molecular Microbiology, vol. 50, no. 1, Aug. 2003, pp. 205-17, doi:10.1046/j.1365-2958.2003.03673.x.

103. Peschel, Andreas. "How Do Bacteria Resist Human Antimicrobial Peptides?" Trends in Microbiology, vol. 10, no. 4, 2002, pp. 179-86, doi:10.1016/S0966-842X(02)02333-8.

104. Guina, Tina, et al. "A PhoP-Regulated Outer Membrane Protease of Salmonella Enterica Serovar Typhimurium Promotes Resistance to Alpha-Helical Antimicrobial Peptides." Journal of Bacteriology, vol. 182, no. 14, 2000, pp. 4077-86, doi:10.1128/JB.182.14.4077-4086.2000.

105. Bren, Anat, et al. "A Comprehensive Library of Fluorescent Transcriptional Reporters for Escherichia Coli." Nature Methods, vol. 3, no. 8, 2006, pp. 623-28, doi:10.1038/nmeth895.

106. Meredith, Timothy C., et al. "Redefining the Requisite Lipopolysaccharide Structure in Escherichia Coli." ACS Chemical Biology, vol. 1, no. 1, 2006, pp. 33-42, doi:10.1021/cb0500015.

107. Sharp, Connor, et al. "O-Antigen-Dependent Colicin Insensitivity of Uropathogenic Escherichia Coli.” Journal of Bacteriology, vol. 201, no. 4, 2019, doi:10.1128/JB.00545-18.

108. G., Stevenson, et al. "Structure of the O Antigen of Escherichia Coli K-12 and the Sequence of Its Rfb Gene Cluster." Journal of Bacteriology, vol. 176, no. 13, 1994, pp. 4144 56, https://jb.asm.org/content/176/13/4144.short.

109. Band, Victor I., and David S. Weiss. "Heteroresistance: A Cause of Unexplained Antibiotic Treatment Failure?” PLOS Pathogens, edited by Jorn Coers, vol. 15, no. 6, June 2019, p. e1007726, doi:10.1371/journal.ppat.1007726.

110. Napier, Brooke A., et al. "Colistin Heteroresistance in Enterobacter Cloacae Is Associated with Cross-Resistance to the Host Antimicrobial Lysozyme." Antimicrobial Agents and Chemotherapy, vol. 58, no. 9, 2014, pp. 5594-97, doi:10.1128/aac.02432-14.

111. Hicks, Kevin G., et al. "Acidic PH and Divalent Cation Sensing by PhoQ Are Dispensable for Systemic Salmonellae Virulence.” ELife, vol. 4, no. MAY, 2015, pp. 1-59, doi:10.7554/eLife.06792.

112. Cho, Uhn Soo, et al. "Metal Bridges between the PhoQ Sensor Domain and the Membrane Regulate Transmembrane Signaling." Journal of Molecular Biology, vol. 356, no. 5, 2006, pp. 1193-206, doi:10.1016/j.jmb.2005.12.032.

113. Allen, Chris A., et al. "Transposon-Derived Brucella Abortus Rough Mutants Are Attenuated and Exhibit Reduced Intracellular Survival." Infection and Immunity, vol. 66, no. 3, 1998, pp. 1008-16, http://iai.asm.org/.

114. Elhenawy, Wael, et al. "Host-Specific Adaptive Diversification of Crohn's DiseaseAssociated Adherent-Invasive Escherichia Coli." Cell Host and Microbe, vol. 25, no. 2, 2019, pp. 301-312.e5, doi:10.1016/j.chom.2018.12.010.

115. Kus, Julianne V, et al. "Bile Salts Induce Resistance to Polymyxin in Enterohemorrhagic Escherichia Coli O157:H7.” Journal of Bacteriology, vol. 193, no. 17, 2011, pp. 4509-15, doi:10.1128/JB.00200-11. 